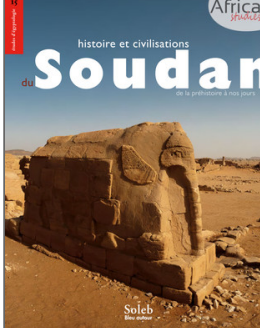

Histoire et civilisation du Soudan

De la préhistoire à nos jours

\title{
5. Le condominium anglo-égyptien 1899-1955
}

\section{Bernard François}

DOI : 10.4000/books.africae. 2907

Éditeur : Africae, Soleb, Bleu autour

Lieu d'édition : Paris, Khartoum

Année d'édition : 2017

Date de mise en ligne : 17 janvier 2022

Collection : Africae Studies

EAN électronique : 9782493207074

\section{(2) OpenEdition}

\section{Books}

http://books.openedition.org

\section{Référence électronique}

FRANÇOIS, Bernard. 5. Le condominium anglo-égyptien 1899-1955 In : Histoire et civilisation du Soudan : De la préhistoire à nos jours [en ligne]. Paris, Khartoum : Africae, 2017 (généré le 28 janvier 2022).

Disponible sur Internet : <http://books.openedition.org/africae/2907>. ISBN : 9782493207074. DOI : https://doi.org/10.4000/books.africae.2907. 


\section{le condominium}

anglo-égyptien $1899-1955$ 
Avant même la disparition du Khalifa Abdullahi (tué en novembre 1899), le traité anglo-égyptien instituant le condominium est signé le 19 janvier 1899, et le vainqueur de Karari, le général Kitchener, en est nommé gouverneur général. Peu apprécié de ses soldats en raison de sa dureté et mauvais gestionnaire, il est appelé à la fin de la même année en Afrique du Sud ${ }^{1}$, et sera remplacé par Sir Réginald Wingate.

\section{L'accord anglo-égyptien de 1899}

Le condominium représente un changement important dans l'administration du Soudan; si formellement l'Égypte et l'Angleterre gèrent de concert, dans la réalité l'Empire britannique devient le véritable maitre du Soudan: le gouverneur général est un officier (qui sera toujours un Anglais) choisi par le gouvernement de Londres et nommé par le khédive. La totalité des pouvoirs revient de fait à l'administration britannique, dont la stratégie sera de "déségyptianiser» le Soudan. Le rôle purement nominal qui échoit à l'Égypte fut une source de frustration pour les politiciens égyptiens pendant des décennies.

Le traité du 19 janvier 1899 est court: douze articles qui stipulent que, désormais, le gouverneur général gérera de façon autonome l'ensemble des pouvoirs exécutifs, législatifs et judiciaires au Soudan (sauf à Souakin qui restait sous la souveraineté égyptienne, mais cette concession anglaise sera supprimée moins d'un an plus tard); il rendra compte a posteriori à l'agent britannique et consul général au Caire, à l'époque Sir Evelyn Baring, coauteur du traité avec Kitchener, qui deviendra Lord Cromer.

Churchill considère que le condominium unit l'Égypte et le Soudan, «liés de façon indissoluble par le Nil». Il constate que l'influence anglaise sur l'Égypte sort renforcée de la création du condominium, et à moindre coût puisque l'Égypte va continuer à payer pour le Soudan au bénéfice du citoyen britannique: le déficit soudanais sera en effet payé par l'Égypte jusqu'en 1913, et celle-ci continuera à financer les dépenses des forces de sécurité même après l'expulsion des troupes égyptiennes en 1924 (voir infra p. 651-653). L'influence de la France sur les Égyptiens a été définitivement détruite après l'épisode de Fachoda. Churchill estime encore que l'Empire britannique a gagné un territoire convoité par les autres puissances européennes. Il prévoit aussi que la voie fluviale doublée du rail permettra de développer les échanges commerciaux entre le Soudan et l'Europe (matières premières contre biens manufacturés), ce processus étant supposé amener civilisation et prospérité.

1 Où la deuxième guerre des Boers a commencé en octobre 1899. 
le Soudan

\section{0}

de 1820

à nos jours

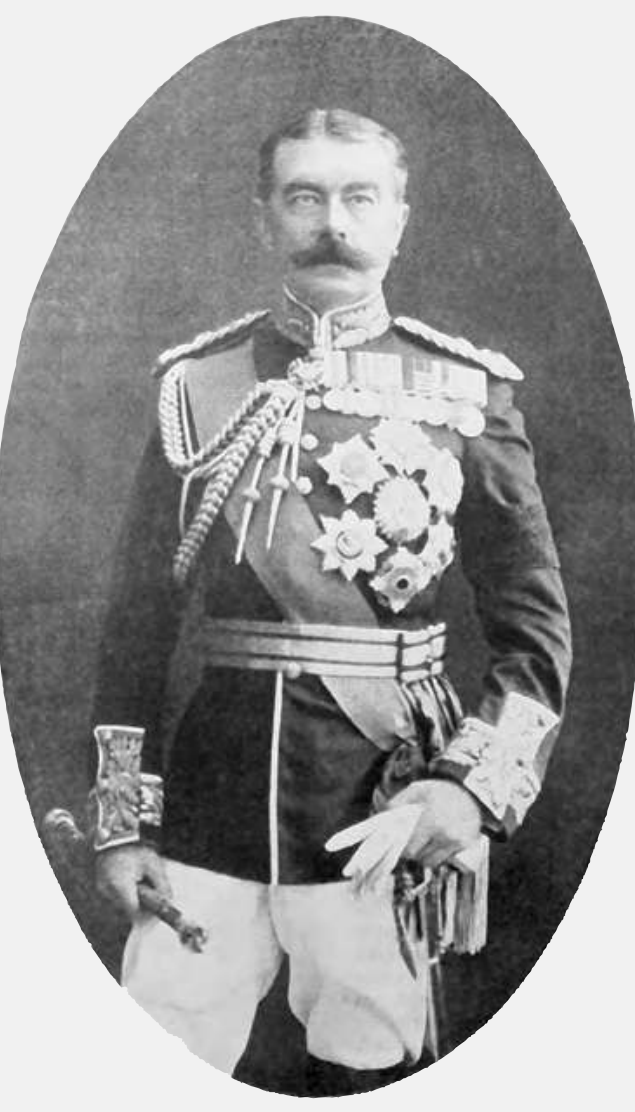

Le Sirdar Herbert H.Kitchener.

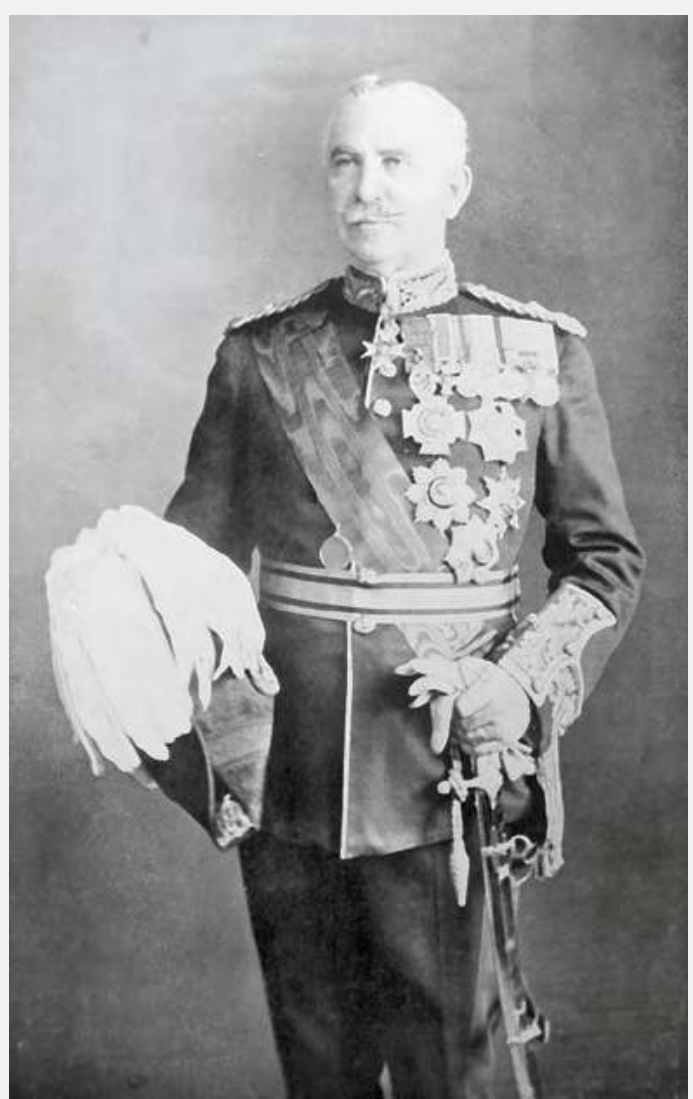

Le Sirdar Reginald Wingate.

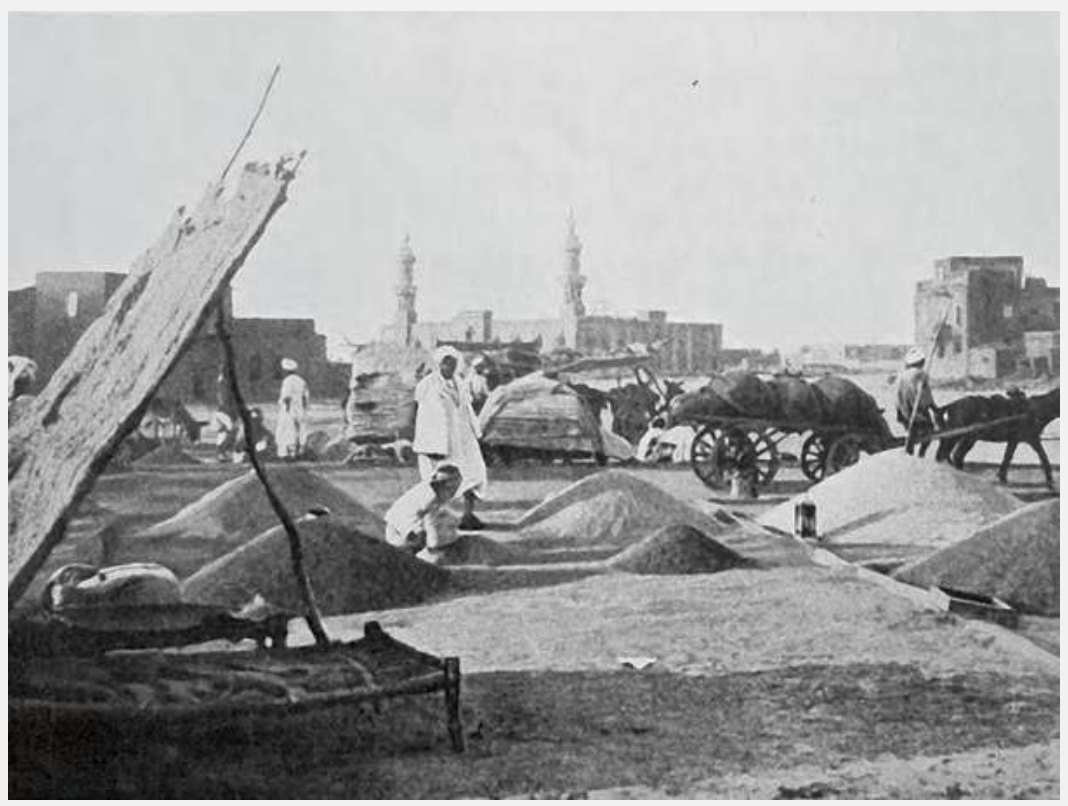

La mosquée de Khartoum en 1909. 


\section{L'administration directe des premières années du condominium (| $899-$ ||924)}

Soulèvements populaires; la question religieuse au Nord ; insurrections au Sud. Pour prévenir l'appréhension des populations locales vis-à-vis du nouveau pouvoir chrétien, Kitchener reprend dans un mémorandum aux mudirs ${ }^{1}$ les orientations développées par Cromer à Omdourman en janvier 1899. Il recommande de veiller à ce que les sentiments religieux de la population musulmane ne soient en aucune manière troublés, que la pratique de l'islam soit respectée et que les mosquées dans les grandes villes soient reconstruites. Par contre, le rétablissement des mosquées privées, des zawiyas $^{2}$ et des tombeaux de shaykh ne sera pas autorisé au niveau des provinces mais devra être demandé à l'autorité centrale, qui veille à ce que des mouvements fanatiques non orthodoxes ne puissent pas à nouveau se développer.

Au départ, la répression anglaise sera sévère contre les mahdistes et en particulier contre la famille du Mahdi. Deux de ses fils sont sommairement exécutés en prison sous le prétexte qu'ils préparaient une rébellion. Son fils cadet (posthume), Sayed Abd al-Rahman, fut seulement blessé, et seul son jeune âge empêcha que le même sort lui fût réservé. L'Empire n'a pas seulement écrasé une rébellion armée; il tient à éradiquer le mouvement religieux. La tenue mahdiste est interdite, ainsi que le ratib.

Certains auteurs considèrent que l'acharnement des autorités est pour une large part due à Rudolf von Slatin, directeur des services de renseignement, dont l'hostilité, au-delà des raisons politiques, avait des relents de vengeance personnelle, après qu'il eut effectué onze ans de captivité éprouvante à Omdourman dans la proximité du Khalifa Abdullahi (voir supra p. 621).

Les autres sectes religieuses sont surveillées. Le gouvernement de Khartoum va ouvertement favoriser la Khatmiyya de la famille Mirghani, une confrérie rivale qui fut ainsi considérée comme la tarîqa du gouvernement.

1 Mudir (arabe) : gouverneur de province.

2 Zawiya ou zaoüa: petite mosquée, pouvant être construite sur le tombeau d'un saint homme, et comprenant des locaux pour la lecture du Coran, la prière, l'enseignement religieux et général, l'hébergement des maîtres, des étudiants, des voyageurs, des mendiants. 
le Soudan

\section{2}

de 1820

à nos jours
Dans le même souci d'entamer la base religieuse du mahdisme, le gouvernement colonial crée en 1901 un Conseil des oulémas ${ }^{1}$ composé de sept sages, organe consultatif chargé de conseiller le gouvernement dans les affaires concernant l'islam: désignation des cadis ${ }^{2}$, création d'écoles coraniques, etc. De plus, il est créé un droit proprement soudanais (voir infra, p. 645 sq.) pour les affaires relatives au statut personnel (le droit musulman s'applique aux musulmans) et des tribunaux musulmans sont institués.

Malgré ces mesures, l'esprit du mahdisme persista, de même que les causes profondes qui l'avaient suscité (restauration d'un islam plus authentique, rejet des étrangers non-musulmans, contestation sociale). Ainsi, des révoltes locales d'inspiration mahdiste sont fréquentes, mais d'importance mineure: peu de belligérants sont impliqués. Elles surviennent de plus dans un contexte nouveau: le doute de la victoire finale s'était installé chez les mahdistes, face à l'armée anglaise auréolée de sa victoire, disciplinée et disposant d'un armement supérieur et d'officiers déterminés. La répression de chaque mouvement fut précoce et se solda par des victoires rapides. Les principaux soulèvements datent de 1903 et 1912 à Teqali, de 1904 à Singa (ex-capitale du royaume Fundj), de 1908 dans la Gézireh, de 1910 au Sennar, de 1915 dans le Gébel Miri, de 1918 à Kassala et de 1921 à Nyala au Sud Darfour.

Lors du déclenchement de la Première Guerre mondiale, les Anglais, soucieux d'éviter que le Soudan ne réponde favorablement à l'appel à la guerre sainte lancé par Constantinople, expliquent que la guerre contre l'Allemagne et son alliée la Turquie est sans lien avec des questions religieuses. Les confréries expriment leur loyauté, et Sayed Abd al-Rahman al-Mahdi, le fils posthume du Mahdi, est autorisé à circuler pour faire la tournée des confréries locales et exhorter les fidèles à l'obéissance aux Britanniques. La Khatmiyya fait de même.

La Senoussiya, importante confrérie bien implantée en Libye et au Tchad, attaque l'Égypte fin 1915. Le sultan Ali Dinar, dont le Darfour est pris en tenailles entre les Français à l'ouest et les Anglais au Soudan, déclare

1 Emprunté à l'arabe ، علما, 'ūlamā’ (" savants»), pluriel de عالم, 'ālim («savant»).

2 Le cadi (arabe:قاضي [qāḍi]], "juge») est un juge musulman remplissant des fonctions civiles, judiciaires et religieuses. Il est un juge de paix et un notaire, réglant les problèmes de la vie quotidienne: mariages, divorces, répudiations, successions, héritages, etc. Le mot «cadi» vient d'un verbe signifiant «juger», "décider». 

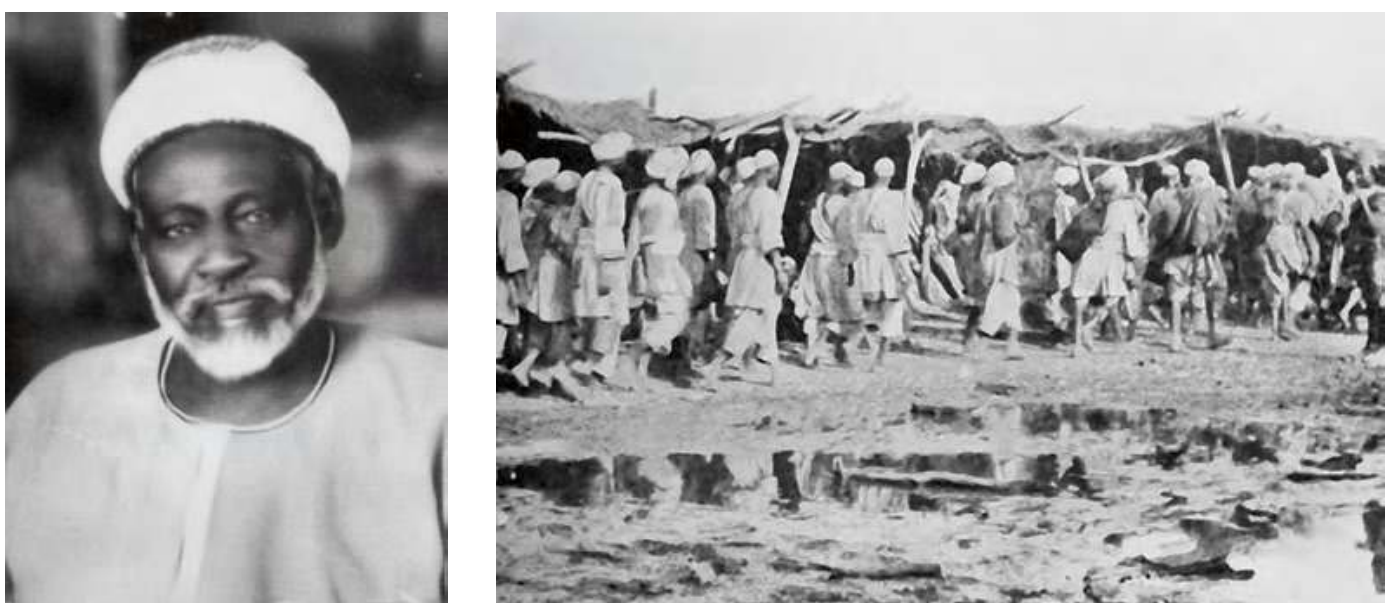

Sayed Abd al-Rahman al-Mahdi.

Derviches prisonniers, 1898.

la guerre sainte. Des opérations coordonnées entre Français et Anglais ont raison du sultan en novembre 1916, et cette victoire met fin de manière définitive à l'existence du royaume indépendant du Darfour.

La barrière du Sudd fut rouverte en 1904 par des prisonniers mahdistes. Des révoltes au Sud (Azandé, Nuer, Dinka et Nouba), sans commune mesure avec les rébellions d'obédience mahdiste, font l'objet d'une répression féroce, sans que dans le Sud ne régresse l'insécurité, qui y perdurera bien au-delà de la Première Guerre mondiale. On procédera à des bombardements aériens après 1918 pour mater ces révoltes.

À partir de 1918, jouant de l'opposition entre le nord et le sud du pays, les Anglais encouragent les missions chrétiennes à s'installer au sud où l'enseignement en arabe et le prosélytisme musulman sont interdits et où un Equatorial Corps, composé uniquement de recrues issues des ethnies locales, est constitué en 1910 pour remplacer les troupes égyptiennes. Ces décisions anticipent le début de la Southern policy qui sera développée formellement à partir de 1924 .

Mise en place de l'administration du condominium. Dès 1902, un régime civil se met en place, dont le leadership est assuré par le gouverneur général, assisté de secrétaires pour les affaires civiles, financières et juridiques, avec les directeurs des départements. À partir de 1910, un conseil de gouverneur général est créé, qui sera l’organe essentiel de gouvernement jusqu'en 1948.

L'administration locale était organisée autour de 13 provinces dirigées par un mudir (deputy governor); les district commissionners et assistant district commissionners étaient chargés d'une partie de province (markaz) 


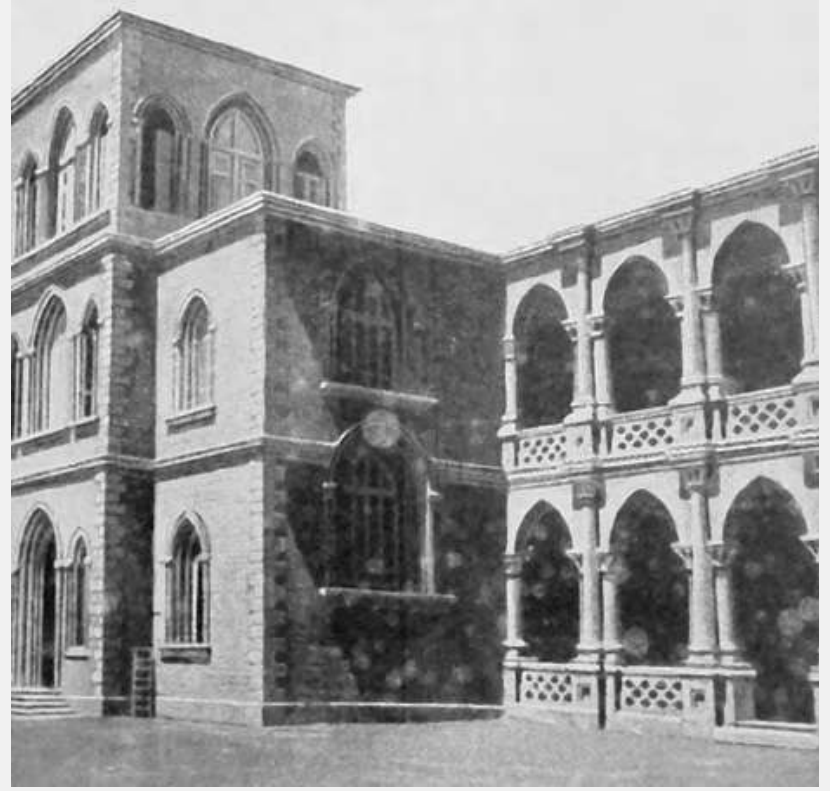

le Soudan

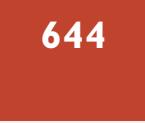

de 1820

à nos jours
Gordon College.

Kitchener

School

of Medicine.

Étudiants diplômés en 1936. 
et ne résidaient pas au siège de la province; le markaz était divisé en ma’muriya administrées par un mámur ${ }^{1}$ (égyptien ou soudanais) qui contrôlait des sub-mámur et des shaykh, les chefs locaux.

Le premier gouverneur civil fut nommé en 1909; il y en avait cinq dès 1909, et 14 en 1930. Auparavant, pour alimenter l'administration en cadres subalternes, le Gordon College avait été créé en 1902: initialement école primaire, il incluait aussi désormais une école secondaire et des formations spécifiques pour les cadres nécessaires: enseignants, juges, techniciens... Cet accent mis sur l'instruction au Nord du Soudan dès les premières années du condominium allait favoriser l'émergence d'une catégorie de lettrés, distincte des notables musulmans traditionnels, sur laquelle le colonisateur s'appuya.

Le contrôle est minimal aux échelons supérieurs de la pyramide et prégnant à la base, où les mámurs ont à rendre compte de tout. Ce régime appelé direct rule (par opposition à l'indirect rule qui lui succédera en 1924) eut pour effet d'affaiblir les chefferies traditionnelles, le district commissionner pouvant casser les décisions prises par les échelons inférieurs. À la différence d'autres colonies britanniques dépendant du Colonial Office, le Soudan dépend du Foreign Office, et l'influence de l'agent britannique au Caire sur la gestion des affaires soudanaises va progressivement décliner. Les administrateurs britanniques sont animés des sentiments qui prévalaient à l'époque: pétris de l'idéologie du "fardeau de l'homme blanc» (Kipling), cultivant le souvenir de Gordon ou un altruisme parfois profondément religieux, ils croient en même temps à la hiérarchie des races et à la nécessité d'éviter le mélange entre les populations locales et les Européens.

Établissement d'un système judiciaire adapté au pays. Les nouveaux bâtiments érigés à Khartoum pour les tribunaux civils et musulmans, ainsi que pour les bureaux de l'administration judiciaire, sont inaugurés en février 1908 par le duc de Connaught, au nom de Sa Majesté le roi Edouard VII et de Son Altesse Abbas Hilmi Pacha II, khédive d’Égypte. À cette occasion, le gouverneur général du Soudan exprime les objectifs de l'administration: 1 ... Ces bâtiments peuvent être considérés comme l'emblème de la Justice que nous souhaitons dispenser ici: une justice qui se concentre sur une route droite, sans tergiverser ni à gauche ni à droite, appuyée sur les fondations solides du respect et de la confiance des cœurs des peuples. Le livre que beaucoup d'entre nous révèrent dit: "Que Dieu demande-t-il de nous, si ce n'est amour, pitié et justice, et de vivre humblement avec lui?"; et le livre sacré des habitants de ce pays dit: "Dieu ne guide pas la multitude

1 Mámur (turc) : littéralement «fonctionnaire aux ordres». 
le Soudan

de 1820 à nos jours

des injustes (Coran LXI 8). Dieu n'aime pas celui qui est injuste. La voie est contre ceux qui sont injustes envers le peuple et qui vivent sur terre sans respect du droit (Coran XLII 40)." La Justice est le fondement solide de tout gouvernement, et un gouvernement doit être jugé comme bon ou mauvais selon qu'il garantit la justice pour ses sujets.

La fierté de notre nation a été de chercher la justice en toute circonstance et de considérer que notre plus important devoir, quel que soit le pays où nous avons été destinés à œuvrer, est d'assurer que chaque homme puisse bénéficier de paix et de liberté. Nous avons fait de notre mieux pour aider et sauvegarder la Justice par l'établissement de ces tribunaux qui appliqueront la loi civile et religieuse, et, pour garantir cette situation, les juges compétents dans chaque branche ont été dûment appointés par le Gouvernement. Je pense qu'on peut affirmer qu'il est reconnu dans tout le pays que chaque personne qui s'estime opprimée ou victime d'une injustice, peut porter plainte devant la cour en confiance: son cas sera patiemment examiné et aussi humainement que possible, son tort sera réparé. [...] Notre but a été de laisser autant de liberté à chaque individu pour autant qu'elle n'empiète sur celle des autres, de rendre nos lois aussi simples que possible afin que même les ignorants puissent les comprendre et, en matière de droit pénal, de réprimer l'injustice et le mal, de protéger le pauvre et le faible, sans oublier, quand l'occasion s'en présente, de tempérer la justice par la pitié. $\$$

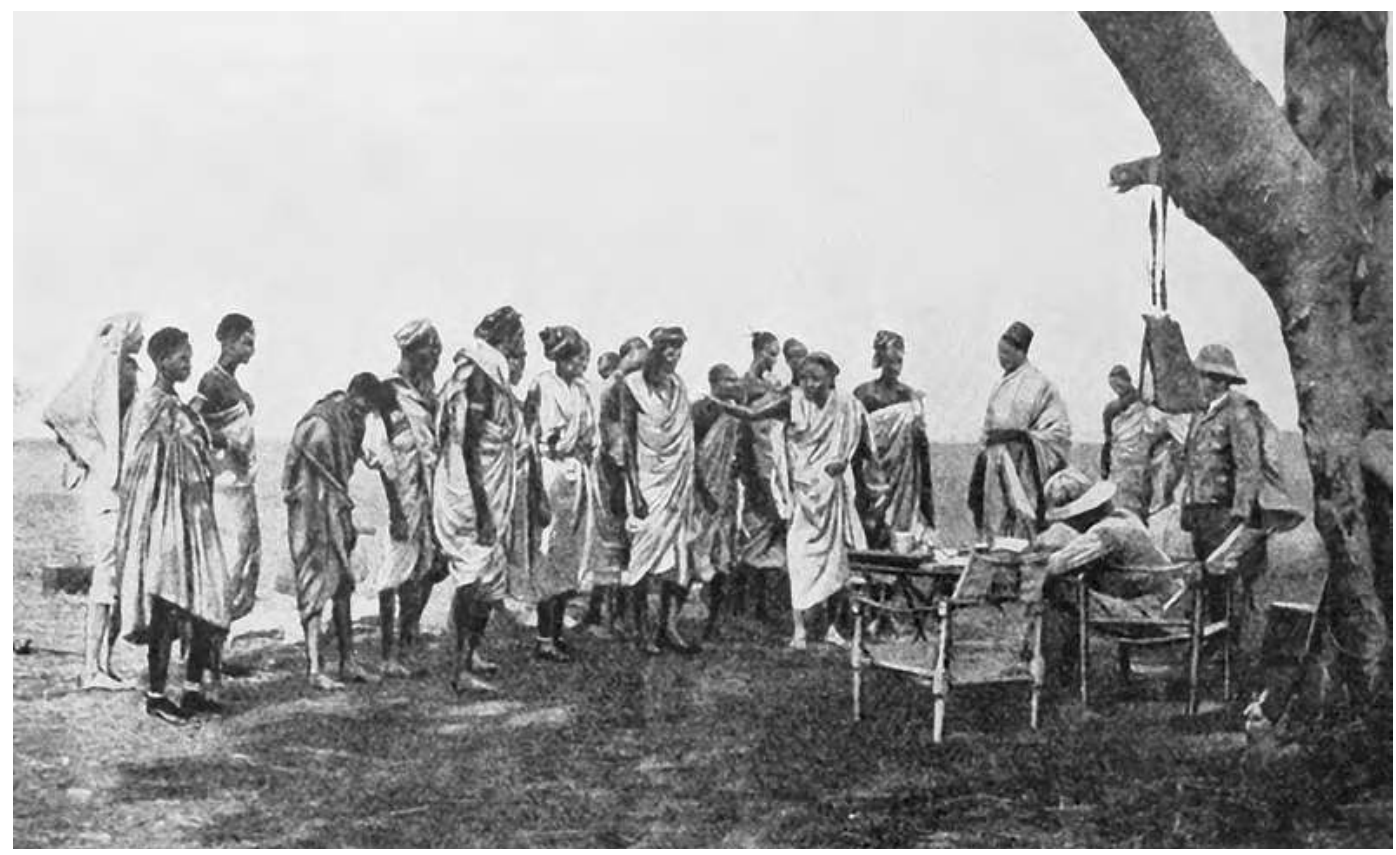

Jugement en brousse (1908, troisième rapport Wellcome). 
Développementsanitaire. Les laboratoires de recherche du Gordon Memorial College bénéficient du mécénat de Henry S. Wellcome. Les laboratoires visent essentiellement à promouvoir l'étude bactériologique et physiologique des maladies infectieuses tropicales chez l'homme et les animaux au Soudan, et ainsi à assister les responsables de santé et les hôpitaux civils et militaires. La mission des laboratoires est aussi de promouvoir l'enseignement technique, de contribuer aux investigations en cas d'empoisonnements par la recherche des toxiques, en particulier les substances méconnues utilisées par les populations locales, à effectuer les tests chimiques et bactériologiques concernant l'eau, les aliments et autres besoins en matière de santé publique et d'hygiène; enfin, les laboratoires se proposent d'expérimenter les substances minérales et agricoles susceptibles de représenter un intérêt dans le cadre du développement industriel du Soudan.

Le premier rapport publié couvre la période du premier février 1903 au premier février 1904. Le directeur Andrew Balfour a rejoint Khartoum le 22 janvier 1903. Les laboratoires sont constitués d'un ensemble de cinq pièces situées dans l'aile ouest du Gordon College, comprenant une cuisine, des locaux distincts pour les analyses bactériologiques et chimiques, une chambre noire pour le développement de photographies, une chambre froide et une pièce servant de musée. À côté se trouvent le bureau du directeur et le musée général et économique. Les retards et désagréments liés au manque de maind'œuvre qualifiée et aux difficultés de transport ont été surmontés avec l'aide des fonctionnaires des gouvernements de Khartoum et du Caire.

Le musée des laboratoires a pour objectif de collectionner et d'exposer des spécimens et des photographies montrant les maladies humaines et vétérinaires rencontrées au Soudan, et de dresser des cartes renseignant sur leur distribution géographique. Il comprend des échantillons illustrant des pathologies humaines tropicales, notamment des exemples des mycétomes si fréquents; des spécimens d'intérêt vétérinaire; une petite série de crânes et une collection de photographies illustrant les maladies locales. En outre, un assortiment de remèdes utilisés par les Soudanais est présenté: une centaine de préparations ont été obtenues de diverses origines et, pour faciliter l'étude des médicaments et poisons végétaux, un jardin thérapeutique a été créé.

Le directeur des laboratoires s'est aussi occupé de lancer le musée économique et général: de nombreux spécimens de maladies du mil, une collection de moustiques (avec des préparations au microscope pour les trois genres les plus communs à Khartoum), des exemples d'insectes nuisibles pour les melons et le mil sont présentés, en contraste avec les coccinelles bénéfiques. Des spécimens de mouches tsé-tsé sont également visibles, ainsi que quelques serpents, scorpions, sauterelles, et des exemples de minerais. 
le Soudan

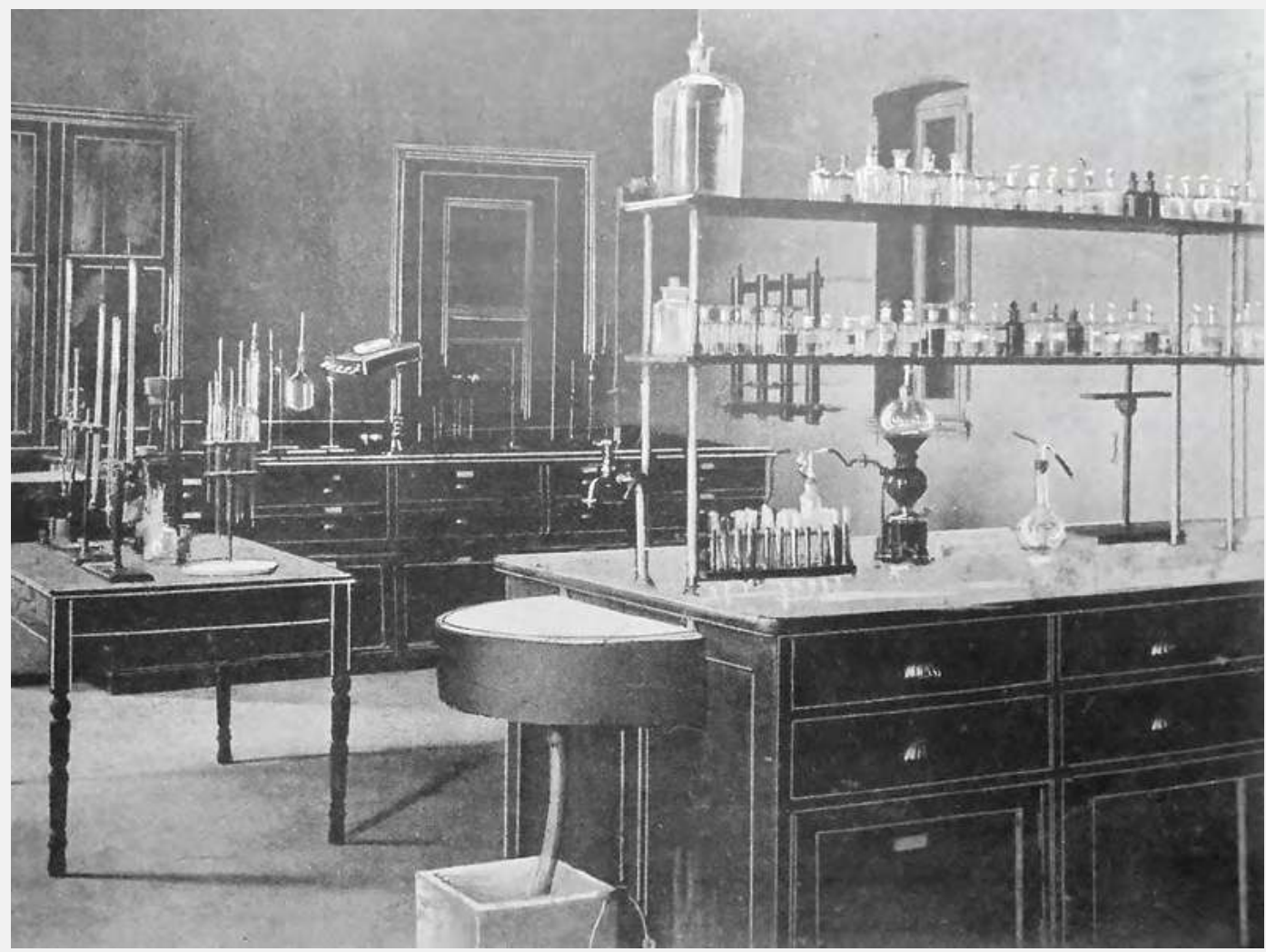

648

de 1820

à nos jours

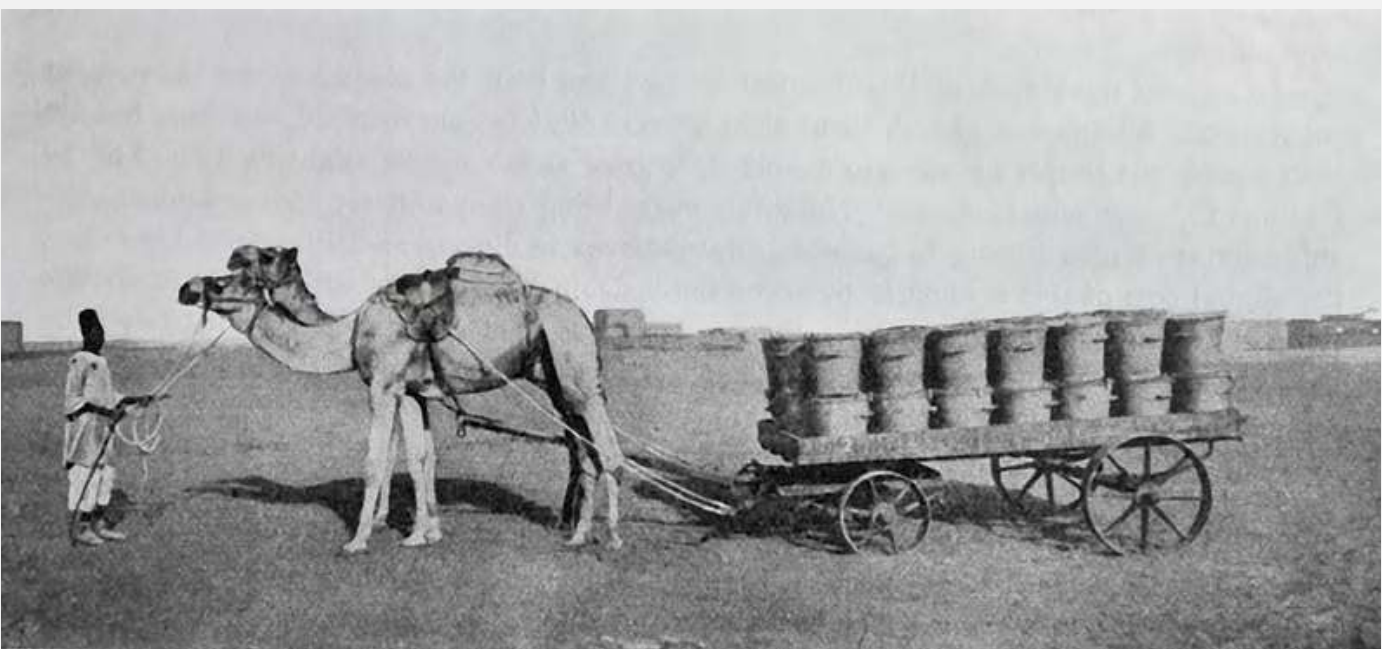

Le laboratoire du Gordon College.

Le véhicule du service d'hygiène de Khartoum. 

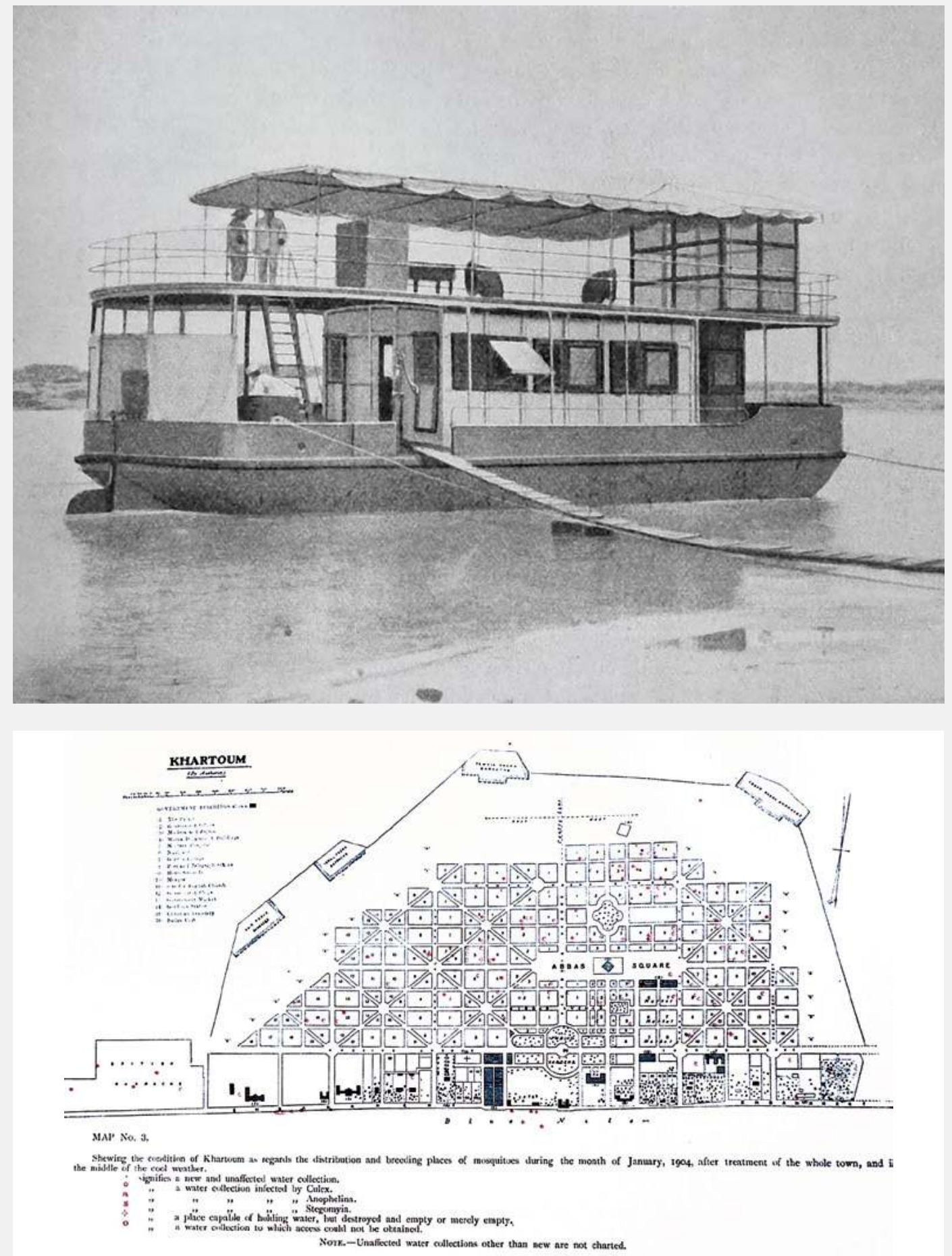

le condominium angloégyptien 1899-1955

Le SS Culex (du nom d'un moustique très fréquent),

laboratoire flottant pour les missions au sud du pays.

Repérages des gîtes larvaires sur un plan de Khartoum. 
le Soudan

\section{0}

de 1820

à nos jours
L'équipe comprend le directeur, un assistant de laboratoire et deux Soudanais, dont un petit garçon. Vu l'importance du travail passé et à venir, du personnel supplémentaire va y être affecté: un chimiste expérimenté, ainsi qu'un agent chargé de collecter des échantillons sanguins, des insectes nuisibles et des parasites et pouvant photographier les conditions pathologiques des Soudanais, les médicaments traditionnels, les poisons et tout élément utile pour approfondir la médecine tropicale au Soudan.

Des efforts importants seront réalisés pour lutter contre les moustiques qui transmettent notamment la malaria: une cartographie des gîtes larvaires est réalisée avant traitement, et des contrôles sont opérés peu après pour contrôler la diminution de la population larvaire.

Les laboratoires travaillent en collaboration avec les écoles de médecine tropicale de Londres et Liverpool. Le département de l'agriculture des États-Unis et le département d'histoire naturelle du British Museum font bénéficier la bibliothèque de nombreux périodiques scientifiques et de leurs publications.

Déségyptianisation au Nord. Les Britanniques, attentifs à ne pas mélanger les conscrits soudanais et égyptiens, créent des régiments distincts. Seul le manque d'officiers soudanais les obligea à nommer des officiers égyptiens dans des unités soudanaises. Tel est le dispositif qui fut installé après la signature du condominium. Il n'allait pas sans risque, puisqu'une compagnie soudanaise dirigée par un officier égyptien se rebella en 1899 à Omdurman, après avoir entendu que le commandement britannique s'apprêtait à l'envoyer en Afrique du Sud, dans le cadre de la répression de la deuxième insurrection des Boers. Les autorités britanniques tinrent compte de cette insurrection en hâtant la création d'une académie militaire qui pût produire localement des officiers soudanais. Pour mieux assurer leur mainmise sur le Sud et sur l'armée, les Britanniques étendent leurs services de renseignement sur la région, créant une branche particulière dédiée au Soudan. Égyptiens et Soudanais sont totalement exclus de cette unité dont le premier objectif est de tenir l'armée à l'œil. Le chef de cette unité peut espérer être promu au rang de Sirdar et de gouverneur général du Soudan, comme l'ont été Sir Reginald Wingate et Sir Lee Stack.

Premiers mouvements nationalistes. En 1918, de jeunes diplômés issus du Gordon College créent le Graduate's Club qui va suivre attentivement l'évolution des mouvements nationalistes en Inde et en Égypte. En 1919, un vent de révolte en Égypte se transforme en tempête qui va inévitablement atteindre le Soudan et bousculer les plans les mieux conçus 
du Colonial Office. L'esprit de la révolution de 1919 touche d'abord les officiers égyptiens à Khartoum. En novembre, soixante d'entre eux se rassemblent dans la capitale soudanaise pour rédiger un communiqué demandant l'indépendance de l'Égypte; le communiqué proteste aussi contre le meurtre de civils sans défense, tués à Alexandrie par les forces britanniques. Ce mouvement, suivi de très près par les services de renseignement, confirme les inquiétudes britanniques sur les répercussions soudanaises des événements en Égypte.

En même temps, les notables musulmans se désolidarisent des nationalistes égyptiens qui revendiquent le rattachement du Soudan à la future Égypte indépendante. Mais une circulaire anonyme soutenant les nationalistes circule dans la capitale, stigmatisant la politique de division que mène l'Angleterre et prônant la solidarité avec les Frères musulmans égyptiens.

Boyd, l'un des meilleurs officiers britanniques du Caire, fut envoyé à Khartoum afin de "protéger" les Soudanais de l'armée contre une possible «contamination». Son rapport soumis à Allenby le 11 mars 1920 décrit l'état de l'armée égyptienne au Soudan, et propose, pour en expurger l'élément égyptien, un scénario, qui sera précisément celui mis en application lors de l'ultimatum de novembre 1924 (voir infra, p. 653). Boyd préconise la création d'une armée purement soudanaise, qui sera ultérieurement dénommée Sudan Defense Force. Ce rapport comprend les bases de la future politique au Soudan: une large décentralisation permettant l'implication des Soudanais, et une politique visant à bloquer la pénétration de l'islam dans le Sud et à rapprocher ce dernier du Kenya et de l'Ouganda. La loi sur les passeports et celle du close district order en 1922 donnent aux gouverneurs le pouvoir de bloquer la libre circulation, notamment entre le Nord et le Sud.

En 1922, en Égypte, l'Angleterre affronte la situation devenue explosive en offrant une indépendance factice, à condition que le statu quo soit maintenu sur quatre points, dont le Soudan. Le nationalisme hostile aux Britanniques s'y développe et une société secrète nationaliste voit le jour: la Ligue de l'union soudanaise.

En 1924, quelques mois après la victoire électorale du parti Wafd indépendantiste au Caire, la situation devient tendue en Égypte. Au Soudan, des postiers nationalistes, qui forment la Ligue du drapeau blanc, protestent contre l'absence des Soudanais dans les pourparlers entre l'Égypte et les Anglais. Des manifestations favorables à l'union avec l'Égypte sont organisées à Khartoum. L'agitation se développe, jusqu'à l'arrestation d'Ali Abd al-Latif qui est détenu pendant un an pour avoir publié un article séditieux, ce qui provoque des manifestations de cadets devant sa prison. À Atbara, 


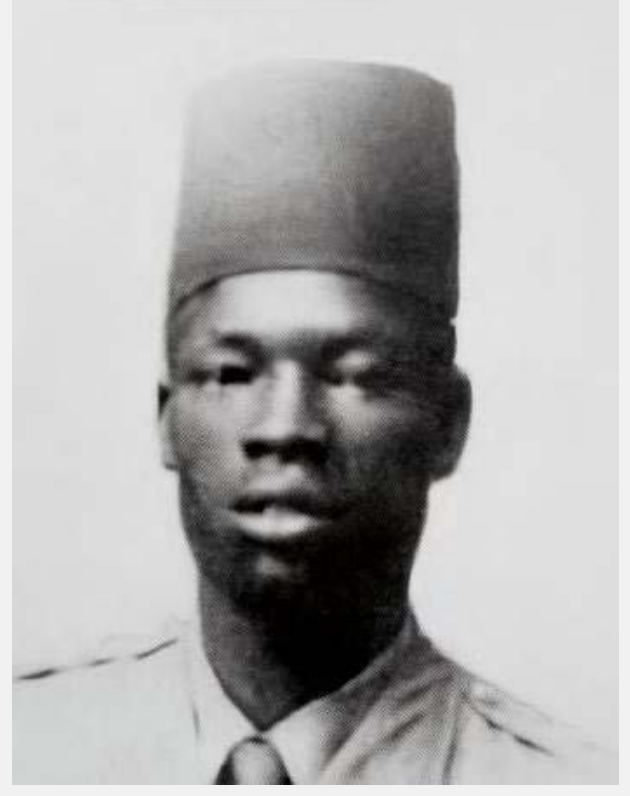

Ali Abd al-Latif.

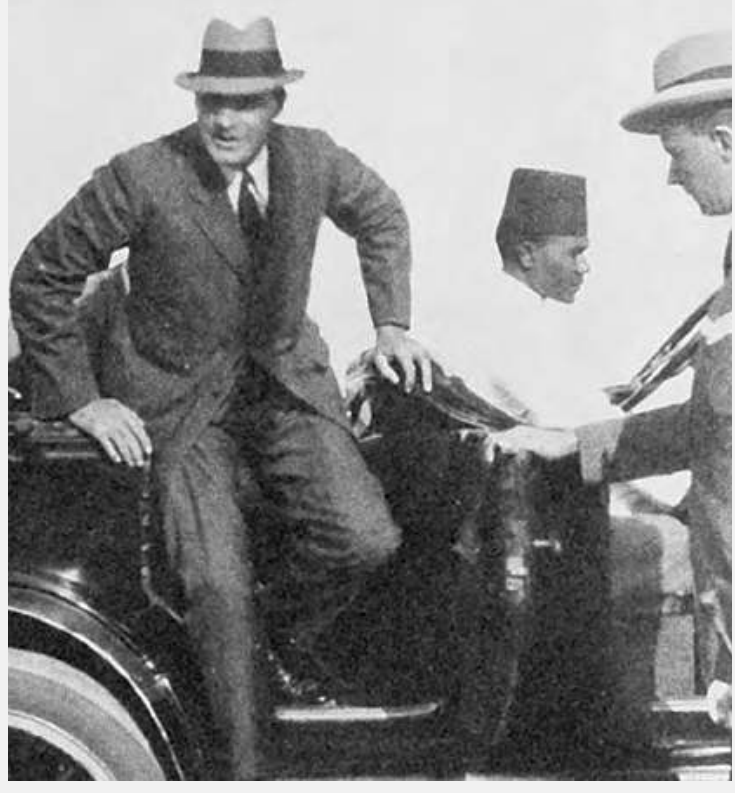

Sir Lee Stack.

le Soudan

652

de 1820

à nos jours

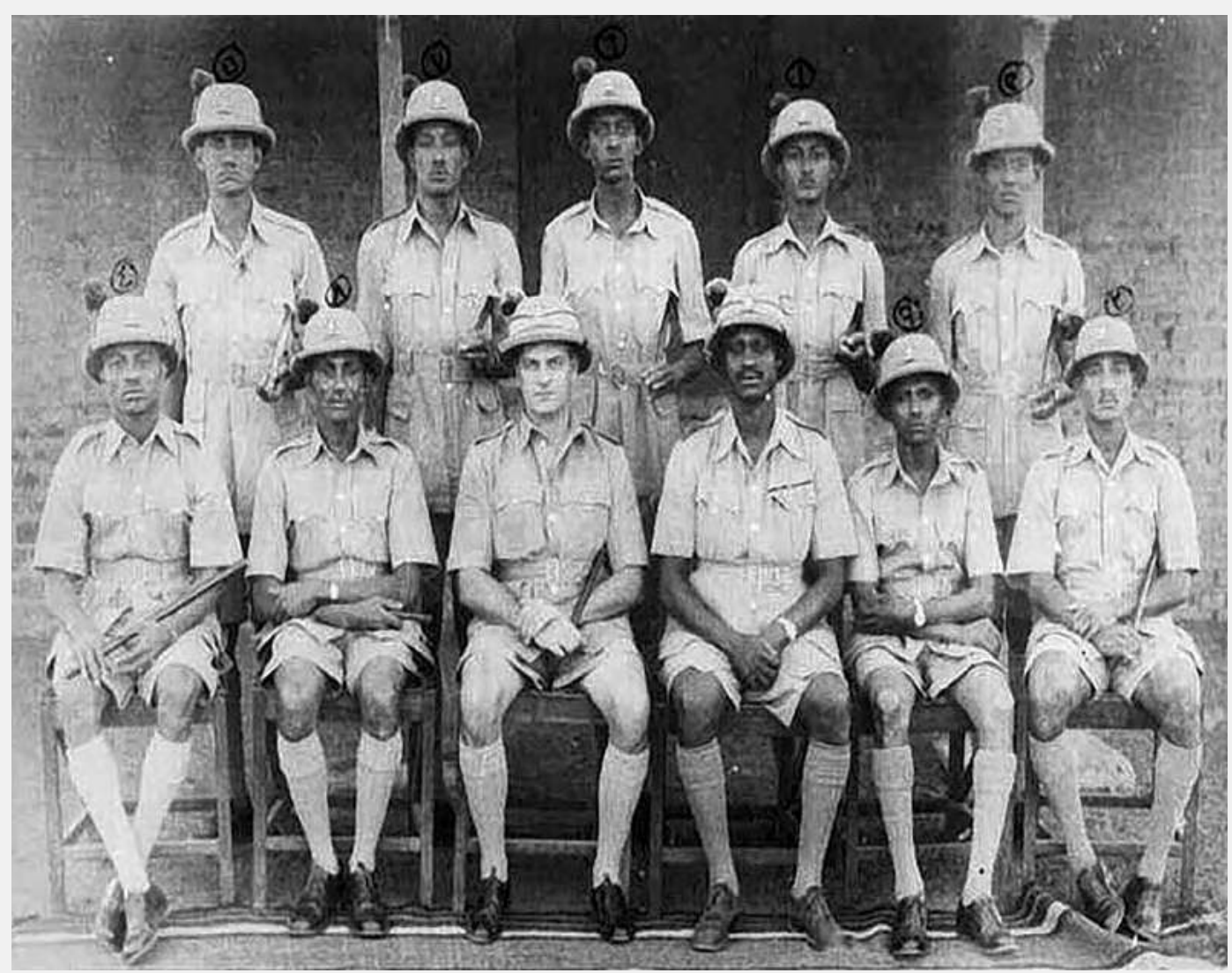

Un groupe d'officiers des Sudanese Armed Forces (SAF). 
le bataillon égyptien des chemins de fer manifeste et essuie des tirs des troupes soudanaises, qui font quelques morts. Le bataillon sera renvoyé en Égypte. Sayed Abd al-Rahman al-Mahdi prend position contre le mouvement pro-égyptien. Pendant ce temps, les négociations anglo-égyptiennes ont commencé à Londres, sans les Soudanais, et le gouverneur général du Soudan empêche tout compromis.

L'assassinat de Lee Stack au Caire en novembre 1924 par des extrémistes égyptiens permet à l'Angleterre de mettre en œuvre le plan conçu dès 1920 pour retirer l'ensemble des troupes égyptiennes du Soudan, tout en continuant à financer son armée. Le même mois, la rébellion d'un bataillon soudanais est écrasée à Khartoum.

L'inertie égyptienne déçoit les Soudanais, et beaucoup rejoignent ceux qui ne veulent pas de l'unité de la vallée du Nil. Le premier accord de partage des eaux du Nil, en 1929, accentue le fossé entre le Soudan et l'Égypte ainsi que la division des Soudanais entre pro- et anti-égyptiens espérant des Anglais l'indépendance; ce clivage va survivre jusqu'à présent et entraîner des relations ambivalentes avec l'Égypte.

L'assassinat de Lee Stack convainc les officiels britanniques du gouvernement soudanais de la nécessité de contenir à tout prix l'influence égyptienne sur le Soudan, et de moins dépendre des Soudanais soutenant l'attitude des Égyptiens.

Le point cinq de l'ultimatum adressé le 22 novembre 1924 par le High Commissionner pour l'Égypte et le Soudan, Sir Allenby, au Premier ministre égyptien Saad Zaghlul précise: «Dans les 24 heures, des ordres seront donnés pour rappeler les officiers égyptiens et les unités de l'armée égyptienne du Soudan.» Dans un mémorandum publié le lendemain, Allenby précise: "Après le retrait des officiers égyptiens et des unités de l'armée égyptienne, les unités soudanaises de l'arme égyptienne vont constituer les forces armées soudanaises (Sudanese Armed Forces, $\mathrm{S}_{\mathrm{AF}}$ ) sujettes et loyales au seul gouvernement du Soudan et placées sous le commandement suprême du gouverneur général du Soudan.» Les Égyptiens acceptent de payer pour manifester le maintien de leur position dominante sur le Soudan. 


\section{La période de l'«indirect rule" (1924-|944)}

Installation de la native administration. À partir de 1924, les militaires et administrateurs anglais développent l'indirect rule, qui va de pair avec la déségyptianisation du Nord, la désislamisation du Sud et le recours aux élites locales. L'éloignement d'avec l'Égypte va progressivement autonomiser la position de Khartoum.

Le principe de l'indirect rule, tel qu'appliqué dans de nombreuses possessions de l'Empire britannique, consiste à responsabiliser les chefs traditionnels dans la gestion des questions non essentielles. Ceci va surtout concerner l'administration de la justice, après une révision du code pénal: seul le jugement de quelques crimes - homicides, crimes contre la sûreté de l'État — n'est pas dévolu aux chefs de tribus (shaykh). Un certain nombre de problèmes vont surgir pour identifier ces chefs de tribus (des aménagements seront nécessaires comme le regroupement des petites tribus...), mais aussi pour administrer les populations urbaines "détribalisées».

$\mathrm{Au}$ Nord, l'enseignement moderne au profit des indigènes est limité (fermeture de l'école militaire et de l'école administrative) pour favoriser les écoles coraniques. Le nombre d'écoles primaires et préparatoires stagne, alors que le nombre de khalwas ${ }^{1}$ explose.

$\mathrm{Au}$ Sud, les tentatives de maintien de la sécurité, souvent par la force, ont concentré l'attention. L'administration est quasi inexistante, Khartoum libère peu de moyens financiers et humains. Dès 1920, l'indirect rule, par l'ordonnance du closed district order, avait été décidé dans le but de préserver le Sud de l'influence musulmane. Les non-Soudanais du Nord, Grecs et Syriens, sont sollicités pour développer le commerce. La ville de Juba est créée en 1922.

Les missions chrétiennes se voient confier le système éducatif, basé sur l'anglais, et accroissent sensiblement le nombre des écoles. Mais les élèves formés dans ces écoles ne furent pas recrutés dans l'administration et la justice, dont la gestion par les chefs de tribu fut délicate et malaisée.

Sur l'ensemble du pays, le fonctionnement de la justice, dont celui des tribunaux indigènes, est réorganisé (1929-1932). Cela s'accompagne de régressions quand le droit musulman (qui avait été modernisé) est supplanté par le droit coutumier qu'appliquent les tribunaux indigènes. 

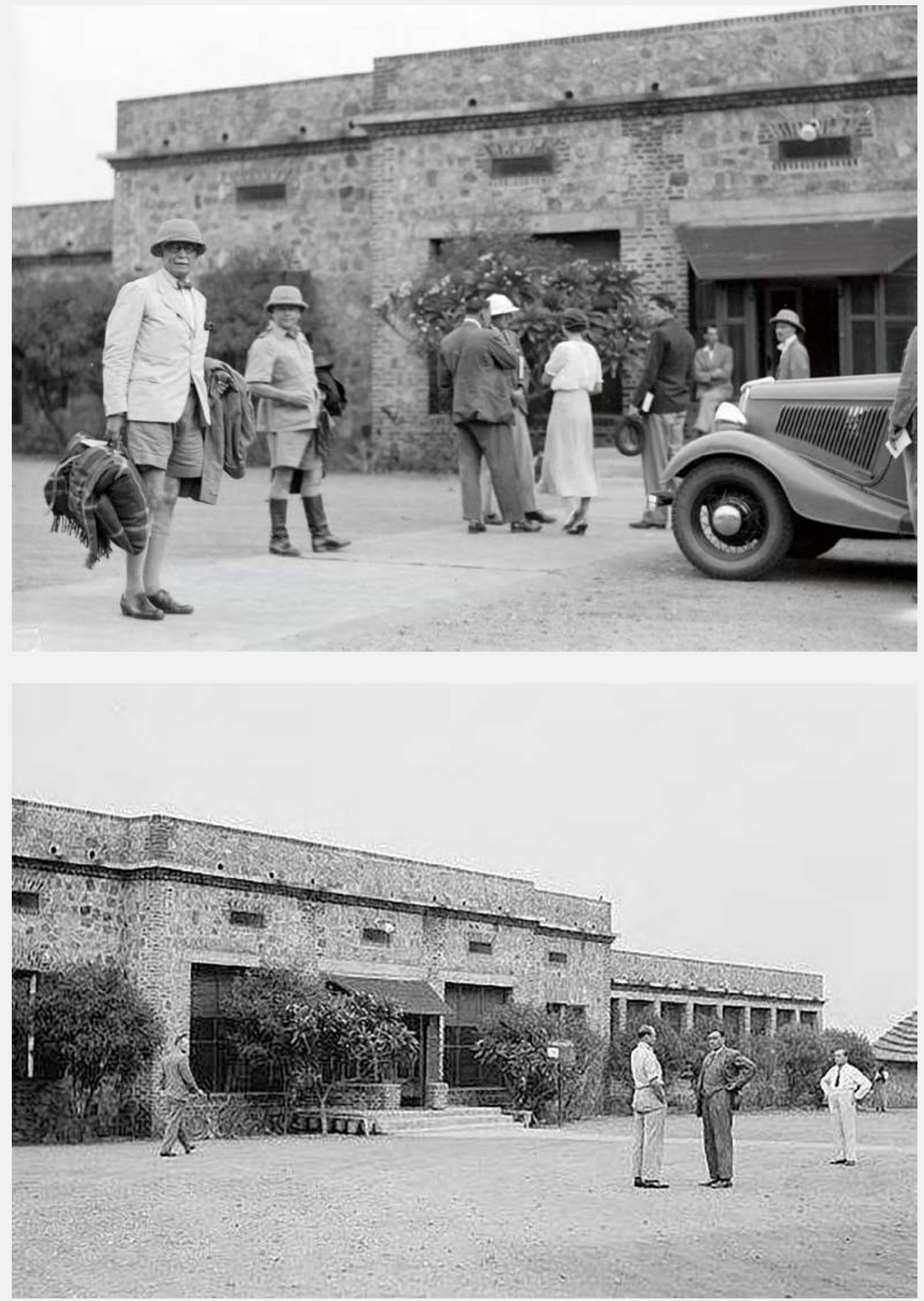

le condominium angloégyptien 1899-1955 Juba Hotel. 
Crise économique et division des nationalistes. La crise économique mondiale de 1929 va provoquer la division entre les deux tendances du mouvement nationaliste. Des réductions de salaires touchent spécifiquement les employés issus du Gordon College, qui reçoivent l'appui du Graduate's Club pour négocier avec le pouvoir colonial; après six mois sans résultats, la grève éclate chez les étudiants. Sayed Abd al-Rahman al-Mahdi intervient pour appuyer une position de compromis. Une tendance modérée (Ansars) l'emporte sur la tendance dure soutenue par la Khatmiyya de Mirghani.

Fin de l'indirect rule, la Seconde Guerre mondiale. En 1935, quand éclate la guerre d'Éthiopie, le nationalisme formulé par les jeunes générations éduquées et remettant en cause la native administration inquiète l'Angleterre. La censure est levée pour amadouer l'opinion publique. Dans l'année qui suit, le Royaume-Uni concède à nouveau, par un traité avec l'Égypte, une indépendance factice: il est décidé que le condominium est maintenu sur le Soudan tel qu'établi dans les accords de 1899. Ce traité déçoit tout le monde, tant les pro-Égyptiens que les indépendantistes, les Soudanais ayant été exclus des débats concernant leur pays.

En 1937, l'échec de la native administration est reconnu. Un véritable plan de développement de l'éducation secondaire et supérieure est proposé: de nouvelles écoles sont créées (droit, agriculture, vétérinaire, sciences et techniques...). Dans l'administration, les postes d'adjoints aux commissaires de districts sont ouverts aux Soudanais; les jeunes diplômés ne sont plus exclus des nouvelles structures. En 1939, on remplace le terme de native administration par celui de local administration.

En juin 1940, l'Italie entre en guerre, s'empare de la Somalie et d'une partie de l'est du Soudan (Kassala et une fraction du Blue Nile). Les forces britanniques, alors peu nombreuses et mal préparées, seront renforcées durant l'hiver par deux divisions ainsi que par deux bataillons français et des éléments belges. Les alliés passent à l’attaque en janvier 1941 et récupèrent Addis-Abeba en avril. Novembre 1941 marque la fin des opérations sur le théâtre éthiopien.

En 1942, le Congrès général des diplômés, créé en 1937 (sur le modèle du parti du Congrès indien de Gandhi), réclame, dans un mémorandum en douze points, le self government, autrement dit «le droit à l'autodétermination après la guerre, la liberté d'expression et le droit des Soudanais à préciser par traité leurs droits naturels vis-à-vis de l'Égypte». Les Britanniques, à ce moment, pensent à initier des conseils consultatifs. En août 1943, un conseil de 28 membres est institué pour le Nord, présidé par le gouverneur général: 18 membres représentent les six provinces et 10, nommés par le gouverneur général, représentent les intérêts des opérateurs économiques. 


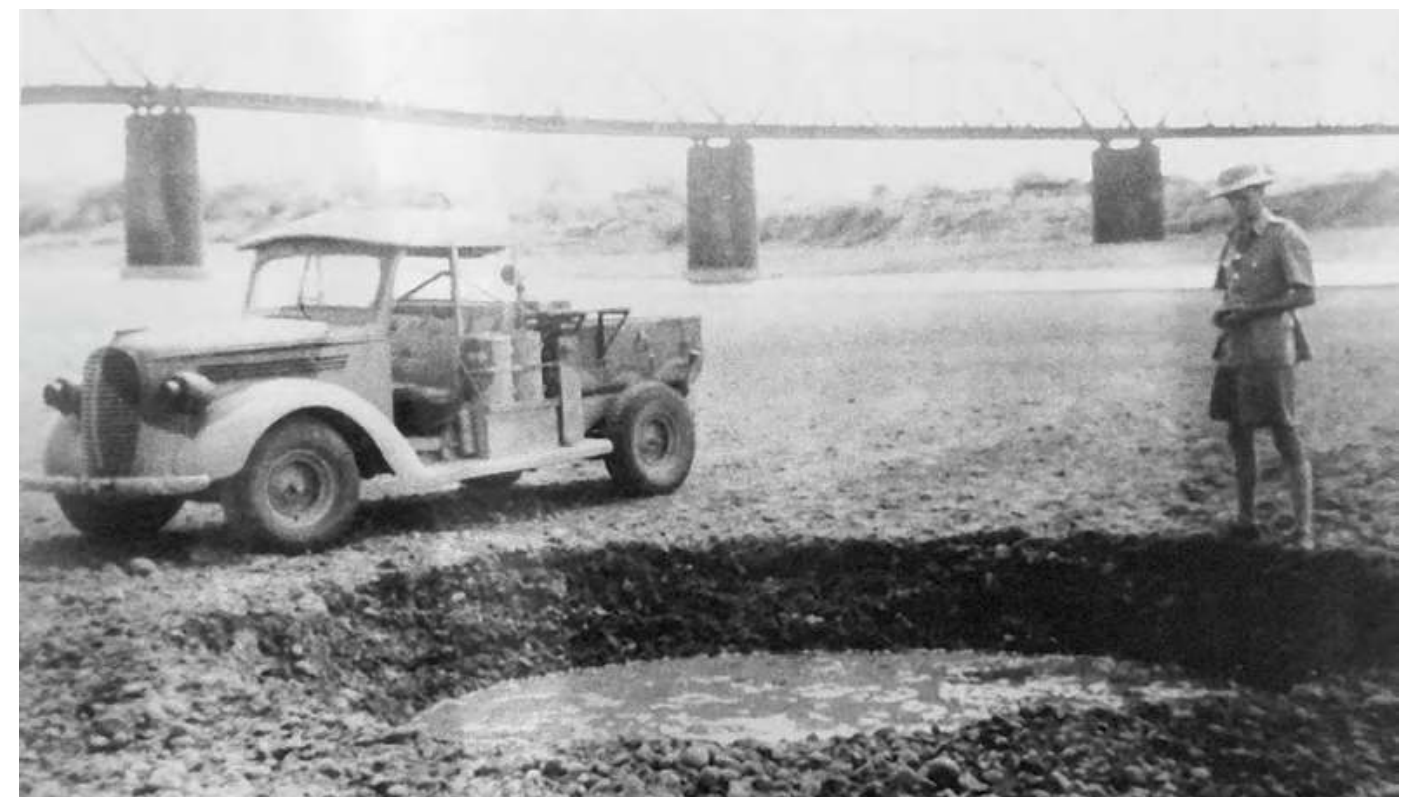

Troupes britanniques franchissant l'Atbara (frontière Soudan-Érythrée) en 1941.

Au sein du Congrès, d'où les membres soutenus par la Khatmiyya ont été éliminés, le mémorandum est l'œuvre des jeunes de la Mahdiyya (l'Ashiqqa), dont le leader est al-Azhari. Une autre tendance plus modérée, constituée de personnes moins jeunes, et proche de la famille d'Abd al-Rahman al-Mahdi soucieuse de garder le leadership, lance avec succès une campagne contre les leaders de la tendance jeune. Al-Azhari, isolé, va rechercher le soutien de la Khatmiyya. Une alliance entre Ashiqqa, Khatmiyya et Wafd égyptien se constitue pour réclamer l'unité de l'Égypte et du Soudan dans le cadre de la royauté égyptienne.

\section{Les prémisses de I'indépendance (1944-|956)}

La création des partis politiques. À la fin de la Seconde Guerre mondiale, le régime colonial favorise la liberté d'expression dans l'espoir que les tendances soutenant la colonisation et défavorables à l'Égypte se développent. Fin 1944 sont créés le Parti unioniste et le Parti libéral (émanation des jeunes mahdistes de l'Ashiqqa), tous deux souhaitant l'union avec l'Égypte, le premier sur un pied d'égalité, le second dans une fédération. Un parti nationaliste voit également le jour (il sera absorbé par l'Oumma). En 1945 est fondé le parti Oumma ${ }^{1}$, dont le leader Abd al-Rahman al-Mahdi va soutenir

1 Oumma (arabe) : la communauté des croyants, en islam. 
L'adaptation de l'administration locale et centrale. Après le refus par le gouvernement de Khartoum des conclusions de la conférence sur l'administration du Soudan lancée en 1946, un expert est mandaté et remet en 1949 un rapport qui souligne la confusion des responsabilités (fonctions judiciaires, exécutives et législatives exercées par les mêmes personnes) et l'inadaptation des lois passées entre 1937 et 1943. Ses recommandations sont adoptées en 1951 par l'assemblée législative et établissent clairement les pouvoirs des conseils des villes et des villages.

Un rapport spécifique propose des réformes pour mieux associer les Soudanais aux décisions prises au niveau central. Est proposée la création d'une assemblée législative consultative ainsi que d'un conseil exécutif du gouverneur composé pour $50 \%$ de Soudanais. Le rapport propose l'abandon de la politique d'isolement et l'extension des mesures au Sud. Les délégués sudistes manifestent pourtant des résistances au changement.

Le rapport est adopté ainsi que son extension au Sud. Le gouvernement du Soudan souhaite décoloniser mais au rythme des modérés. L'Égypte refuse les conclusions du rapport mais le gouvernement britannique l'accepte en juin 1948. Le texte de la loi précise la composition du conseil exécutif et précise certaines limitations au pouvoir de l'Assemblée (modifications constitutionnelles et relations internationales).

Les unionistes s'opposent à la mise en place des nouvelles institutions; il y a dix morts et une centaine de blessés lors des élections mais l'Assemblée législative se réunit pour la première fois en décembre 1948; les partis indépendantistes ont naturellement remporté les élections.

L'Assemblée législative. Une partie de la Khatmiyya souhaite participer à l'assemblée, et des tractations ont lieu avec les Ansars mais sans qu' un accord soit obtenu. Les mahdistes, soucieux de briser leur image de collaborateurs zélés des Britanniques, se mobilisent pour exiger une autonomie immédiate. Les Britanniques appuient l'accélération du processus et tentent d'impliquer la Khatmiyya; en décembre 1950, une commission pour la réforme de la constitution est formée, ainsi qu'une commission électorale.

En mars 1950, l'Égypte, ayant compris que les Britanniques préparent le Soudan à l'autonomie, abroge les traités de 1899 et de 1936 et propose une nouvelle constitution pour les deux pays réunis sous sa couronne. Le Soudan perçoit très mal ces décisions auxquelles, une fois de plus, il n’a pas été associé. Mais, juridiquement, le condominium a cessé d'exister. Sans le reconnaître, les Britanniques préparent la création d'un véritable gouvernement où chaque ministre sera doublé d'un conseiller anglais, mais où le gouverneur général ne gardera que le contrôle de l'armée et des forces de sécurité; en outre un ministère sera réservé à un Sudiste. 
Un projet anglais de réforme du système exécutif et législatif est présenté à l'assemblée législative en avril 1952: il prévoit un Premier ministre élu par l'Assemblée et nommé par le gouverneur général. Adopté, le texte est envoyé aux gouvernements anglais et égyptien. Les mahdistes tentent sans succès de convaincre les Égyptiens, qui refusent de l'accepter...

Le coup d'État des Officiers libres égyptiens transforme la situation: le nouveau Premier ministre, le général Neguib, soutient la position mahdiste. Un accord est signé, qui propose une période transitoire d'autonomie sous contrôle international, puis l'auto-détermination du Soudan.

En mars 1953, les Anglais signent avec les Égyptiens le dernier acte du condominium, dans lequel ils acceptent les propositions des Égyptiens et des Soudanais. Une commission électorale est formée en vue des élections pour la fin de l'année 1953.

Le groupe Ashiqqa fonde le National Unionist Party (Nup) qui regroupe tous les Unionistes sous la houlette d'al-Azhari. L'Oumma est battue aux élections de décembre 1953: sa collaboration, réelle ou supposée, avec les Britanniques, mise en avant par le Nup, a joué en sa défaveur. Mais il s'agissait plus d'un vote négatif contre la Mahdiyya, la monarchie et le colonisateur.

L'autonomie. Après la victoire du Nup, le parlement se réunit et al-Azhari est élu Premier ministre. L'ouverture solennelle du Parlement en mars 1954, à laquelle doit assister le général Neguib, est transformée en émeute mortelle par la Mahdiyya qui envoie ses Ansars en masse à l'aéroport.

de 1820 La propagande égyptienne pour l'unité, l'arrestation du général Neguib et l'interdiction des Frères musulmans vont renforcer l'animosité soudanaise vis-à-vis de l'Égypte et de Nasser. Al-Azhari cherche à négocier avec l'Oumma, pendant que des ministres liés à la Khatmiyya démissionnent et fondent un parti modéré mais indépendantiste... Al-Azhari, isolé, change son fusil d'épaule et se rallie aux thèses indépendantistes, ce qui contribue à désintégrer le Nup mais lui attire le soutien de l'Oumma.

Dès cette période, les indices de détérioration des relations entre Khartoum et le Sud du pays s'accumulent. Vers la fin de 1954, les autorités publient une liste de 800 postes de fonctionnaires voués à remplacer les Britanniques en train de partir, et les Sudistes constatent que seuls... six postes leur sont destinés! En décembre 1954, l’Oumma et un parti sudiste réalisent une tournée dans le Sud afin de lancer l'idée d'une solution fédérale pour rétablir l'équité entre le Nord et le Sud. Le Premier ministre al-Azhari réagit de façon disproportionnée contre cette... «tentative d'atteinte à l'unité nationale». En juillet 1955, le député de Yambio est arrêté après une série de réunions critiques vis-à-vis du gouvernement. Des manifestations 


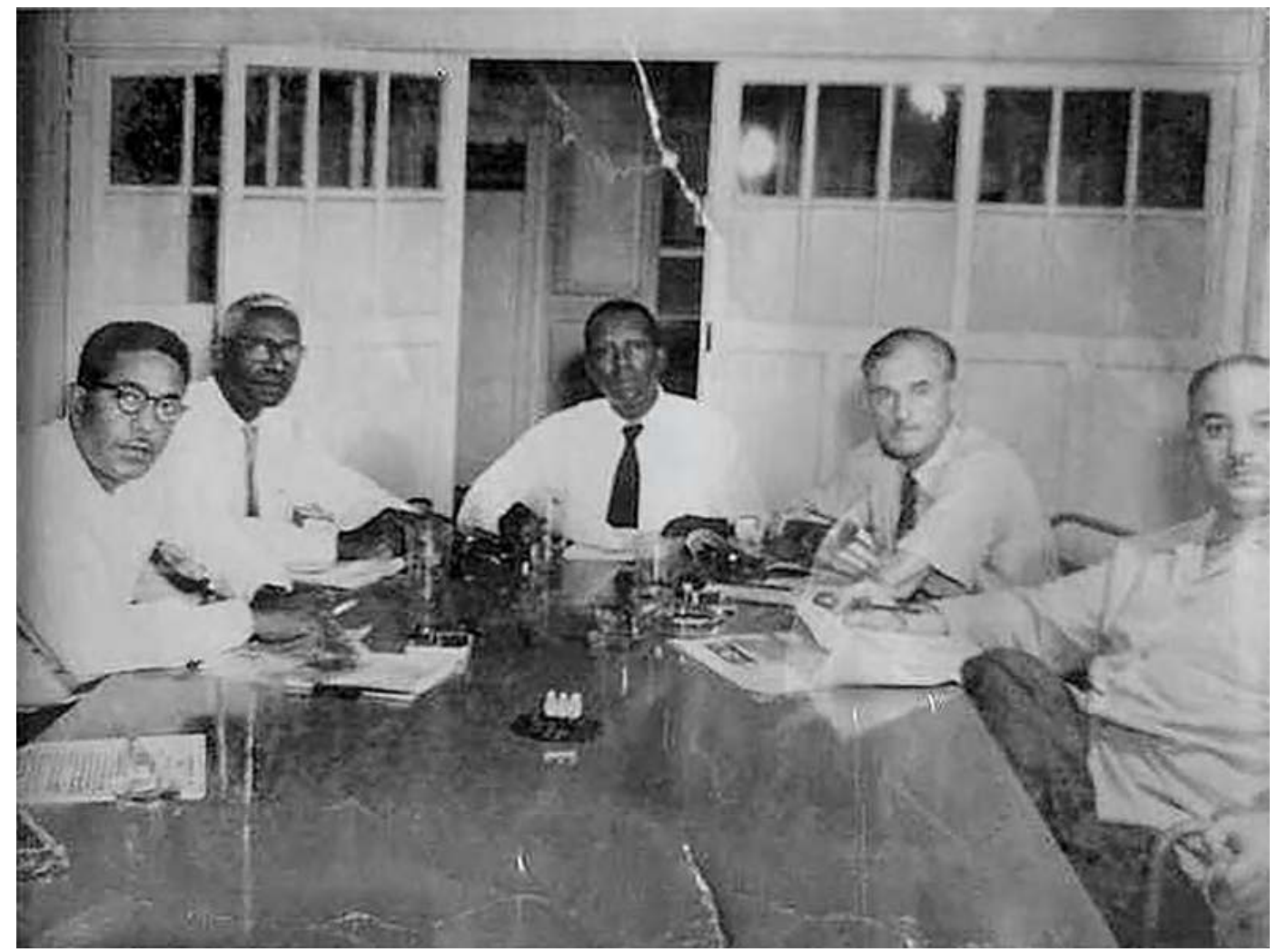

Le comité pour l'indépendance du Soudan à l'œuvre.

en sa faveur dégénèrent et l'armée réprime l'émeute, tuant huit personnes. De plus, dès juillet 1954, les officiers britanniques encadrant les 1600 soldats de l'Equatorial Corps ont été remplacés par des officiers arabes, qui ignorent les coutumes locales. Les émeutes de Yambio provoquent une mutinerie à Torit le 18 août 1955: les officiers sont massacrés. En quelques jours, les civils du Nord sont poursuivis par les populations sudistes. Les soldats en rébellion appellent les Britanniques à l'aide, mais, lorsque les troupes du Nord transportées par la RAF arrivent à Torit, les mutins, craignant des représailles, ont pris le maquis malgré les assurances du gouverneur général.

En août, le Parlement demande l'indépendance immédiate. En août toujours, les troupes anglaises évacuent le Soudan et le gouverneur général quitte Khartoum le 17 décembre. Les leaders de deux confréries conviennent d'un projet de gouvernement d'union nationale.

Lorsque la proclamation d'indépendance est présentée au Parlement, le 19 décembre 1955, les Sudistes hésitent à la soutenir et préféraient demander un statut fédéral; des promesses leur ayant été faites, le 22 décembre 
les députés sudistes votent en bloc la motion d'indépendance, sans chercher à obtenir ce statut fédéral. Le 31 décembre, la constitution est adoptée, et le Soudan devient indépendant le $1^{\text {er }}$ janvier 1956.

\section{Développement économique sous le condominium}

le Soudan

\section{2}

de 1820

à nos jours
L'établissement d'un système foncier est, dès 1899 , l'une des priorités de l'administration nouvellement installée à Khartoum. Après une régularisation par un enregistrement prenant en compte les droits acquis, les transactions sur les terres non enregistrées ne sont pas autorisées, ce qui protège les droits des petits paysans soudanais, et — l'administration craignant l'arrivée de colons ou de businessmen occidentaux - empêche une colonisation européenne basée sur l'agriculture. De même, la présence étrangère dans les autres secteurs de l'économie demeure très faible, ce qui est une des causes de la faible industrialisation du Soudan.

L'agriculture et l'élevage vont se développer avec l'instauration de la pax britannica; à titre d'exemple, la valeur de la production cotonnière passe de 1916 à 1917 de 269993 à 564303 livres sterling, alors que ne sont pas encore lancés les grands programmes d'irrigation des années 1920. Et la production de bovins et d'ovins va également croître de façon considérable.

Les impôts sont modérés et respectent les habitudes des Soudanais, dont certains peuvent seulement payer en nature. Les impôts directs touchent la terre, les troupeaux, les palmiers. L'impôt indirect est prélevé sur les productions locales: la gomme arabique en fournit l'essentiel, qui est complété par les taxes touchant l'ivoire, les plumes d'autruche et le caoutchouc.

Les douanes apportent peu de recettes: $8 \%$ sur les importations - sauf sur celles provenant d'Égypte qui en représentent l'essentiel, en application de l'article 7 de l'accord établissant le condominium; et $1 \%$ sur les exportations.

Le budget soudanais est équilibré jusqu'en 1913 par une subvention de l'Égypte, dont la seule justification repose sur le fait que le Soudan n'était pas indépendant. À titre d'exemple, voici le budget de l'année 1907, tel que présenté dans le Journal officiel du Soudan.

Budget 1907. Les recettes (1355723 livres égyptiennes) proviennent d'abord du service des vapeurs, bateaux et chemins de fer, géré par le gouvernement $(31 \%)$, ensuite de la subvention du gouvernement égyptien $(28 \%)$, puis des différentes taxes $(21 \%)$ : essentiellement taxe foncière, taxes sur les animaux, les habitations et les routes, droits d'enregistrement et de douane, royalties sur la gomme arabique, l'ivoire et les cuirs. Les départements, le gouvernement égyptien, et des provinces alimentent 
Le budget 1907.

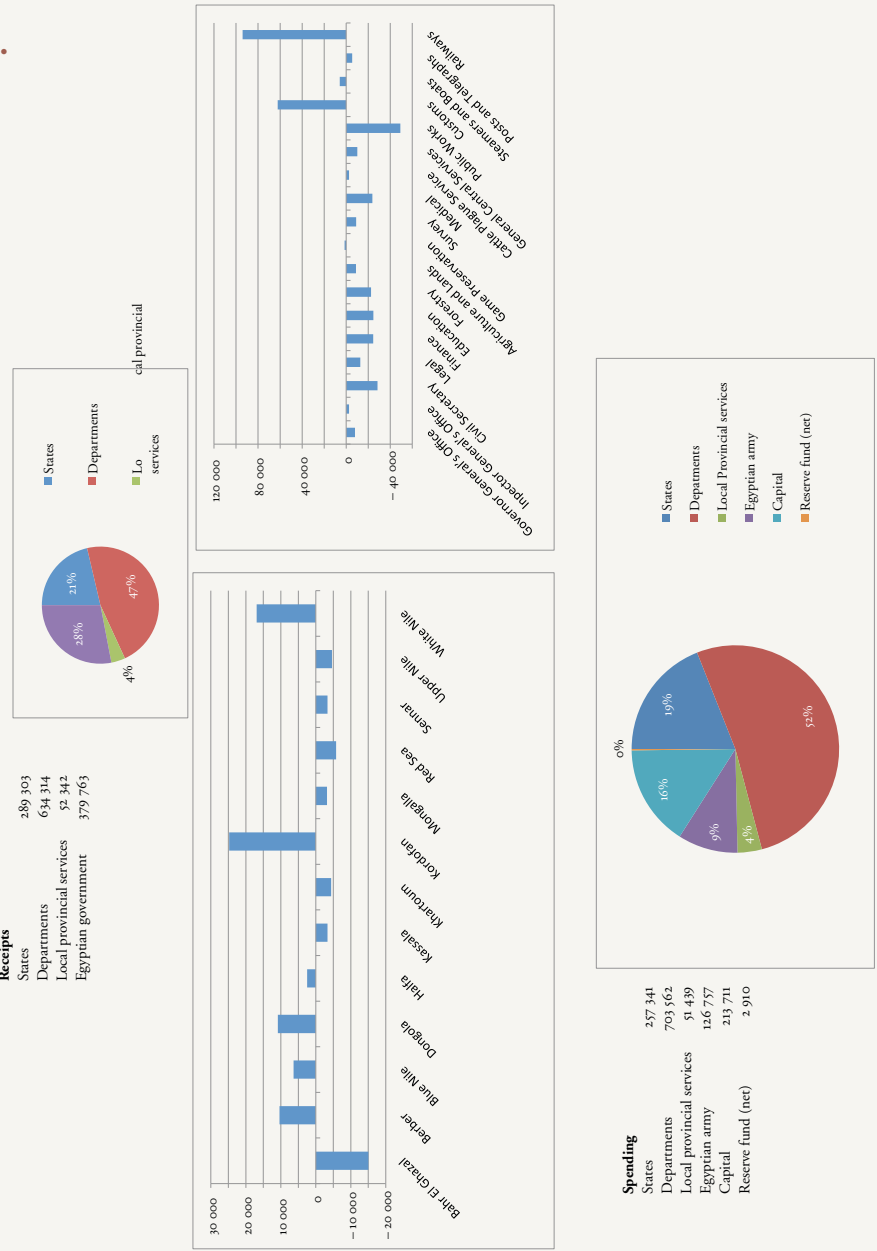

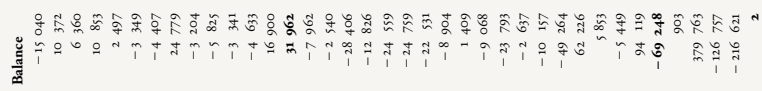

\section{3}

le condominium angloégyptien 1899-1955

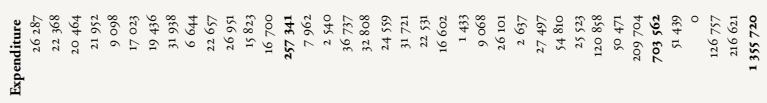

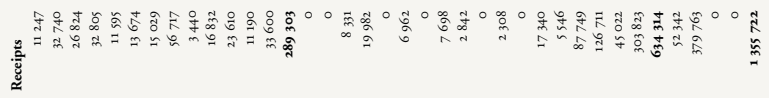

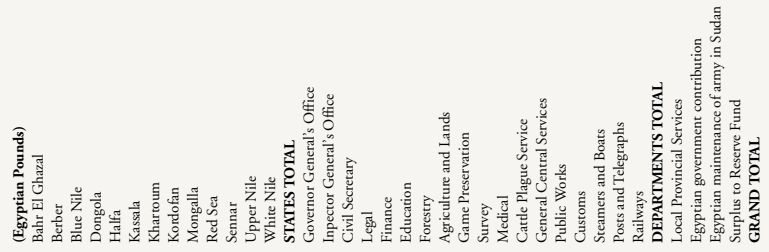


respectivement $47 \%, 28 \%$ et $21 \%$ des recettes. Certaines de ces dernières présentent un bilan excédentaire: Berber, Dongola, Wadi Halfa, Nil Bleu et Nil Blanc, et surtout Kordofan; les provinces déficitaires sont le Bahr el-Ghazal, Mongalla (future Équatoria), Upper Nile, le Sennar, Red Sea, Kassala et Khartoum.

Les dépenses (1355734 livres égyptiennes) se répartissent entre les départements $(57 \%)$, les provinces $(19 \%)$ et l'armée égyptienne (9\%). Elles sont essentiellement constituées de salaires (41\%), d'allocations et services $(30 \%)$ et d'investissements $(16 \%)$. Les provinces où les dépenses les plus importantes ont été réalisées sont celles du Kordofan, du Sennar, du Bahr el-Ghazal, puis celles de Red Sea, Berber et Dongola. Les secteurs qui bénéficient le plus des dépenses sont ceux des chemins de fer, des vapeurs et bateaux $(25 \%)$, des travaux publics $(18 \%)$, des routes et moyens de communication ( $13 \%)$ et des extensions du réseau télégraphique $(11 \%)$.

Même si la politique des closed districts est officiellement terminée après 1944, on retrouve néanmoins encore, dans l'almanach 1952 édité par le gouvernement du Soudan, un article relatif aux zones de commerce avec restriction. Il informe que les Non-Soudanais, de même, du reste, que les Soudanais, sont interdits d'entrée ou de commerce dans certaines provinces sans permission spéciale du secrétaire civil ou du gouverneur : il s'agit des provinces d'Équatoria, du Haut Nil et du Bahr el-Ghazal, de la région des Monts Nouba, de l'ouest du Darfour et du sud de la province du Nil Bleu (district de Fundj).

Le transit, l'importation, la production et le commerce de boissons alcoolisées sont strictement réglementés. Un résident souhaitant importer de l'alcool pour sa consommation personnelle doit demander un permis au gouverneur de la province; une licence d'importation délivrée par le département de l'économie et du commerce est également requise.

\section{Développement des infrastructures et projets de développement.} La construction du chemin de fer entre Wadi Halfa, où elle a commencé en 1896 , et Khartoum Nord visait à faciliter la pénétration militaire angloégyptienne lors de la reconquête du Soudan, achevée en 1898. Le premier pont ferroviaire sur le Nil Bleu est édifié en 1909 par Georges Camille Imbault pour la Cleveland Bridge \& Engineering Co. Ltd; il réunit Khartoum Nord à Khartoum; d'une longueur totale de 560 mètres, il est constitué de sept travées fixes et d'une travée mobile de 30 mètres permettant le passage des bateaux (voir photo p. 665). 


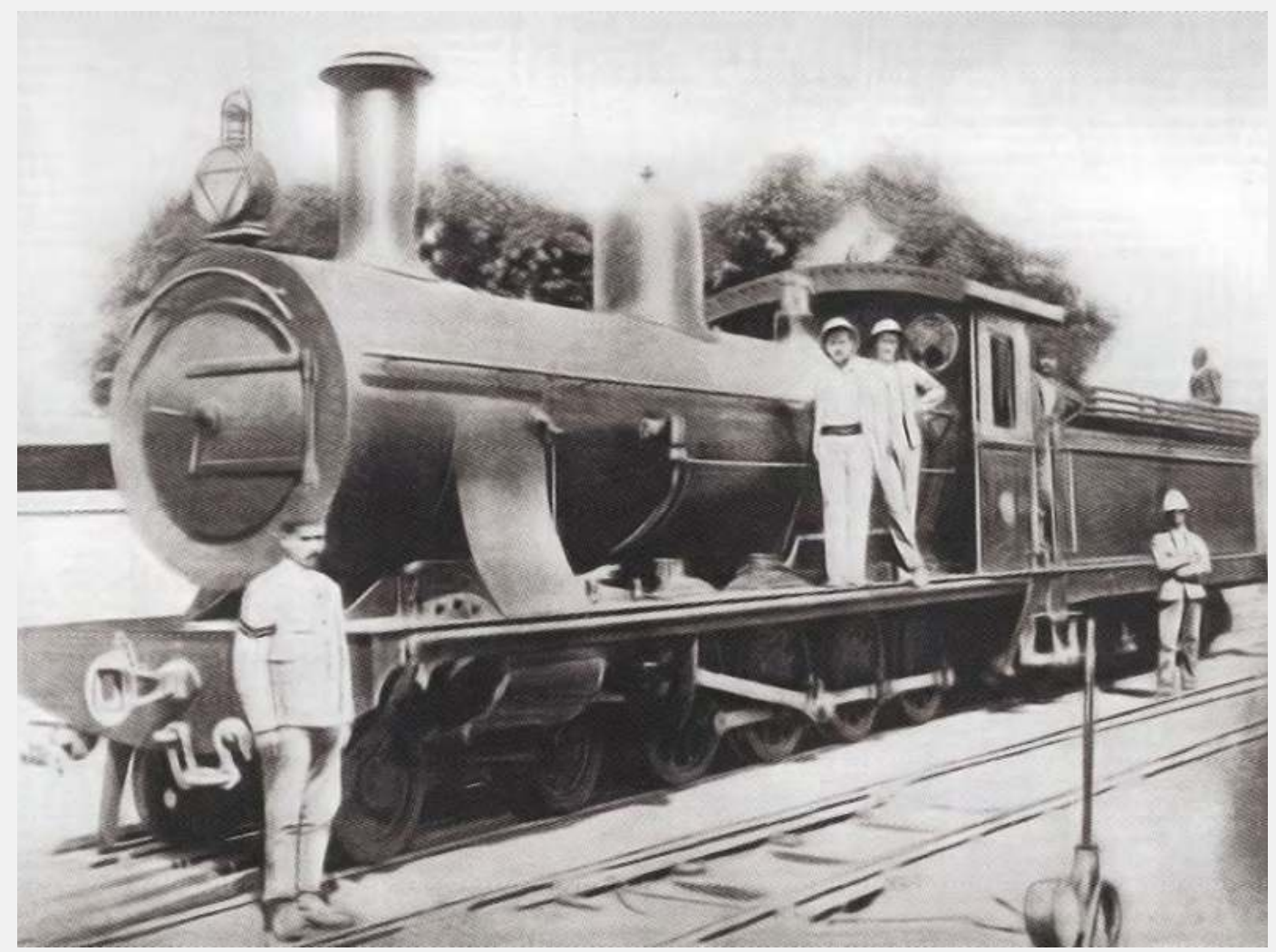

Locomotive classe «Dongola », 1898.

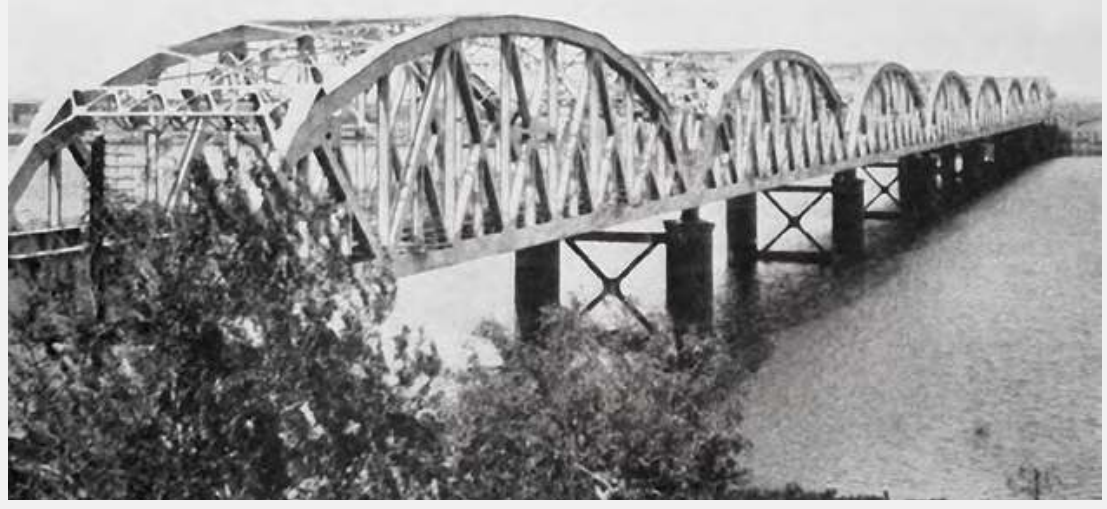

le condominium angloégyptien 1899-1955

\section{Le Armed}

Forces Bridge

vu des casernes

de Khartoum.

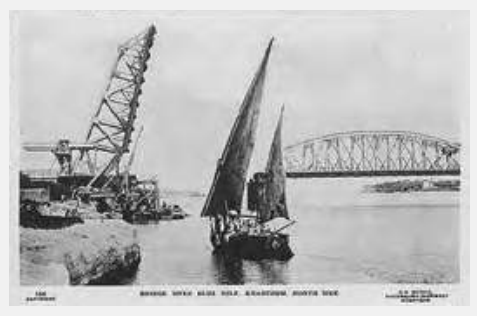

Le pont mobile en fonctionnement. 
le Soudan

\section{6}

de 1820

à nos jours
Le réseau ferroviaire est poursuivi jusqu'au Sennar en 1909 ainsi que vers le Kordofan (el-Obeïd 1912). Une seconde ligne va relier Port-Soudan en passant par Kassala en 1924: le réseau de chemin de fer dessert les zones cotonnières et favorise l'exportation du coton. Après 1927, le réseau ne sera plus étendu.

L'administration va également construire des barrages au Sennar ainsi qu’à Gébel Aulia.

Khartoum est bientôt doté d'un aéroport qui assure des liaisons avec Le Caire, l'Ouganda, le Kenya, les Indes, et aussi l'est du Congo belge via Juba. En 1932, les Imperial Airways réalisent le premier vol KhartoumCapetown. En 1935, il y a deux vols par semaine pour Le Caire et Capetown. À cette époque, on compte 118 terrains d'aviation officiels, et 38 sites pouvant recevoir des hydravions. En 1935 est ouverte une liaison KhartoumAsmara, opérée par la compagnie italienne Ala Littoria qui assure à partir d'Asmara la liaison avec Rome via Benghazi et Le Caire.

En 1926, le projet de développement de la Gézireh est lancé. Après les accords sur les eaux du Nil de 1929 (qui constitueront un obstacle à l'extension des surfaces irriguées), l'irrigation s'étend et couvre une surface de 500000 feddans ${ }^{1}$. Le programme implique trois partenaires: le gouvernement qui reçoit $40 \%$ des recettes et prend en charge l'infrastructure et le remboursement des prêts; le Sudan Plantation Syndicate, société privée qui a charge de commercialiser le coton produit et reçoit $20 \%$ des recettes; les paysans soudanais qui reçoivent chacun 40 feddans et auxquels reviennent $40 \%$ des recettes.

Mais la crise mondiale de 1929 entraîne une mévente du coton et alors que le budget de l'État était bénéficiaire depuis quelques années, il sera désormais déficitaire jusqu’à la Seconde Guerre mondiale. Durant la décennie 1930-1940 le développement marque le pas: le budget de l'État diminue presque de moitié; les investissements sont très réduits (il faut rembourser le chemin de fer de Kassala); et si quelques projets voient le jour au Nord, au Sud on n'en lance pratiquement pas. Par contre, l'élevage va connaître un essor considérable entre 1936 et 1946, à la faveur, notamment, de la mise en place de services vétérinaires pendant cette période.

1 Feddan: unité de mesure de surface utilisée en Égypte, au Soudan et en Syrie; un feddan correspond à 4200 mètres carrés, soit 0,42 hectare. 

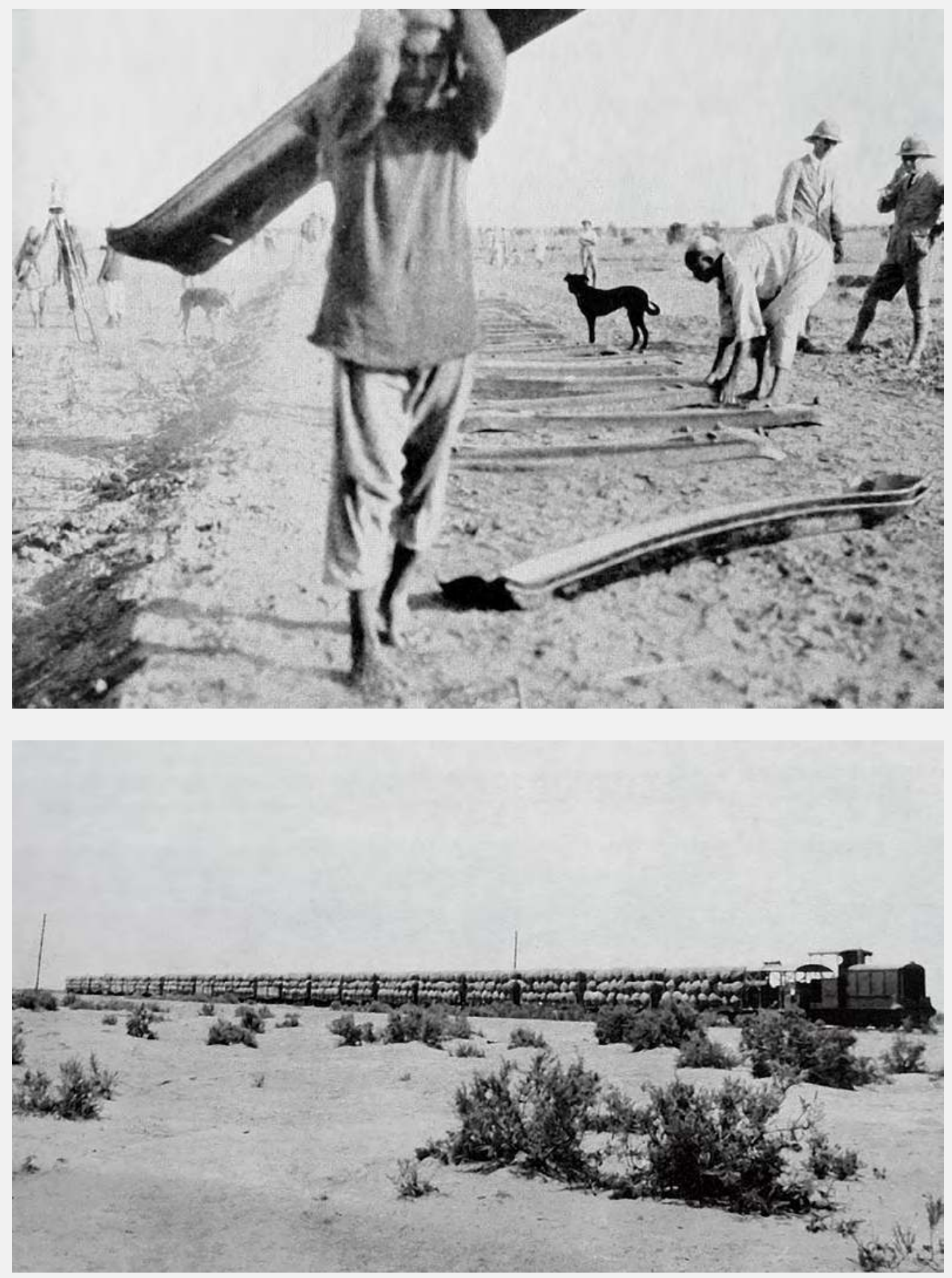

le condominium angloégyptien 1899-1955

Construction du chemin de fer vers Kassala.

Le train allant de Tokar à Trinkitat en 1934. 


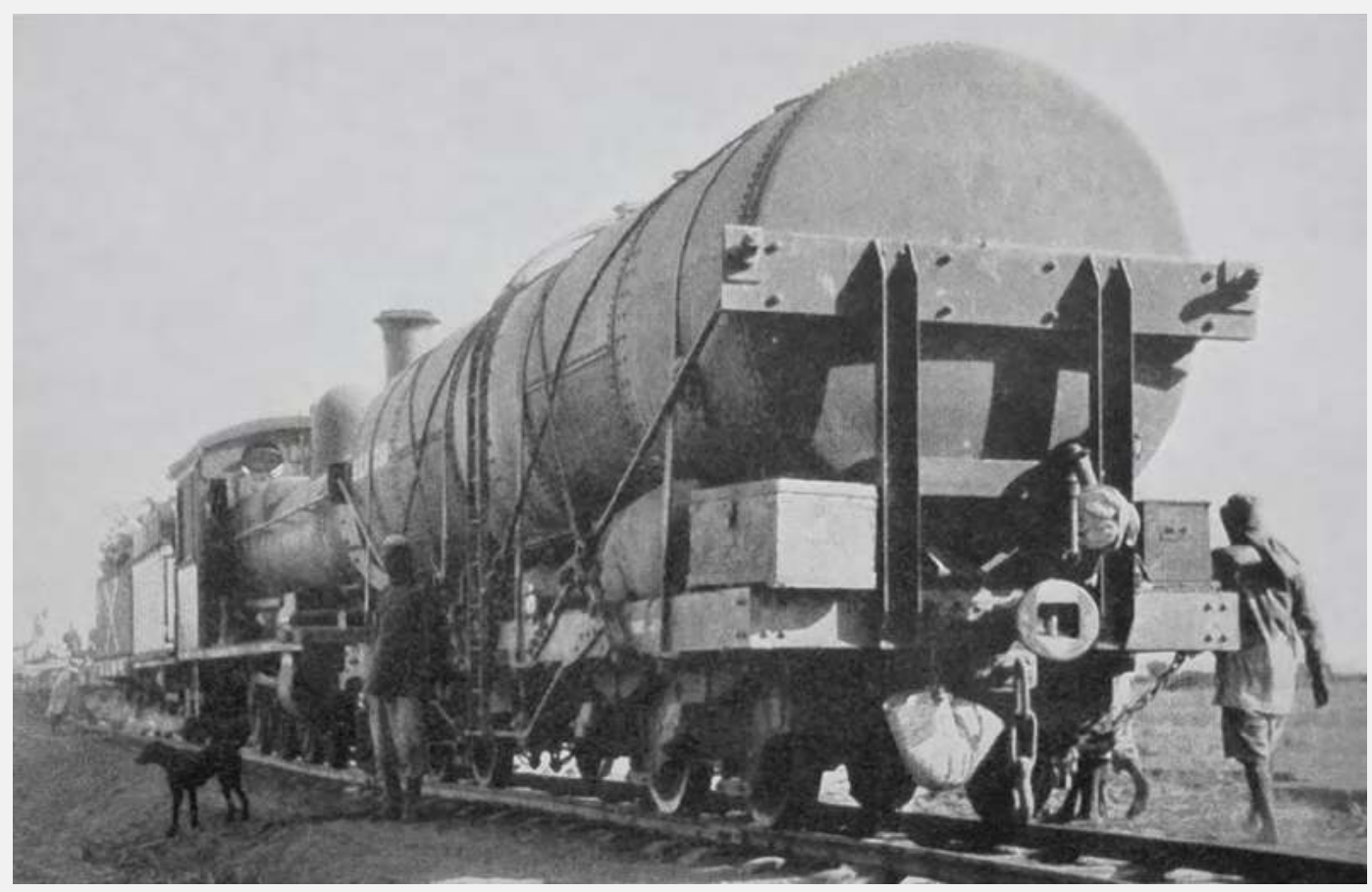

le Soudan

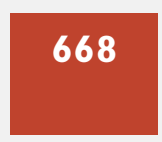

de 1820

à nos jours

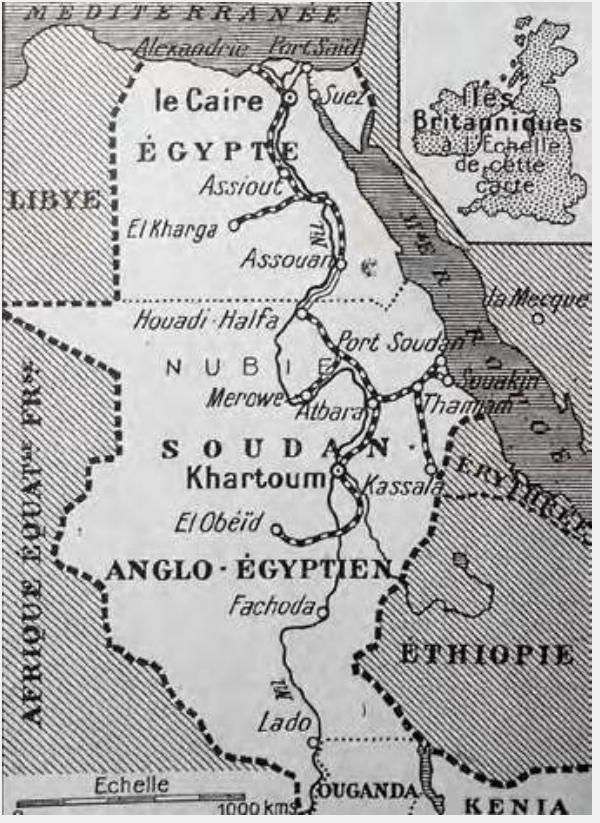

Le train pour Kassala en 1924.

Le réseau ferroviaire du Soudan en 1925.

Le pont Khartoum-Omdurman.

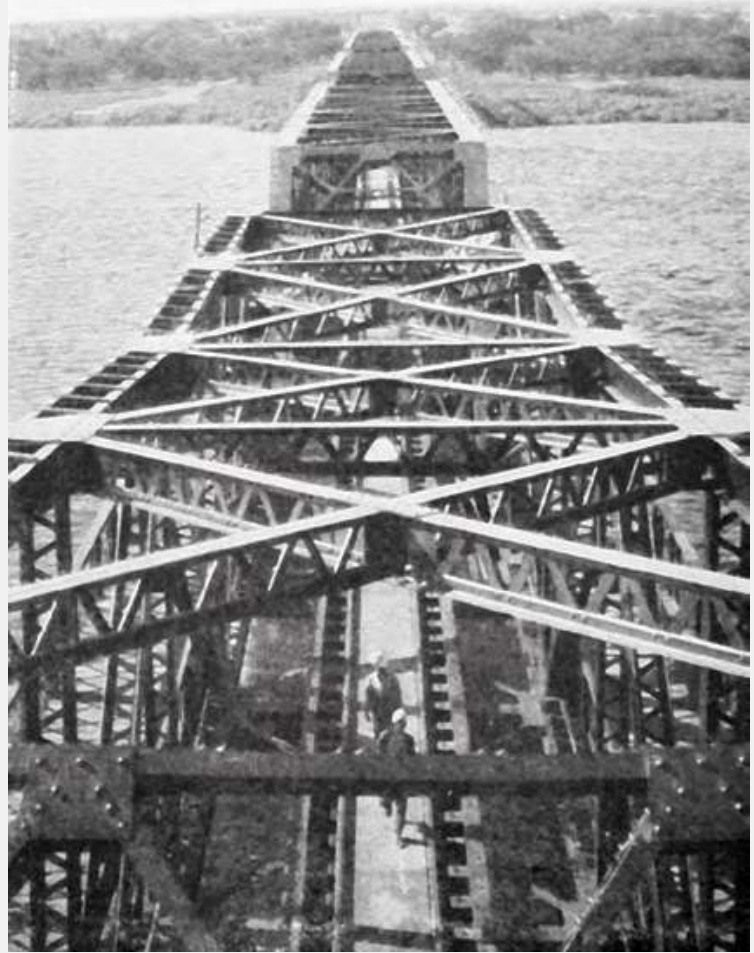




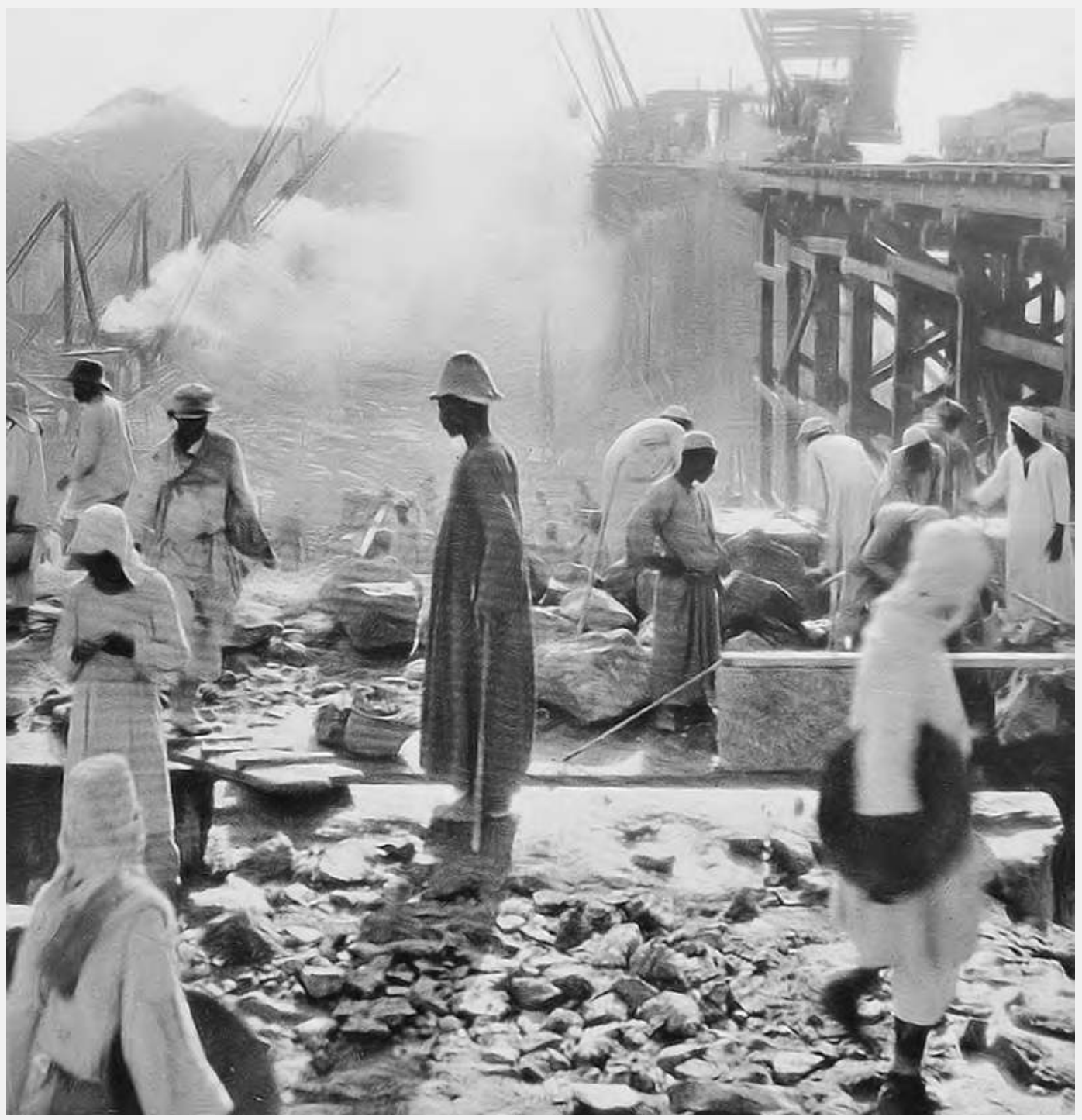

Construction du barrage sur le Nil Bleu (Sennar). 


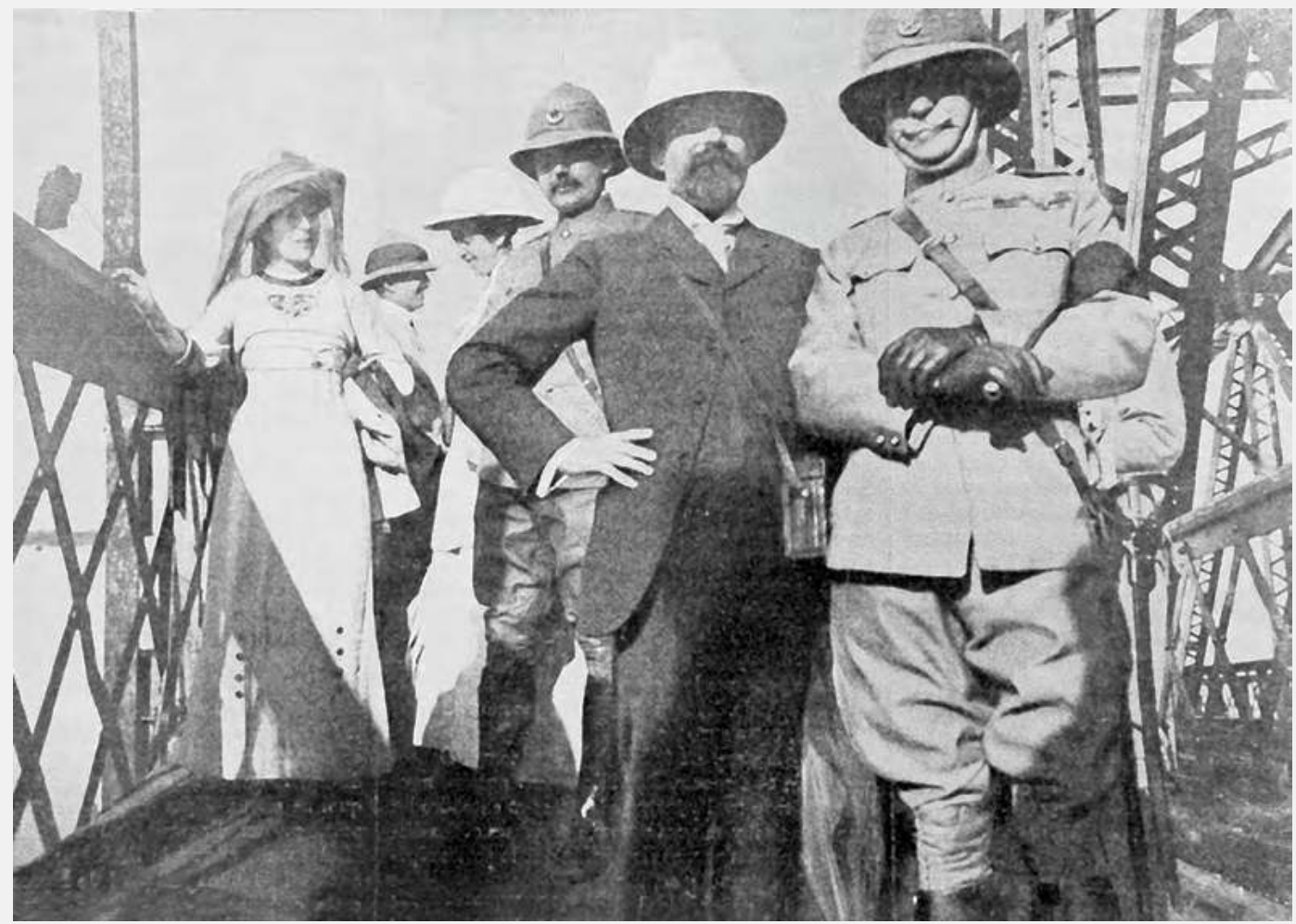

\section{0}

de 1820 à nos jours

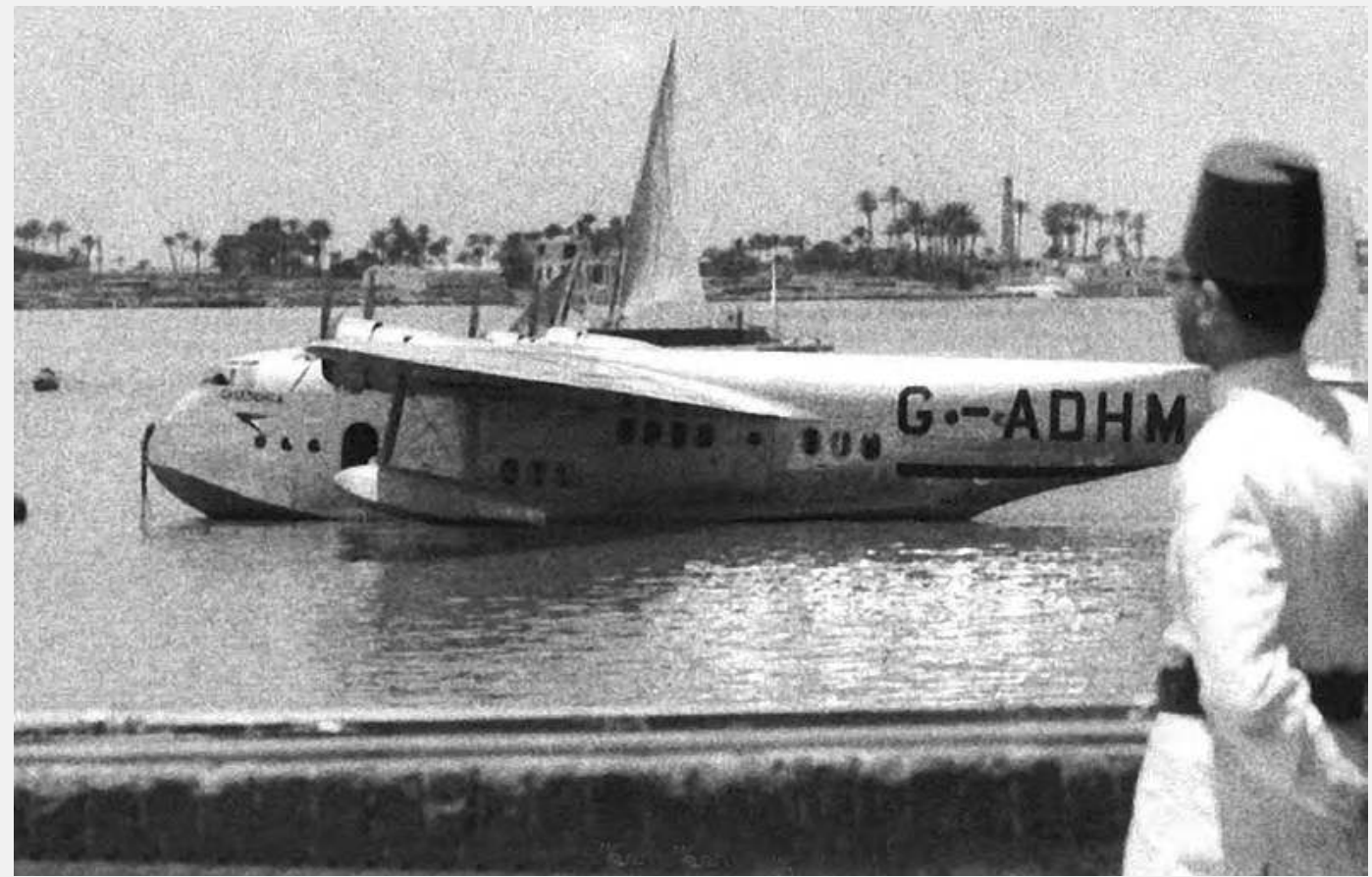

L'inauguration du pont de Kosti en 1911.

Hydravion posé sur le Nil. 
Rapport officiel du gouvernement du Soudan sur l'administration, les finances et la situation du Soudan en 1935 (extraits). Ce rapport, préparé par le gouverneur général du Soudan, Stewart Symes, est présenté au ministre britannique des Affaires étrangères par l'ambassadeur pour l'Égypte et le Soudan.

《LLe redressement économique et financier du Soudan, entamé en 1934, s'est accéléré en 1935. Les revenus ont augmenté de 3774911 à 4098413 livres égyptiennes. [...] Les taxes ont été collectées avec une relative facilité, l'épargne a augmenté, et les ventes de sucre ont progressé de $34 \%$. De bonnes récoltes, en particulier celle du coton — le rendement de la Gézireh a augmenté de 99000 balles (moyenne des dix dernières années) à 165000 balles —, sont les principales causes de cet accroissement de la prospérité, reflété par les recettes douanières et celles des chemins de fer, et dans une augmentation du trafic maritime à Port-Soudan, passant de 886 à 1181 navires.

Dans le retour progressif à la prospérité d'avant 1930, la valeur totale du commerce extérieur a augmenté de $28,7 \%$. [...] La GrandeBretagne compte pour $47 \%$ des exportations et fournit $32 \%$ des importations, suivie de l'Égypte, responsable de $12,5 \%$ des exportations er de $16 \%$ des importations.

Des firmes anglaises s'établissent, versées pour la plupart dans l'importexport, ainsi que de nombreuses succursales de banque. La guerre, entraine une flambée du prix du coton, ce qui renfloue les caisses du gouvernement... mais la forte inflation générale qui l'accompagne suscite des tensions sociales et, partant, la création de syndicats que les communistes vont dominer.

Afin de remédier à la carence des investissements, deux programmes quinquennaux de développement sont conçus pour la période 1946-1956. Ils portent sur le renforcement des équipements de l'État, la mécanisation de l'agriculture, l'enseignement supérieur et la santé, le développement du Sud et la production d'énergie. L'industrialisation ne fait pas partie des priorités.

À leur terme, les surfaces irriguées se sont beaucoup accrues, l'élevage d'est développé de façon significative, quelques usines nouvelles ont été créées, les écoles primaires et secondaires se sont multipliées, mais le Sud reste très défavorisé (il n'accueille, par exemple, qu'une seule des vingt écoles secondaires créées pendant la période). 
Croissance démographique et main-d'œuvre. En 1930, la population soudanaise est le double de celle estimée en 1900 et atteint quelque 6 millions d'habitants. Le premier recensement, organisé en 1956, fait apparaître, après ajustement, un chiffre de population de 10,3 millions d'habitants.

Malgré cette croissance, la main-d'œuvre est insuffisante, ce qui constitue un frein important au développement économique. Depuis l'époque mahdiste, à la suite de la fermeture des marchés du Caire et de l'Empire turc, le trafic d'esclaves a fortement diminué. Le Sud est peu accessible dans les premières années du condominium. L'agriculture pâtit alors de la mobilisation d'une importante main-d'œuvre dans la construction des chemins de fer, la reconstruction de Khartoum et la création des bâtiments administratifs dans les grandes villes.

Limmigration fut encouragée: ainsi celle des Fellata de l'Afrique de l'Ouest encore installés de nos jours dans la Gézireh et jusqu’au Nil Bleu. En 1911, Khartoum compte 18235 habitants, Khartoum Nord 35285 et Omdourman 42779. En 1952, Khartoum en compte quatre fois plus (7500o habitants), tandis que la population de Khartoum Nord n’a presque pas évolué (34000) et que celle d'Omdourman a été multipliée par deux et demi (125000).

le Soudan

672

de 1820

à nos jours

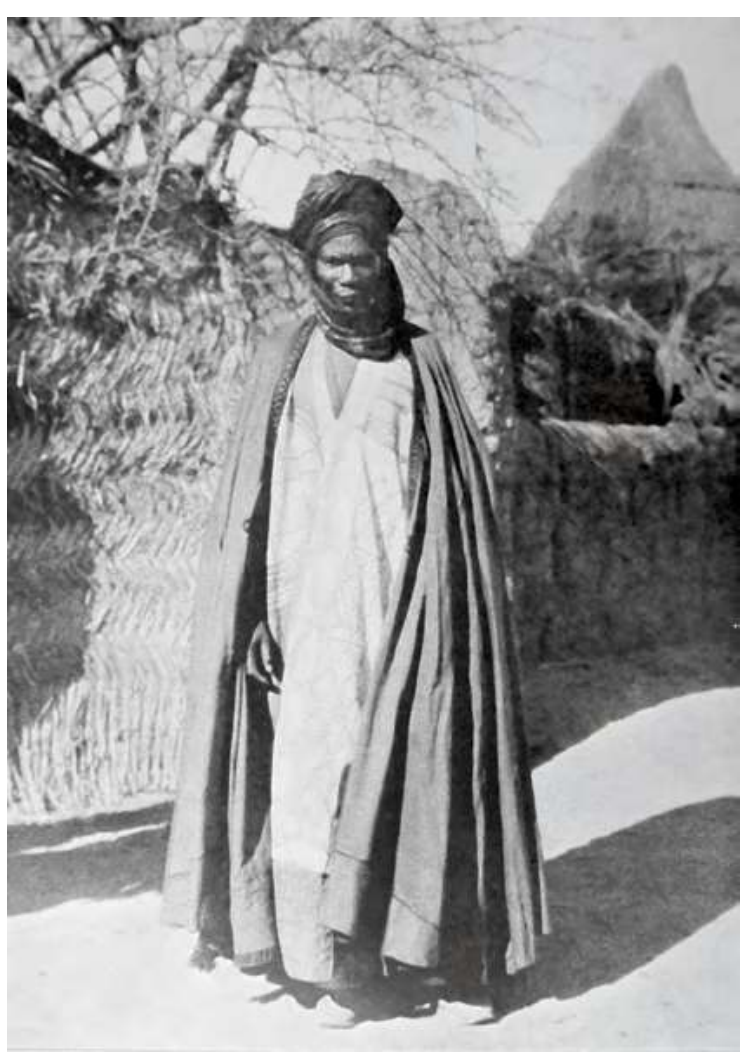

Chef Fellata

(Dugmore 1924). 


\section{Développement du tourisme}

C'est dès avant la période mahdiste, à partir des années 1870 , que le tourisme a commencé à se développer. Le pratiquent surtout des militaires anglais accompagnés de leur famille, ainsi que des voyageurs français et américains. Certains touristes, à partir de la vallée du Nil, font une incursion jusqu'à Khartoum pour visiter les vestiges de l'Égypte ancienne, d'autres continuent vers le sud du Soudan qui est très recherché pour le big game de par sa richesse en gros gibier (l'administration du condominium réglemente strictement la chasse, tant pour le nombre d'animaux que les chasseurs peuvent abattre que pour les armes et munitions autorisées, et pour le permis de chasse obligatoire).

Quelques voyageurs viennent aussi des colonies de l'Ouganda et du Kenya. Et des ressortissants Belges organisent des croisières entre la Belgique et l'est congolais via le Nil. La photographie ci-dessous, en couverture du journal français L'Illustration du 30 décembre 1905, est assortie de ce titre: "Villégiature d'hiver en Afrique centrale: sur les rives du Nil Blanc: touriste anglaise et beautés du Soudan».

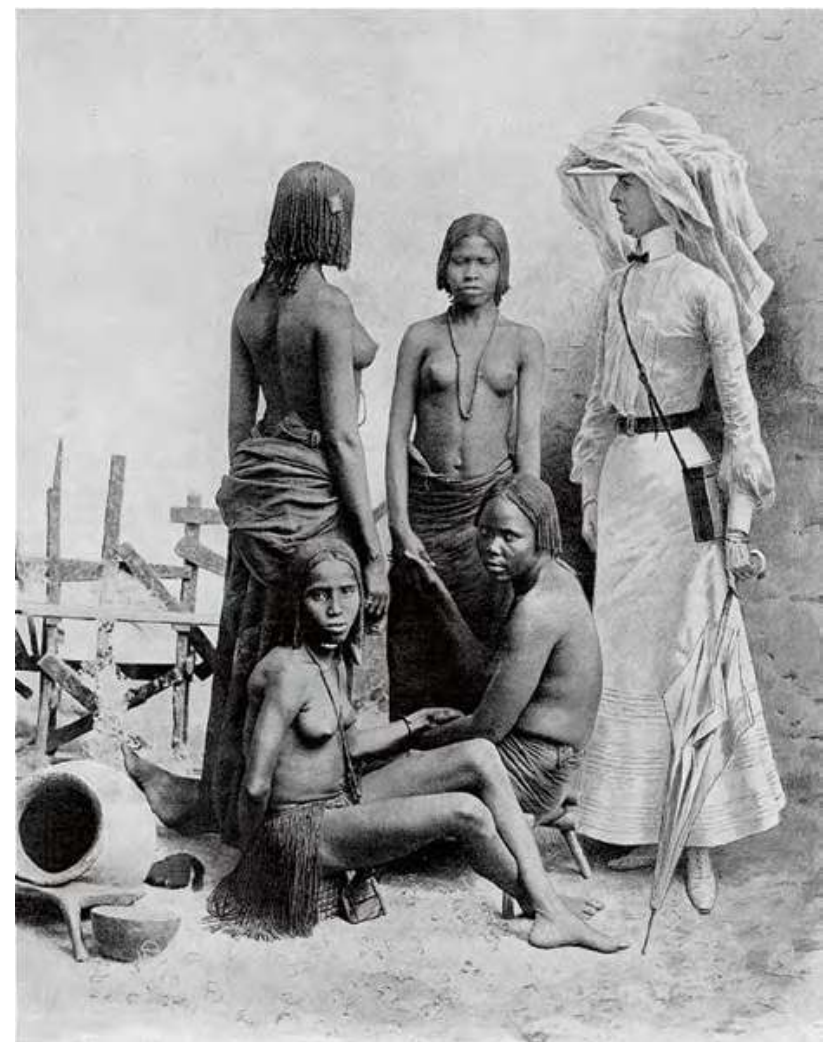

Touriste

britannique

(avant 1905). 
le Soudan

\section{4}

de 1820

à nos jours
L'auteur de l'article explique qu'il est alors possible de voyager jusqu'au centre de l'Afrique, avec tout le confort du vingtième siècle, et que des dames et même des enfants peuvent se rendre, sans difficultés et sans aucun danger, là où à peine six ans plus tôt seuls les Stanley et les Marchand pouvaient parvenir, et au prix de quels efforts.

Il est maintenant possible aux chasseurs d'atteindre, en moins de deux semaines, en bateaux à vapeur et en trains de luxe, les rivières peuplées d'hippopotames et de crocodiles, les forêts habitées par les lions, les éléphants, les buffles, les antilopes... et ces voyages et ces chasses sont à la portée de ceux qui disposent de moyens relativement modestes. Pour quatre mille francs (français) par personne, on peut se rendre de Paris au cœur même du Soudan anglo-égyptien par un voyage de deux mois via Marseille, Naples, Alexandrie, Le Caire, Louxor, Assouan, Khartoum, le Nil Bleu, et remonter le Nil Blanc jusqu’à Fachoda et plus loin encore.

Les voyageurs inexpérimentés peuvent se procurer à Paris même, à l'Agence Cook, tous les billets de chemin de fer, de wagon-lit, de bateau à vapeur, tous les coupons d'hôtels dont ils auront besoin, au moins jusqu'à Khartoum. Partout ils trouveront des interprètes qui s'occuperont de leur personne et de leurs bagages.

De Paris à Marseille, c'est le grand luxe et la rapidité: le fameux train Côte d'Azur, qui fait le trajet en dix heures, est incontestablement ce qui se fait de mieux en Europe. De Marseille à Alexandrie, le voyage est de cinq à six jours et de nombreux services réguliers sont disponibles: les Messageries Maritimes de France, le Peninsular and Oriental et autres grandes lignes anglaises, la Lloyd de Brème ont établi un service bihebdomadaire de grand luxe, avec escale à Naples. Le prix des cabines est élevé, mais il est impossible de rêver mieux. Enfin, une ligne anglaise, The Bibby Line, qui a de superbes bateaux, vend des billets aller et retour de Marseille pour 550 francs.

À Alexandrie, le voyageur a sa première vision d'un Orient à moitié européen, où la pauvreté, la misère et la saleté se retrouvent à côté des somptueux palais. D'excellents express avec wagons-restaurants de la Compagnie Internationale font le trajet d'Alexandrie au Caire en trois heures.

Nous appellerons la capitale de l'Égypte notre première grande étape, et je calcule qu'on peut y parvenir, de Paris, pour la somme de 900 francs aller et retour, en $1^{\text {re }}$ classe, bien entendu.

Notre seconde étape nous conduira à Louxor, l'ancienne Thèbes, où sont les merveilleuses ruines du temple de Karnak et les fameuses tombes royales, puis de là à Assouan, située à la première cataracte, sur la frontière avec la Nubie. Par train, une nuit suffit jusqu’à Louxor, dans de superbes 
wagons-lits appartenant à la Compagnie Internationale. On passera deux jours à Louxor dans l'un ou l'autre des excellents hôtels (Grand ou Karnak) appartenant à un Français, M. Pagnon. Huit heures de chemin de fer sont nécessaires entre Louxor et Assouan. Dans cette dernière ville, nos "luxes" trouveront deux admirables palaces hôtels, le Cataract et le Savoy, de 20 à 40 francs par jour. Mais le moyen le plus agréable, même si le plus dispendieux, est par le Nil-même, sur l'un des magnifiques bateaux Touristes. Il y a deux compagnies: Thomas Cook and Son, la plus importante, et The Anglo-American. Ces bateaux sont d'un luxe vraiment incroyable, et les cabines, la table, le service, sont parfaits.

D'Assouan commence la troisième étape, de la première à la deuxième cataracte, jusqu’à Wadi-Halfa. Le Nil coule superbe et majestueux. Nous entrons en pays noir. Trois lignes de bateaux à vapeur, chacune offrant tous les conforts modernes, font le service d'Assouan à Wadi-Halfa. Les bateaux du gouvernement du Soudan accomplissent le trajet en moins de deux jours, avec arrêt de quelques heures aux fameux temples d'Abou Simbel, que l'impératrice Eugénie vint visiter en 1869 et, de nouveau, l'hiver 1904. Les bateaux de la Compagnie Anglo-Américaine et de la Compagnie Cook font de plus nombreuses escales et mettent trois jours et demi pour se rendre à Wadi-Halfa.

Wadi-Halfa est la tête de ligne du fameux chemin de fer soudanais qui, traversant les grands déserts de sable, nous conduit en vingt-sept heures jusqu’à Khartoum. Construite par Lord Kitchener lors de la campagne contre les derviches en 1898 , cette ligne militaire a rendu d'incalculables services. En dehors des express et des trains ordinaires, il y a, trois fois par semaine, un "train de luxe limité", composé de wagons-lits et d'un wagon-restaurant.

Les cabines sont d'une grandeur inconnue en Europe et contiennent, outre deux lits, une grande table, une chaise et un grand fauteuil. Les repas sont excellents et les menus écrits en français. Grand choix de vins et de liqueurs; lumière électrique et, dans toutes les cabines, un grand éventail électrique qui assure la fraîcheur de l'air. C'est une sensation étrange que de se sentir entrainer à travers les déserts soudanais tout en mangeant un repas aussi bien cuit et aussi bien servi que dans un grand restaurant du boulevard.

Le train de luxe quitte Wadi-Halfa à 8 heures du soir et, le lendemain matin, à 7 heures, il s'arrête à Abou Hamed. On peut imaginer la surprise du voyageur quand on le réveille en lui disant de se dépêcher, car son bain l'attend! S'enveloppant de son pardessus ou de sa robe de chambre, il descend du train et se trouve dans un grand établissement de bains, construit expressément pour les voyageurs. Il n'y a pas de ville, pas d'hôtel, 


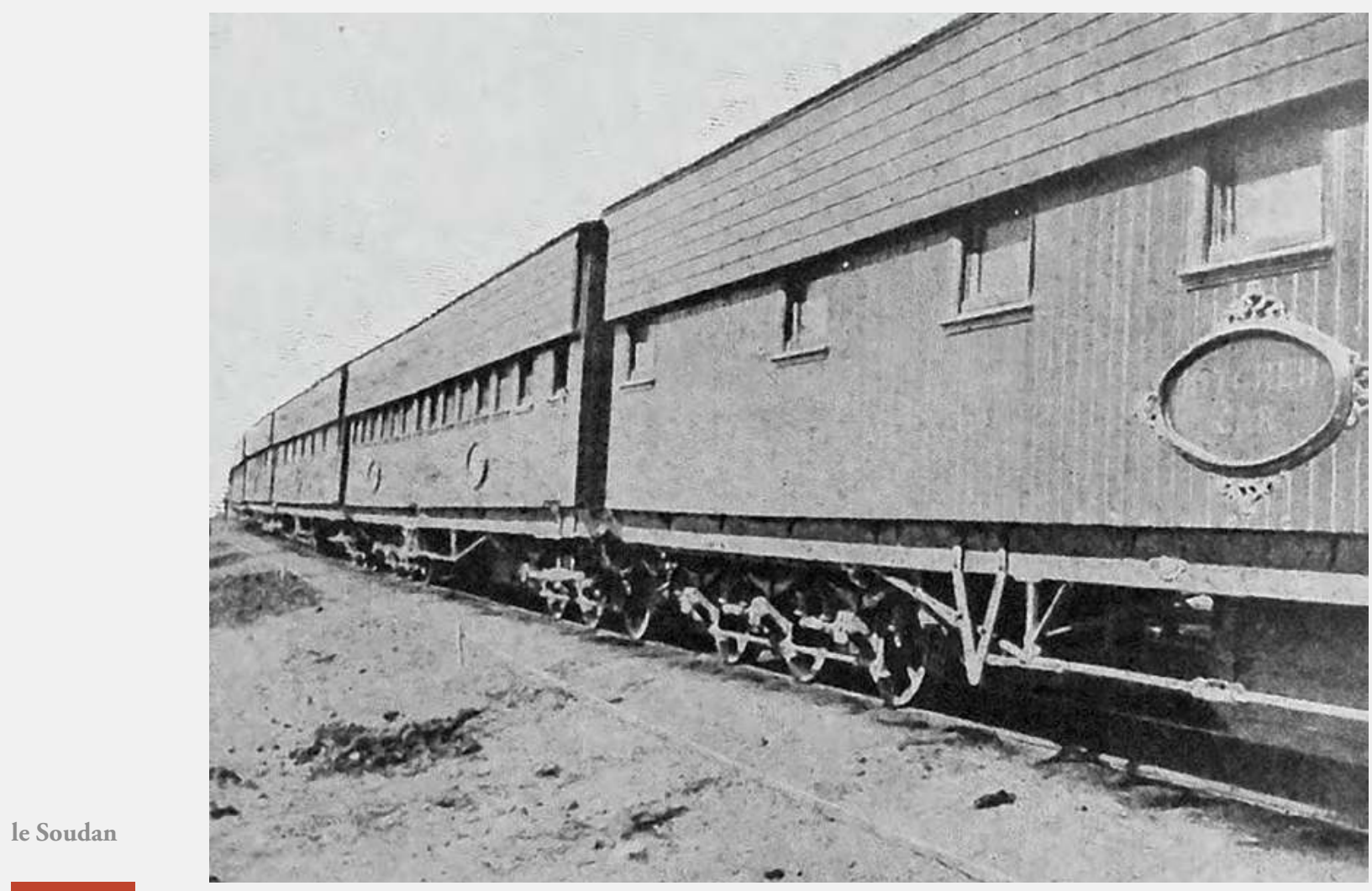

\section{6}

de 1820

à nos jours

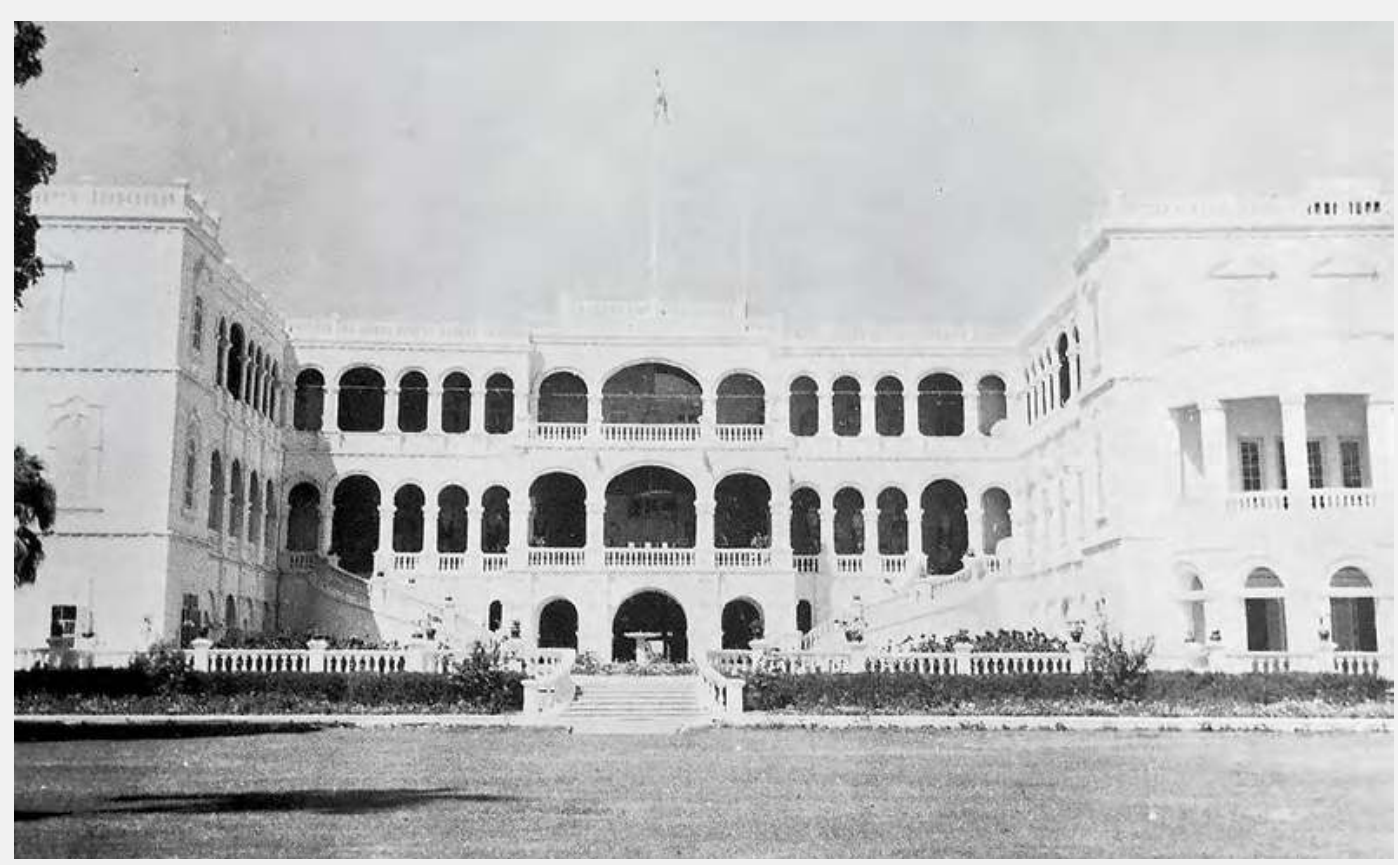

Train de luxe Wadi Halfa-Khartoum (1905).

Palais du Sirdar. 
simplement cet établissement au milieu du désert et des pompes puissantes qui y amènent l'eau du Nil. Des domestiques nègres vous ouvrent les portes, et chaque personne se trouve dans une immense salle de bains, avec une grande baignoire, un lavabo à l'anglaise, de grosses serviettes éponges, eau bouillante et froide à volonté. Le train s'arrête une heure afin de donner tout le temps nécessaire à une toilette des plus complètes. Pendant ce temps, le wagon-restaurant est nettoyé à fond; quand vous sortez de votre salle de bains, vous allez vous asseoir aux tables toutes préparées et le train repart jusqu’à Khartoum.

Khartoum a été reconstruite sur les ruines de l'ancienne. C'est aujourd'hui une fort jolie ville avec de belles maisons, de gracieuses villas, de charmants jardins. Le palais du gouverneur est superbe et les ministères spacieux. Il y a un Grand Hôtel. Le climat y est merveilleux en hiver. Le gouverneur général, Sir Reginald Wingate, et lady Wingate, ainsi que la plupart des officiers du gouvernement et du palais, parlent admirablement le français et reçoivent de la façon la plus gracieuse les étrangers qui leur sont recommandés.

Un service mensuel de bateaux à vapeur sur le Nil Blanc relie Khartoum à Gondokoro dans l'Ouganda. Il faut vingt-huit jours pour accomplir le voyage aller et retour et les bateaux s'arrêtent à el-Duem, Melut, Fachoda, Tawfikia et Lado (Congo belge). Il est possible de louer un steamer au Département des bateaux et steamers du gouvernement du Soudan. Parmi ceux-ci, le steamer Abbas-Pacha, qui dispose de trois ponts. Sur le pont d'en bas, il y a à l'arrière une grande salle à manger; le milieu est occupé par les machines; l'avant abrite les cuisines, l'office, les magasins à provision et une véritable étable où sont installés des poulets, pigeons, dindons, des moutons, et une vache afin d'avoir du lait frais. À fond de cale, 300 kilos de glace sont stockés, et différents bateaux remontant le Nil permettent le réapprovisionnement.

Sur le deuxième pont, dix magnifiques cabines offrent deux couchettes, deux salles de bains avec baignoires et douches froides et chaudes, un salon et, au milieu du pont, dans toute sa largeur, au-dessus des grandes roues, un endroit ouvert formant un grand "hall", meublé de tables, de fauteuils et de canapés. Enfin, le troisième pont, tenant toute la longueur et toute la largeur du bateau, était pour la promenade. Ponts, cabines et salons étaient éclairés à l'électricité. Nous payâmes pour la location seule de ce bateau 500 francs par jour au gouvernement. La maison Angelo Capato, de Khartoum, peut fournir cuisiniers, domestiques, provisions fraîches, conserves, vins, liqueurs, bières, eaux minérales, glace, etc. Dans les différents villages, le cuisinier achète de la volaille, des poissons, des œufs, des légumes. 


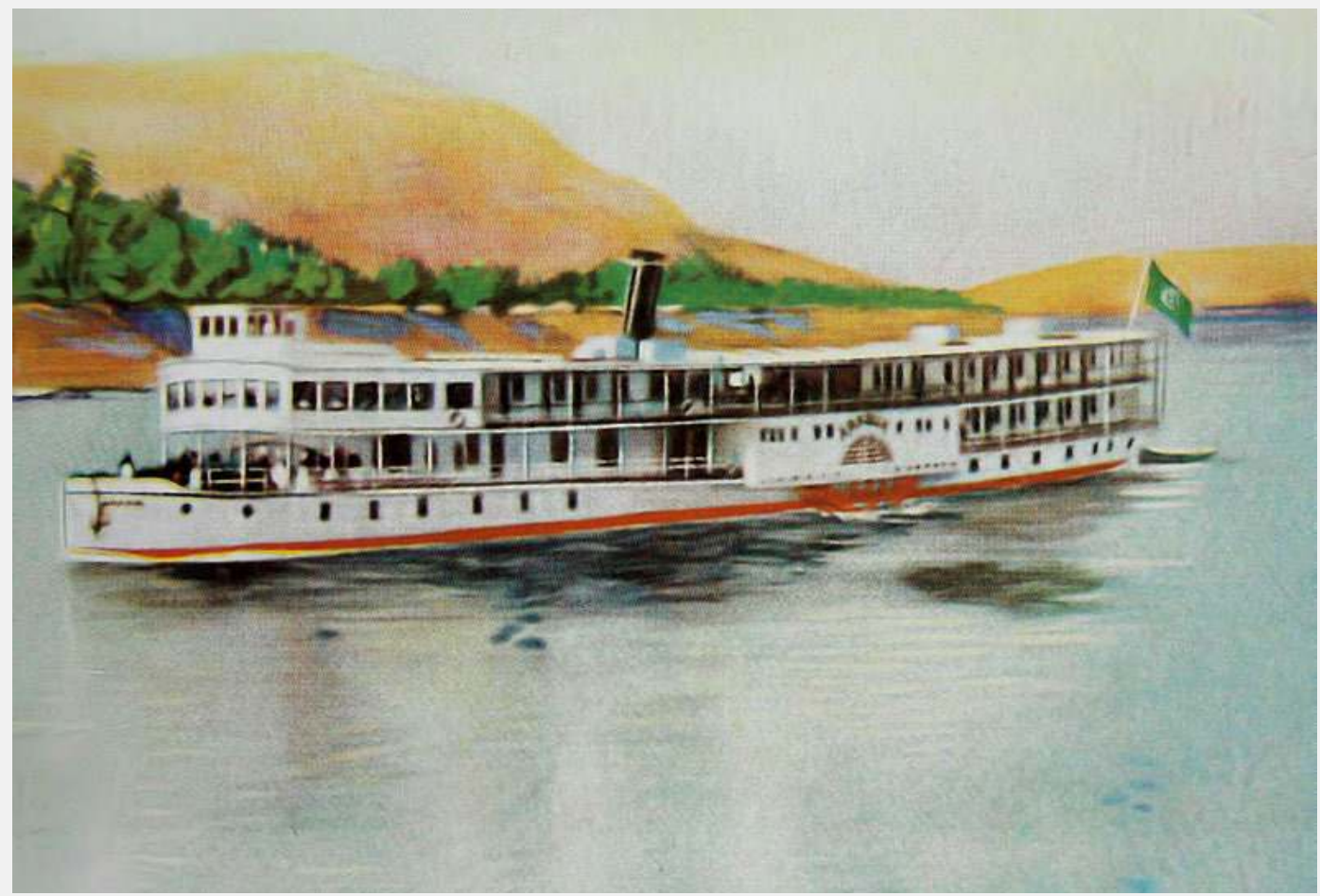

le Soudan

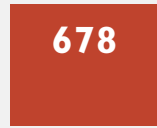

de 1820

à nos jours
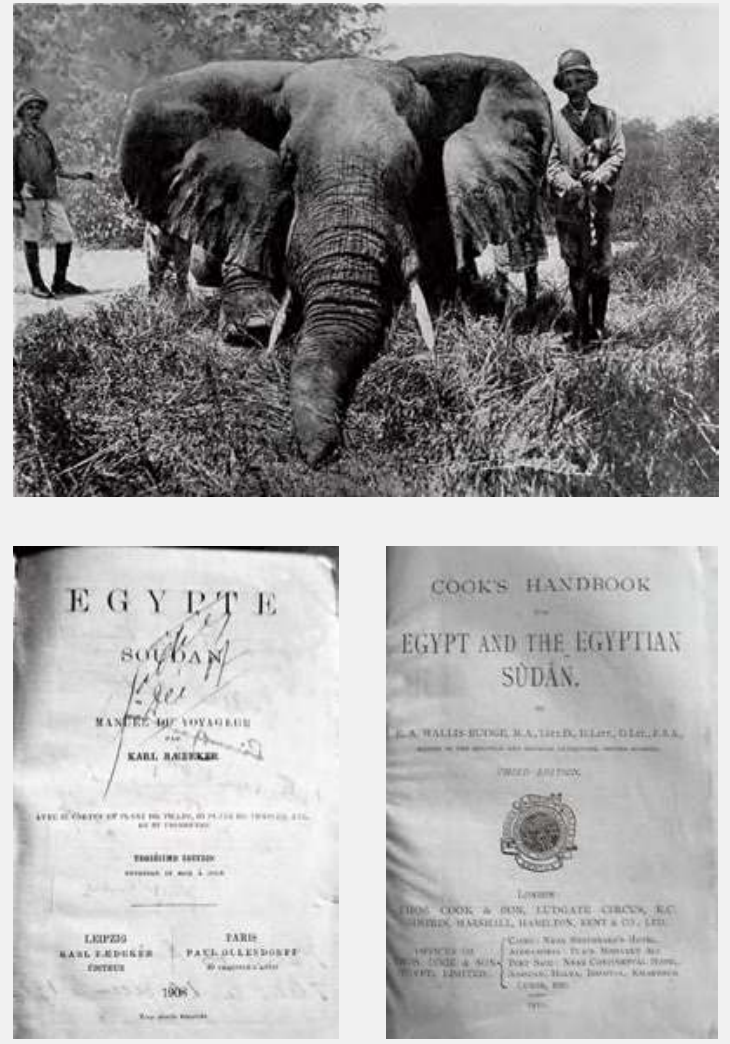

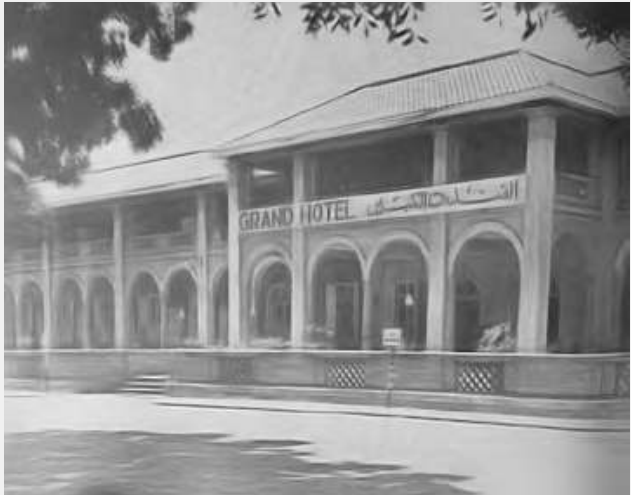

Steamer loué par des touristes.

Chasse au gros gibier.

Grand Hôtel.

Guide Baedeker 1908.

Guide Cook 1911. 


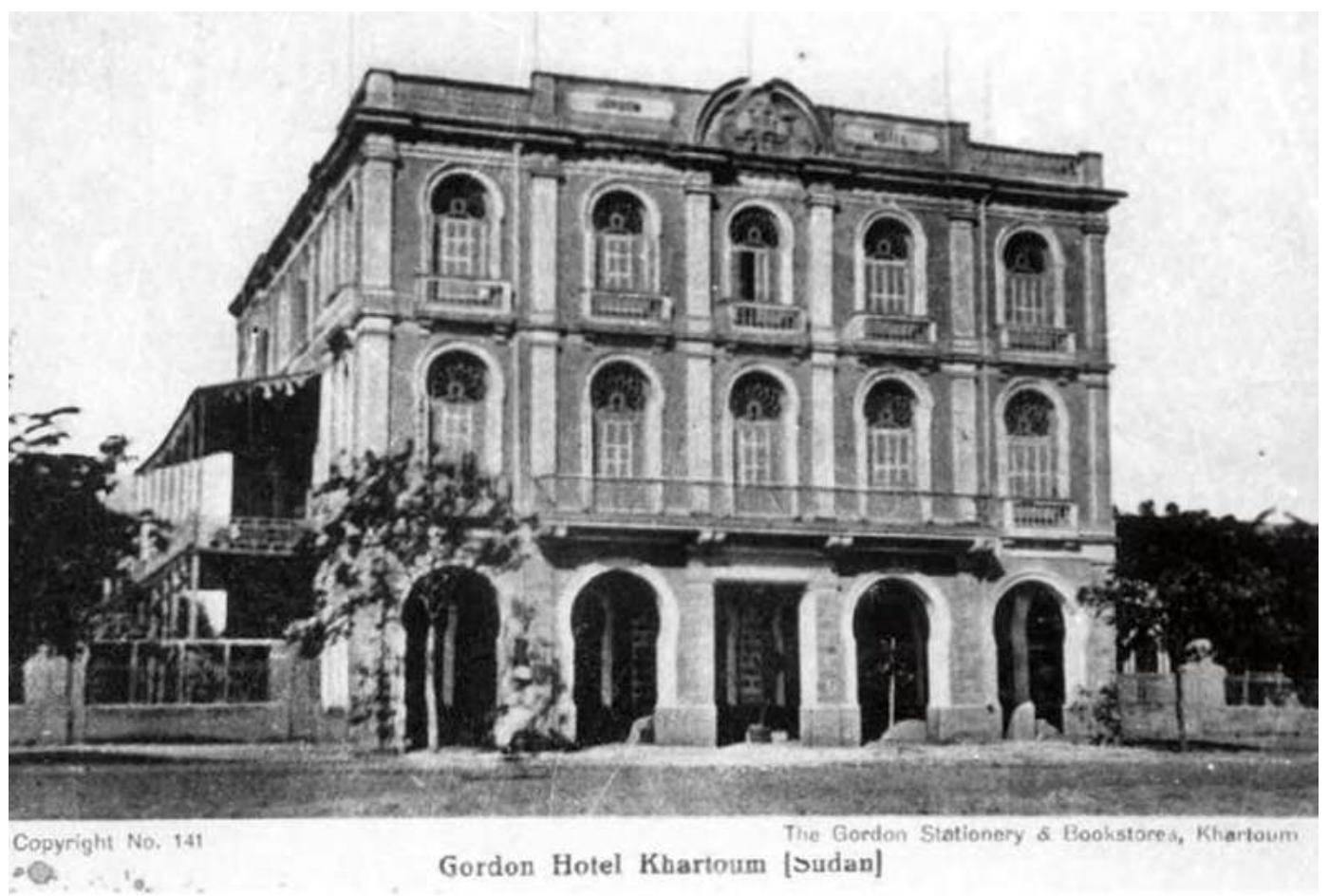

Gordon Hotel.

Enfin, si l'on préfère voyager plus simplement, on suivra l'exemple de deux Rouennais qui vinrent à Khartoum l'hiver 1904 et louèrent un seul bateau à fond plat. MM. Capato le leur fournirent avec un cuisinier, six domestiques ou matelots, et la nourriture de tout ce monde, pour 500 francs par semaine.

Un permis de chasse est nécessaire. Le gouvernement en vend deux - le petit pour 50 francs, le grand pour 500 francs. - Le premier donne le droit de tuer les lions, les crocodiles, les gazelles et quantité de gibier à plumes et à poils, mais défend de toucher aux éléphants, aux hippopotames, aux buffles et aux antilopes. $)$

Dans les années qui suivent, le Soudan est mentionné dans les guides de l'époque (Baedeker et Cook); le gouvernement du Soudan publie lui-même un guide (1911) pour les voyageurs, en anglais et en français: Chemins de fer et paquebots.

En 1927, le voyagiste Thomas Cook recommande Khartoum comme résidence hivernale "délicieuse et saine», où l'ensoleillement constant est tempéré par une brise douce. Il décrit les deux hôtels de standing, le Grand Hôtel et le Gordon Hôtel, le premier étant sous le patronage des Chemins de fer du gouvernement soudanais. Le voyage se fait à partir d'Assouan: d'abord par bateau entre Assouan et Halfa — soit par 


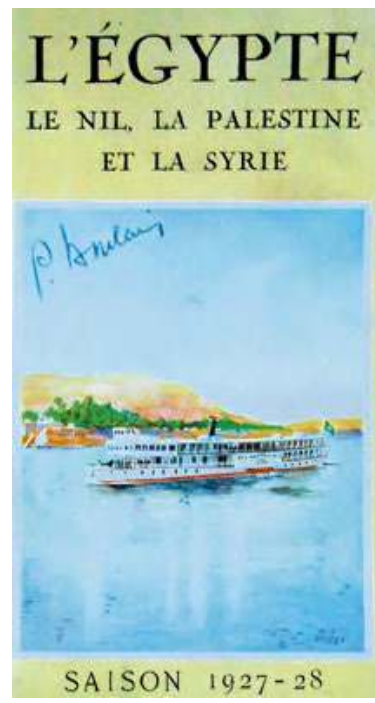

Guide Cook 1927

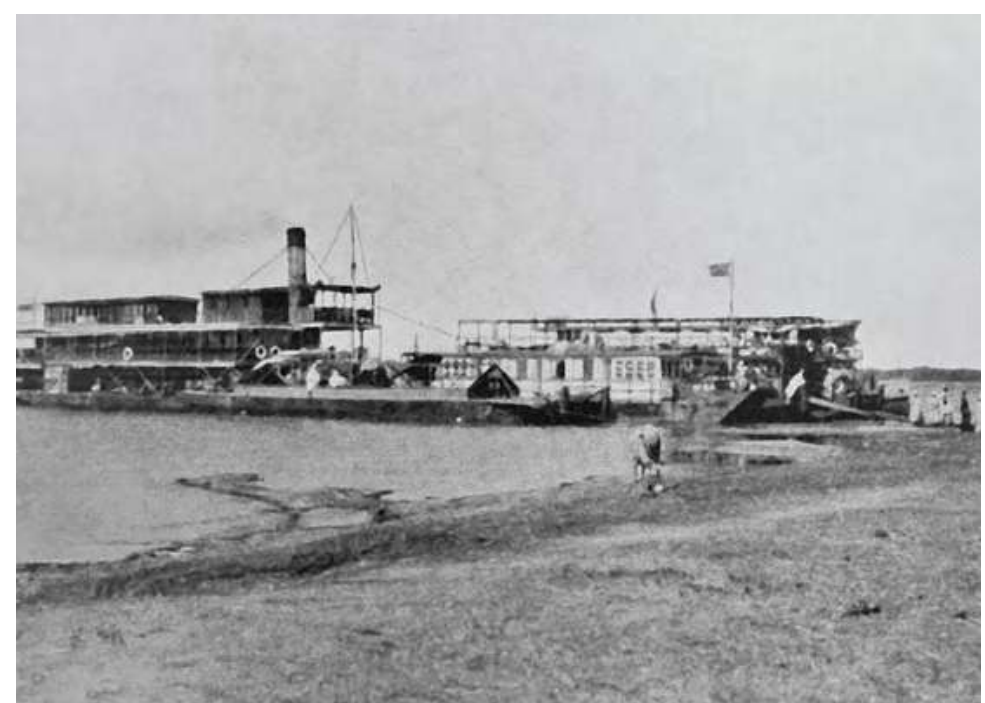

Le Fatheh, steamer de luxe reliant Khartoum au Sud Soudan (1929). le Soudan

680

de 1820

à nos jours

le Thèbes de la compagnie Thomas Cook, soit par un bateau express du gouvernement soudanais. Ensuite le voyage se poursuit à partir d'Halfa jusqu'à la gare centrale de Khartoum par le train de luxe du gouvernement soudanais. Ce train est présenté comme un des plus confortables trains de luxe, spécialement construit pour la traversée du désert, avec wagons-restaurants et wagons-lits pourvus de la lumière et d'éventails électriques.

《Le bateau part d'Assouan les lundis à $15 \mathrm{~h} 30$, pour arriver à Halfa le jeudi après-midi (après la visite d'Abou Simbel); le train de luxe quitte Halfa le vendredi à $8 \mathrm{~h} 40$ pour arriver à Khartoum le samedi à 10 heures. Les tarifs proposés (aller-retour) pour le trajet en bateau sont de 30 livres, et de 18,17 livres pour le train (rabais pour les domestiques européens et les domestiques indigènes).

À partir de Khartoum, les bateaux du gouvernement du Soudan assurent les liaisons avec Mongalla et Redjaf, points de correspondance avec le Kenya et l'Ouganda. Ces bateaux sont pourvus de cabines confortables, disposent de lumière et d'éventails électriques, de bains chauds et froids ainsi que de moustiquaires. Deux services distincts sont proposés, le service «accéléré» ou «normal» reliant Khartoum à Nimule en 15 ou 26 jours, à raison d'un départ par semaine en alternance. Le service accéléré relie Khartoum à Redjaf en 14 jours et le trajet de Redjaf à Nimule est effectué en 24 heures en voiture; le service normal relie Khartoum à Redjaf en 16 jours, suivi d'un trekking de 10 jours pour atteindre Nimule.

De courtes croisières sont aussi possibles sur le Nil Bleu et le Nil Blanc, par les bateaux du gouvernement égyptien. Une excursion au barrage de Sennar est combinée avec une croisière de quatre jours sur le Nil Bleu. 


\section{Le condominium au quotidien impressions des voyageurs}

En passant, le Nil, Khartoum, simples notes de voyage. $\mathrm{M}^{\mathrm{me}}$ Quenedey publie ce récit de voyage en 1901. Il offre une description de la ville de Khartoum telle qu'elle se présente à la voyageuse française, trois ans seulement après la bataille de Karari et la chute des mahdistes.

《 Nous débarquons à Tewfikiyé, où stationne le chemin de fer pour Khartoum. [...] Ce train ne part qu'une fois par semaine: c'est le chemin de fer militaire construit sous les ordres du Sirdar Kitchener, au moment de la campagne du Soudan; les autorités anglaises n'accordent le passage aux touristes que conditionnellement, ne répondant ni d'eux ni de ce qui est à eux, et se réservant de ne pas les prendre, $s^{\prime}$ il y a des militaires à transporter. [...] Nous sommes séparés, les femmes d'un côté, les hommes de l'autre. [...] Une demi-heure après, nous sommes à Wadi-Halfa où nous stationnons pendant plus de trois heures [...]; à huit heures, nous nous mettons à table et nous repartons. [...] Je grimpe sur mon lit ou plutôt sur ma pierre, et j'y passe une horrible nuit. Le vent s'élève et fait rage; chaque mouvement, sur ce grabat, soulève un nuage de poussière. Nous sommes en plein désert de Nubie, le sable et la poussière deviennent tellement pénétrants que, malgré toutes les précautions prises, nous en croquons, nous en avons dans les oreilles, dans le nez, nous en trouvons dans nos poches et dans nos chaussures; nos livres en sont pleins.

Le soleil se met de la partie et, en dépit des abris-soleils, sortes de toits supplémentaires en bois, descendant de chaque côté des compartiments, jusqu'au tiers de la hauteur, nous cuisons au point d'ouvrir les fenêtres, préférant encore, pour avoir de l'air, l'ennemi poussière à l'ennemi feu concentré. Tout ce que nous touchons est brûlant et chaque fois qu'on s'assoit, on croirait s'installer sur un fourneau.

De Wadi-Halfa à Abou Hamed, pas une habitation, pas un arbre; les stations ont des numéros en fait de noms; elles se composent d'un ou deux murs en limon gâché, toit en fibres tressées et de deux ou trois bonshommes assis ou accroupi, à côté les uns des autres. Crac! Un accident à la machine qui, trop faible pour nous traîner, a encore la force d'aller seule jusqu'à Abou Hamed, afin qu'on nous en envoie une autre; cela nous fait une panne de cinq heures, au milieu d'une étendue illimitée de sable jaune.

Nous sommes obligés de nous arrêter souvent, car ce sable envahit tout et encrasse les locomotives, qui sont pourtant enfermées dans un compartiment de bois; il faut les nettoyer chaque fois; nous profitons de ces haltes pour descendre, avec expresse recommandation de ne jamais rester la tête découverte. 


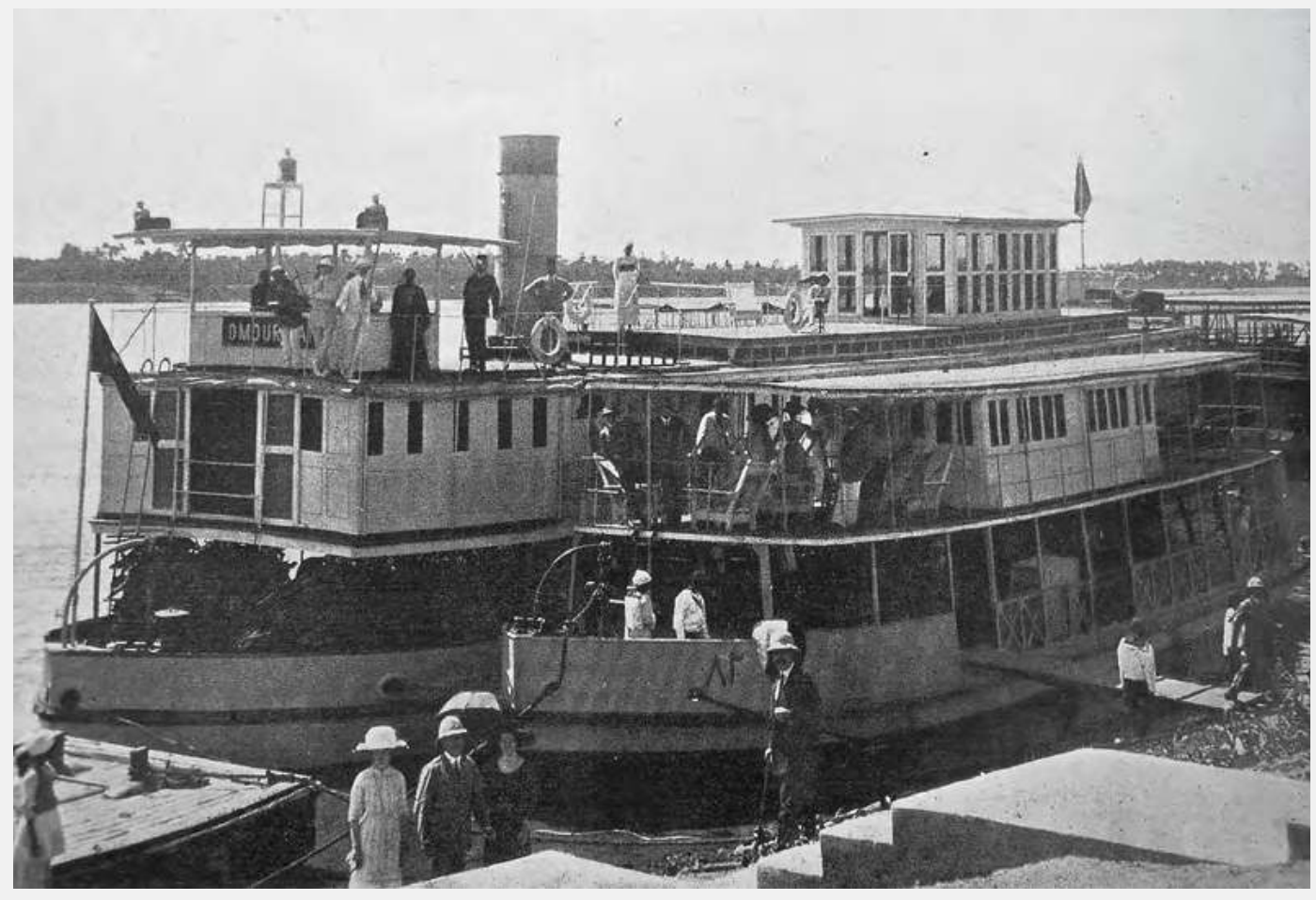

le Soudan

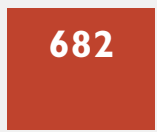

de 1820

à nos jours
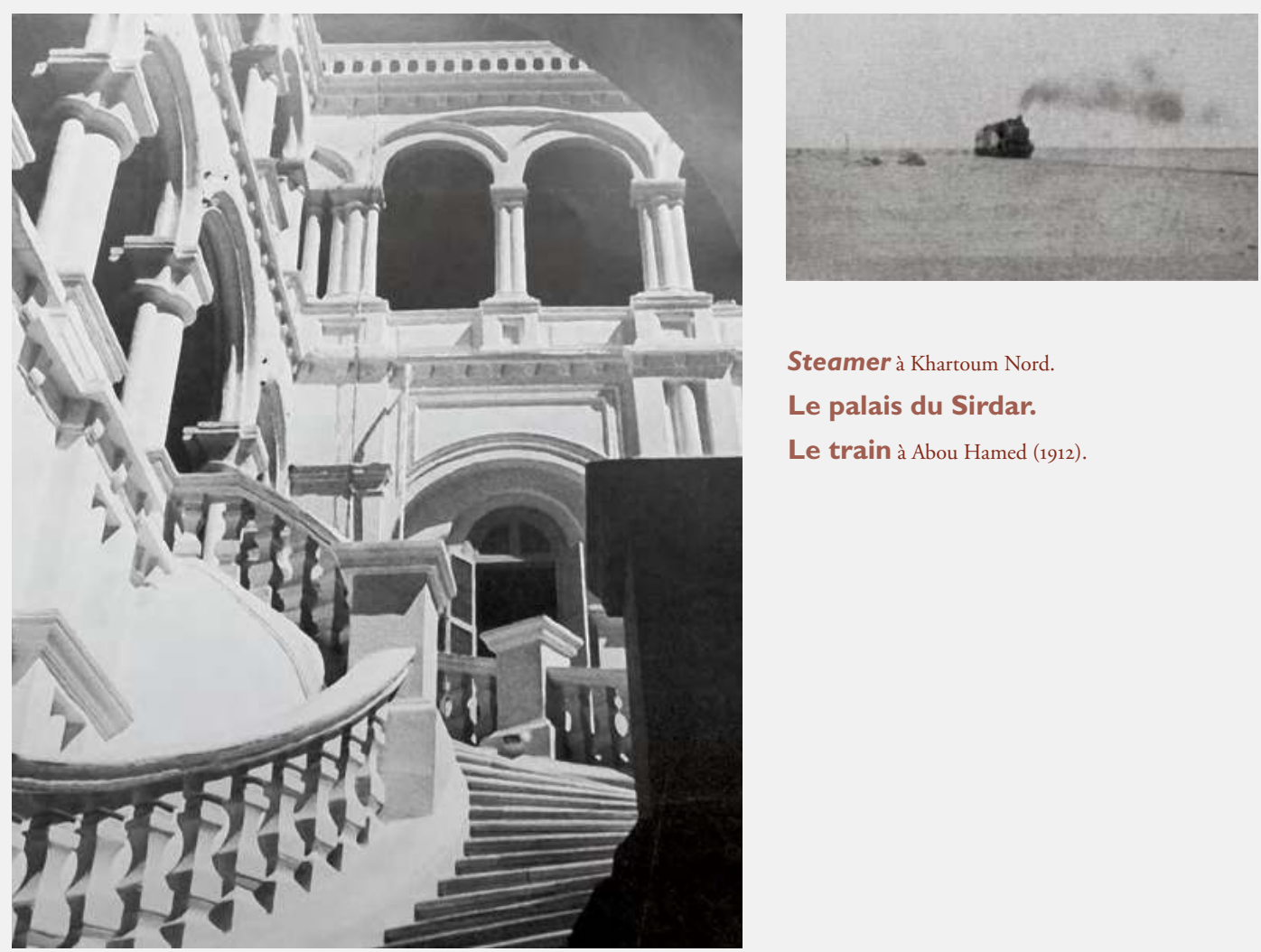

\section{Steamer à Khartoum Nord.}

Le palais du Sirdar.

Le train à Abou Hamed (1912). 
On s'arrête aussi pour les repas; du thé et du café confectionnés avec de l'eau grasse et le reste à l'avenant: l'air est si sec, qu'à peine coupées, les tranches de pain se transforment en toasts. La salle à manger sert aussi de salon et c'est assez commode, car chaque couple a sa table sur laquelle il peut, dans l'intervalle des repas, installer ses petites affaires.

Deux nuits et un jour en chemin de fer, au travers du désert, voilà qui n'est pas banal: une mer de sable et tout est sable autour de nous.

La joie d'arriver est immédiatement tempérée par une attente de deux heures en plein soleil, rien pour s'asseoir que les marches d'un escalier. Nous apercevons Khartoum de l'autre côté du Nil Bleu, car la station de Halfaya, où nous sommes, est en face...

Le bateau à vapeur vient enfin nous prendre et ne nous débarque qu'après avoir stationné devant le palais du gouverneur et fait toutes ses petites commissions; c'est impatientant!

L'hôtel est rudimentaire, il vient d'ouvrir et n'est pas achevé; il y a, donnant dans un enclos, sur les bords du Nil, un premier corps de bâtiment avec quelques grandes chambres à la file, où nous trouvons, ô bonheur!, de vrais lits avec moustiquaires, bains... Assez loin, en arrière, et dans un jardin qui contient avec quelques palmiers et deux grands carrés cultivés, plus de poussière que de verdure, est la seconde partie, le cœur pour ainsi dire de l'hôtel: salle à manger en vérandah, vaste salon, cuisines, etc., murs en briques non crépis, menuiserie sans peintures; encore plus loin, une série de chambres. Bon service, bonne organisation, chose étonnante dans un pays nouveau et où tout est absolument sens dessus dessous. C'est une ruine générale: toutes ces malheureuses habitations en terre ont été démolies [...] sur ordre du Khalifa.

Il y a le palais du Sirdar, en briques et pierres de taille et quelques jolies maisons neuves d'officiers anglais; une banque à peine finie, un hôpital et un collège en construction; enfin le commencement d'hôtel où nous sommes, et c'est tout. On établit de larges voies, plantées d'acacias gros comme un petit doigt pour le moment, et soigneusement arrosés et protégés; on fabrique considérablement des briques cuites ou non, avec lesquelles la ville ne tardera pas à se rebâtir; les indigènes travaillent à ces briqueteries élémentaires; en plein air, des forçats, chaînes aux pieds, y sont également employés; il y a beaucoup de ces fabriques sur le rivage; nous sommes passés à l'intérieur de la ville près de l'une d'elles qui avait l'importance d'un village, les gens logés dans les paillotes.

L'eau a ici, comme en Égypte, une importance capitale: les sakiehs et les chadoufs sont nombreux; des quantités de femmes passent leur vie à transporter des seaux, vases de terre, bidons, etc., sur leur tête, d'un pas tranquille et lent, après les avoir remplis au bord du Nil. L'hôtel 
le Soudan

\section{4}

de 1820

à nos jours est ainsi approvisionné par une théorie de Soudanaises d'aspect très divers [...]; en général, la nature leur a accordé [...] les bras les plus jolis de forme et la peau la plus belle qu'on puisse voir, elle est mate ou satinée, quelle qu'en soit la couleur, variant du bronze à l'ébène; les attaches du cou sont délicates et la poitrine est ferme; leur port a de l'élégance et de la majesté à la fois [...]. Elles se teignent volontiers les lèvres et les dents en bleu et les ongles en rouge.

Les hommes, parfois beaux de visage, étant donnés leur type et leur couleur, partagent avec les femmes la qualité de la peau, des attaches et des bras qui sont chez eux plus féminins que musclés; ils n'ont pas l'air robuste [...]. Les femmes qui travaillent aux champs, principalement les esclaves, dont il y a encore un petit nombre, se laissent voir jusqu'à la ceinture [...]. Elles cultivent la terre, bêchant, cueillant les haricots [...]

Dès notre arrivée, une cavalcade, composée des voyageurs du train, se forme pour voir Khartoum [...]. Nous nous mettons donc à trotter à pied, dans la poussière, tellement épaisse qu'elle recouvre nos chaussures; le thermomètre marque $40^{\circ} \mathrm{C}$.

Nous passons notre seconde journée en bateau à voile (felouca) mené par des mariniers soudanais [...] Rives plates, avec un peu de culture de haricots et de lupins; quelques esclaves piochent la terre; quelques autres femmes lavent, dans l'eau bourbeuse du rivage, le morceau d'étoffe noire ou bleu foncé dans lequel elles s'enveloppent. [...] À l'approche du bateau, ces femmes s'enroulent d'un tour dans leur étoffe tendue, quitte à se dérouler après notre passage, au grand ennui du photographe.

[...] Notre troisième journée est consacrée à visiter Omdurman; nous nous en allons à dos d'âne jusqu'en face de la ville; nous traversons en bateau le Nil Blanc, déjà très large, et nous abordons. Dès la rive, il règne une animation qui annonce une place vivante et peuplée; notre drogman nous a découvert la seule voiture qui existe peut-être ici.

C'est d'abord le musée: après avoir traversé les bâtiments d'entrée, on arrive à une galerie en arcades, entourant une construction quelconque et entourée d'une cour qui l'encadre; cette galerie contient ce qui reste des dépouilles du Khalife Abd-Allah et de son armée: des voitures, dont une espèce de calèche à deux chevaux, rouge, bariolée de toutes sortes de couleurs, est tout abîmée et poussiéreuse. Contre le mur, est un vieux piano hors de service, ayant perdu la voix et une partie de ses touches.

Des quantités d'armoires à glace et de commodes en pitchpin, façon faubourg Saint-Antoine commun, gisent là, tristes épaves de mobilier féminin. Des milliers de selles de chameaux, d'ânes, etc.; encore des milliers de fusils et de pistolets de tous systèmes démodés européens, ainsi que quelques canons, et quels canons? 

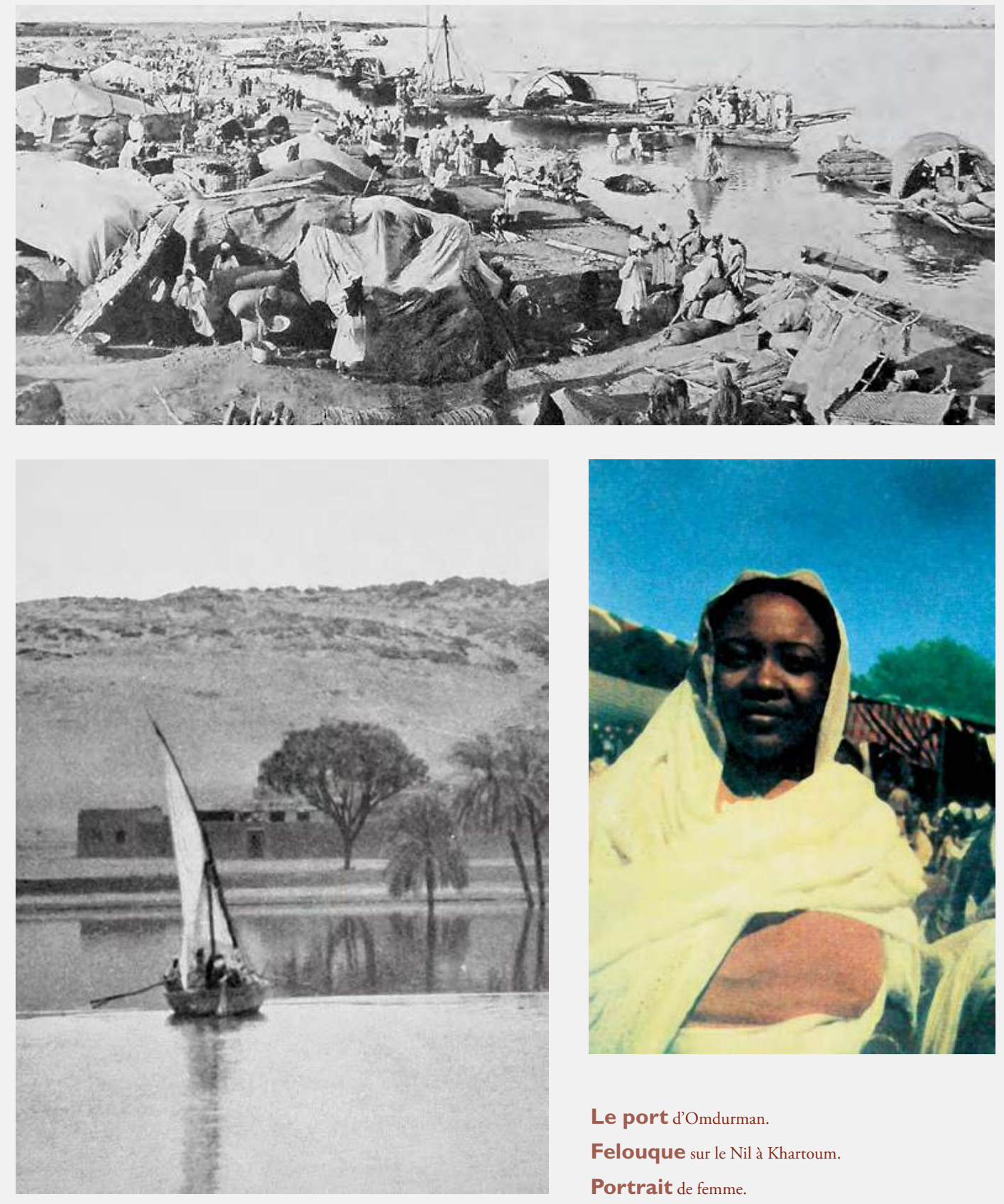

le condominium angloégyptien 1899-1955

Le port d'Omdurman.

Felouque sur le Nil à Khartoum.

Portrait de femme. 


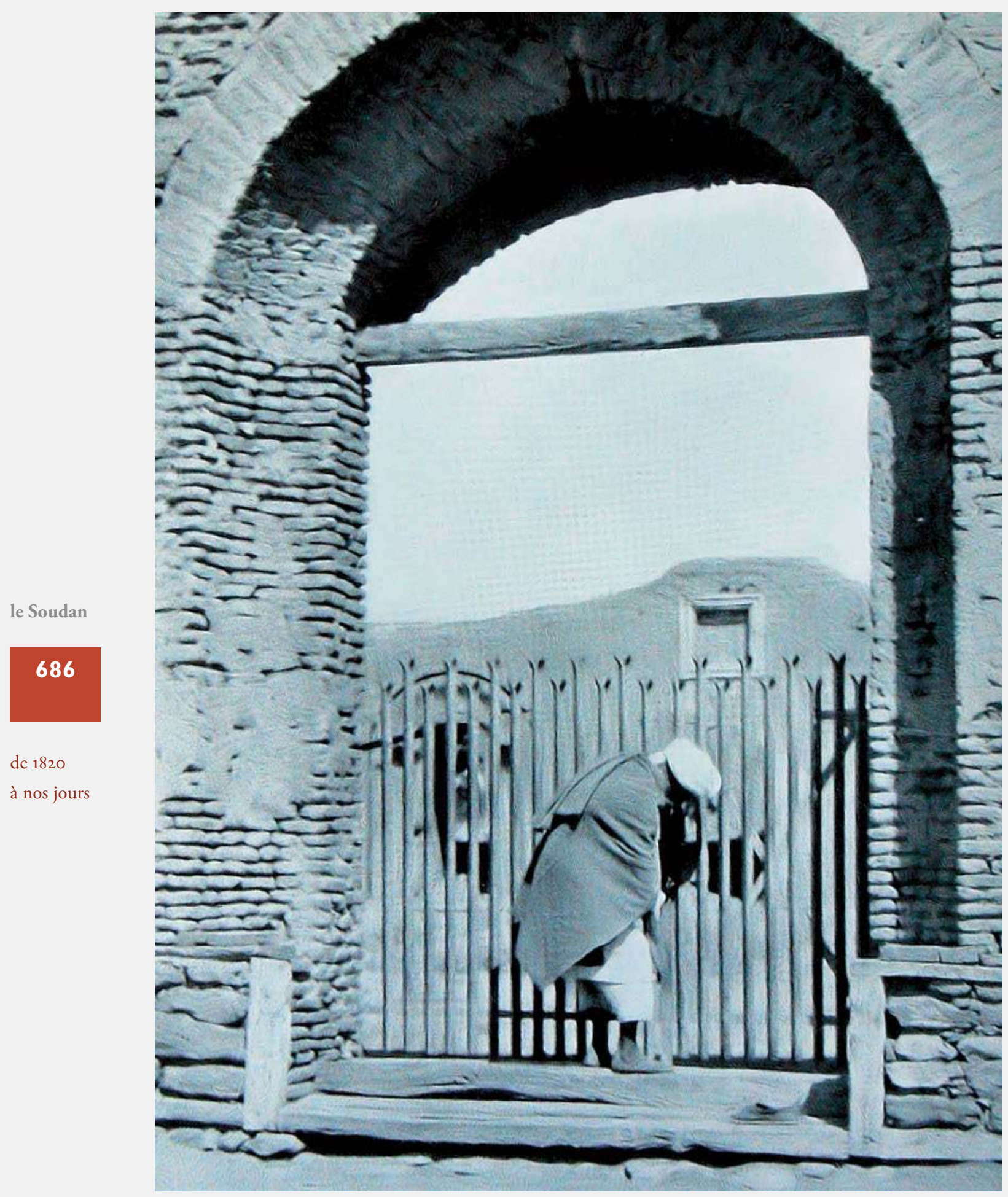

Le tombeau du Mahdi (1924). 

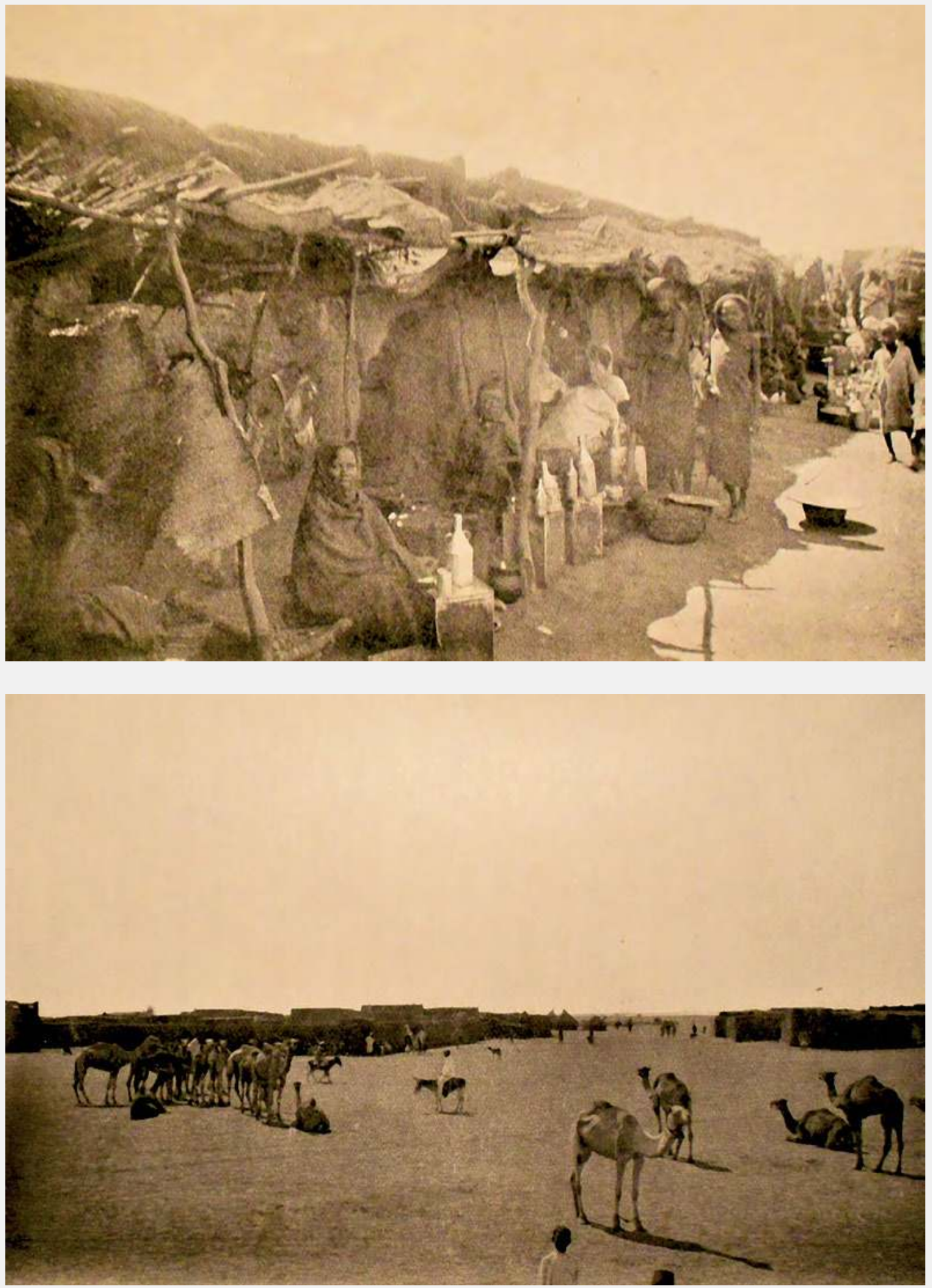

le condominium angloégyptien 1899-1955

Le marché d'Omdurman (1906).

Le marché aux chameaux, Omdurman (1906). 
Le tombeau du Mahdi est aux trois-quarts détruit par les Anglais qui, avec leur magnanimité ordinaire, ont fait jeter les restes de l'héroïque révolté dans le Nil! Son palais est une simple maison de pisé qui, de plus que les autres, a une vraie porte et de vraies petites fenêtres au complet. Une place, très spacieuse, entourée de murs, est tout ce qui reste de la mosquée entièrement disparue. Le tombeau et la mosquée sont les seules destructions qui aient été faites dans cette ville qui occupe une vaste étendue; elle est entièrement construite en terre et briques de terre; ce sont de petites maisons basses, tenant les unes aux autres; de fenêtres, peu ou point; de simples ouvertures, le plus souvent en guise de portes; on n'y voit pour ainsi dire pas de meubles; il y a de très larges rues.

Une chose qui frappe et qui est absolument incompréhensible, c'est l'absence complète d'arbres: pas un brin de quoi que ce soit ne pousse là; les indigènes n'ont pas l'air de redouter d'être rôtis au soleil, c'est à peine s'ils cherchent l'ombre quand il y en a un peu autour des maisons ou sous les rares paillotes de la place du marché.

Le bazar, formé de rues étroites, couvertes de fibres de palmiers tressées, a de l'ombre enfin; c'est plein de monde; nous retrouvons là les éternels persécuteurs du voyageur Européen, et le refrain "bakchich" qui nous poursuit partout et toujours. Rien à acheter, sauf quelques armes soudanaises. Sur la place du marché se vendent des chameaux, des ânes, des moutons, des chèvres, etc. Le vrai commerce consiste en dents d'éléphants, plumes d'autruches, graines variées, gomme, etc.; c'est un débouché important pour les produits du Soudan, du Darfour et du Kordofan; un emplacement spécial est affecté à ces transactions.

Nous déjeunons dans un restaurant élémentaire, tenu par des Grecs, au sol de terre battue. Par un semblant de porte qu'on oublie constamment de fermer, passent poulets et dindons, qui grattent sous les tables. Dans la cour, véritable ménagerie, où sont parqués des autruches et d'autres animaux, nous serrons la main à trois singes qui acceptent nos morceaux de sucre avec la rapacité d'un naturel à qui on offrirait un bakchich. Un beau léopard, tout moucheté, tout velouté, l'œil clair, la patte solide, est enchaîné dans un coin, je me risque à le caresser, il veut aussitôt me rendre ma politesse en me prenant dans ses bras. J'en cours encore.

Au bord du Nil, les laveuses sont entre elles, et se mettent à leur aise pour travailler; les jeunes filles ont le buste découvert et souvent les femmes, par contrebande, ôtent à peu près tout. Ce groupe original attire les étrangers dont il pique la curiosité, et plus d'un appareil photo se braque; mais le fameux voile, qu'on voit si souvent sécher, se déroule vivement, et ce paravent improvisé vient s'interposer [...]. Des vautours perchés sur des murs, avec la quiétude de bêtes qu’on ne dérange jamais, nous regardent partir. 
Omdurman a un aspect absolument spécial: c'est la ville soudanaise, très étendue, toute de maisons basses en pisé; rien d'européen; la population, très nombreuse, est bien chez elle, avec ses coutumes, son marché, etc. On nous assure que d'ici un très petit nombre d'années, elle se transformera, comme toutes les colonies anglaises; la civilisation s'y installera avec la langue, les écoles, l'administration, le télégraphe et les tramways. Ces pauvres gens en seront-ils plus heureux? Il est permis d'en douter: leur vie, sans besoins, dans de pauvres maisons, avec des vêtements sommaires, leur suffit; ils sont contents ainsi, pourquoi leur imposer un pseudo-bonheur qu'ils ne demandent pas? Il y a encore parmi eux des partisans de la liberté et toute fermentation n'est pas éteinte, mais les Anglais sauront les user.

Ceux qui visiteront, dans l'avenir, cette partie du Soudan, voyageront plus confortablement que nous, qui avons eu, à notre tour, plus de facilités que ceux qui nous ont précédés; mais ils ne verront pas, comme nous, la vraie ville soudanaise, exempte de toute empreinte étrangère.

Le thermomètre continue à marquer $40^{\circ} \mathrm{C}$ le matin! On ne sait plus où se fourrer et on souffre tellement, la nuit, dans les chambres. [...] Nous devons nous estimer heureux d'avoir trouvé ce commencement d'hôtel; car, l'année dernière, on couchait en bateau; il y a deux ans, sous la tente; il y a trois ans, on ne venait pas, c'était la guerre, la destruction et toute la misère qui s'ensuit.

Cinq ans au Soudan. L'arrivée d'Edward Fothergill à Khartoum en 1901, réflexion sur le pays et les contacts entre Soudanais et Européens.

Ma première impression du Soudan fut plutôt floue et incertaine; j'étais beaucoup plus intéressé par moi-même que par ce qui m’entourait. J'aurais tout le temps de m'intéresser au pays plus tard. Je percevais surtout que si ma langue continuait à enfler, elle allait finir par toucher le plancher de ma bouche pendant que je promenais, et ceci était pour moi un sujet sérieux de préoccupation.

Un thé assez boueux et très sucré contribua à restaurer mon intérêt émoussé, et je sortis sur la plateforme goudronnée pour regarder Khartoum telle qu'elle apparaissait en 1901, trois ans après la bataille d'Omdurman et la chute du Khalifa. Je dois confesser une première impression de déception; aussi loin que je puisse regarder, la ville consistait en un palais vaste, blanc et quelque peu isolé; le célèbre Gordon College, à ce moment en train de sortir de terre, et un pâté de maisons miteuses s'élevant un peu en retrait du fleuve, visiblement non encore terminées. J'appris que ces constructions allaient héberger les nouveaux bureaux de l'armée et de l'administration. Les palmiers dattiers qui s'alignaient au long de la rivière à l'ouest réalisaient une rupture bienvenue à la monotonie 
du paysage même dans ces jours où les larges avenues bordées d'arbres, et les bungalows bordés de végétation qui embellissent maintenant la ville n'avaient pas encore fait leur apparition. Le paysage était pittoresque, une fois qu'on s'était habitué à le contempler. Le chemin de fer avait son terminus au nord du fleuve à cette époque, et je me rappelle, assis dans la chaleur du matin avec une brise brûlante qui me projetait de fines particules de sable dans les yeux, à Halfaya [...] Le nom a depuis été transformé en celui plus imposant de "Khartoum Nord"; y sont situés les bureaux du département des navires et vapeurs, et c'est une ville en plein épanouissement, mais je me rappellerai toujours ce premier contact, quand l'atmosphère était seulement faite de chaleur et de désolation.

Le bateau qui devait me convoyer à Omdurman n'était pas encore arrivé; malade à mourir du train dans lequel j'avais cuit lentement les dernières 24 heures, je m'assis sur la berge et je contemplai le flux rapide des eaux du Nil Bleu qui descend pour rejoindre les eaux plus calmes du Nil Blanc, environ un mille plus loin au nord. Vingt-quatre heures de repos à Wadi Halfa, en route pour Khartoum, m’avaient donné un premier aperçu du Soudan [...] Quelques effendis égyptiens au voisinage immédiat de la gare, et un soldat qui passait, de même nationalité, étaient les seuls témoins de l'occupation que mes yeux rencontrèrent, mais de l'autre côté de la rivière, les drapeaux britanniques et égyptiens flottaient côte à côte au palais du Sirdar, témoins silencieux du nouveau régime. Au nord s'étendait une mer de sable sans limite; les lignes brillantes d'acier du tracé du chemin de fer, et les poteaux du télégraphe courant tout au long rappelaient seuls la présence de la civilisation occidentale. Vers le sud, sur la rive opposée, s'étendait Khartoum.

Il n'y avait aucune boutique européenne dans la ville. Nous étions arrivés peu après le lever du soleil et comme, à l'exception du thé, je n'avais pris aucun petit-déjeuner, j'étais impatient d'arriver à Khartoum, où j'imaginais pouvoir me procurer de la nourriture avant d'aller à Omdurman. Mais mes rêves d'œufs et de bacon, et d'autres luxes chers au cœur d'un Anglais, firent place à un cauchemar de faim et de désespérance, quand je me rendis compte qu'il m'était impossible de prendre ce repas, et il me fallut jeûner jusqu'au repas de treize heures.

Omdurman était à cette époque le centre commercial du Soudan, quelques échoppes locales misérablement achalandées constituant l'ensemble de la marchandise dans la capitale actuellement florissante. Les routes brillaient par leur absence, mais déjà on voyait clairement le dessin de l'urbanisme aux lignes modernes et spacieuses qui ont permis de donner à la cité sa salubrité et sa santé actuelles. Les bords du fleuve et aussi la plus grande partie de la ville sont infestés de moustiques; 

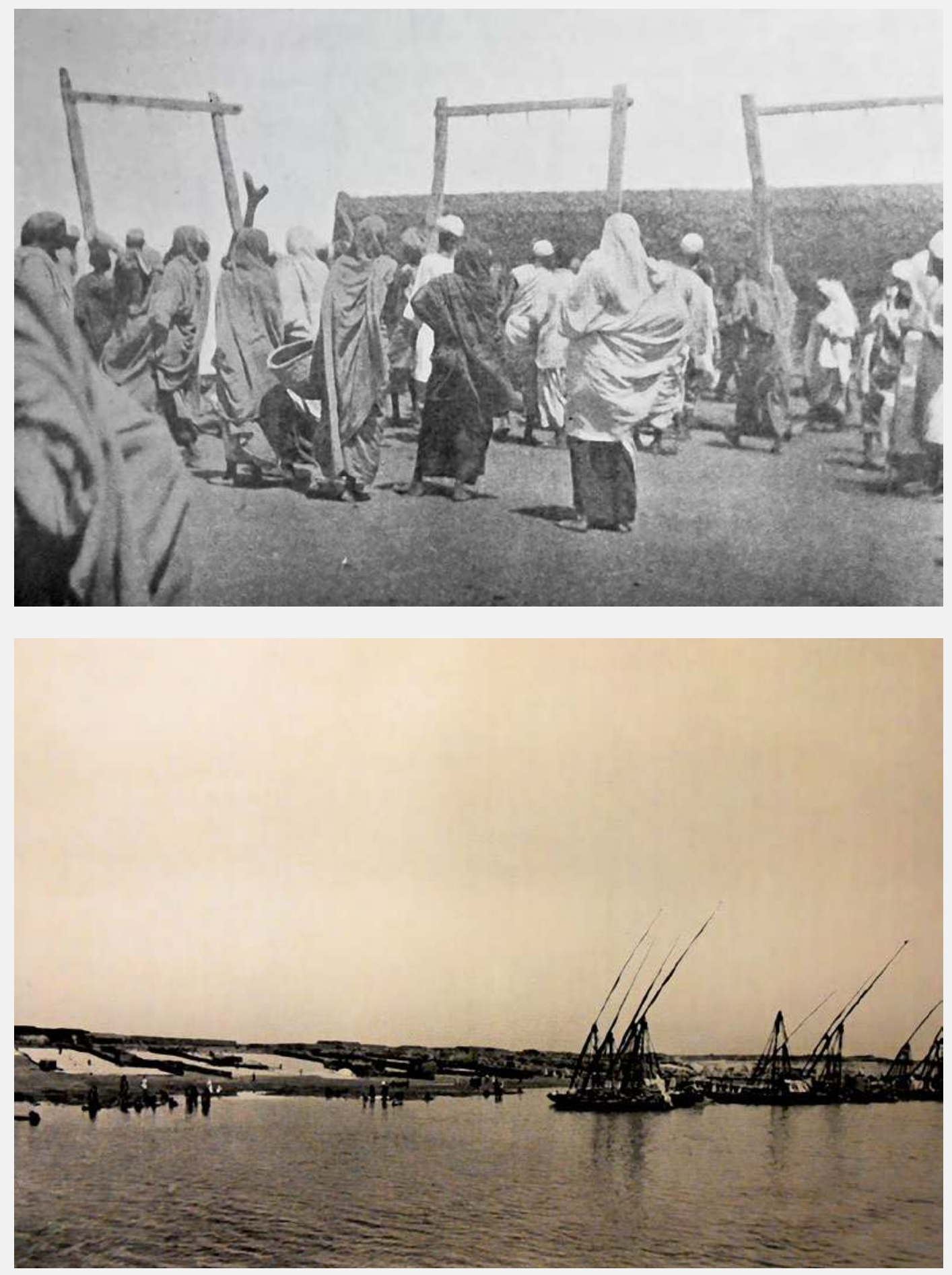

le condominium angloégyptien 1899-1955

Les potences du Khalifa en 1898 .

Le port d'Omdurman en 1906. 
le Soudan

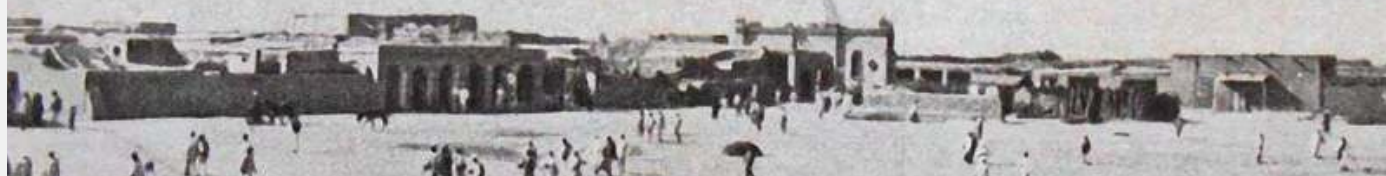

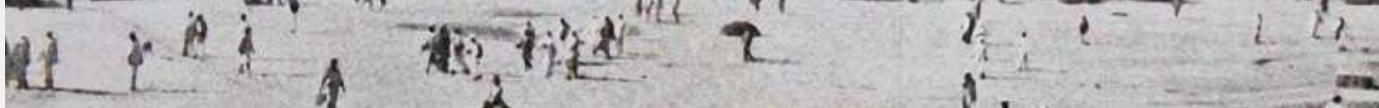
2 $-1,2$

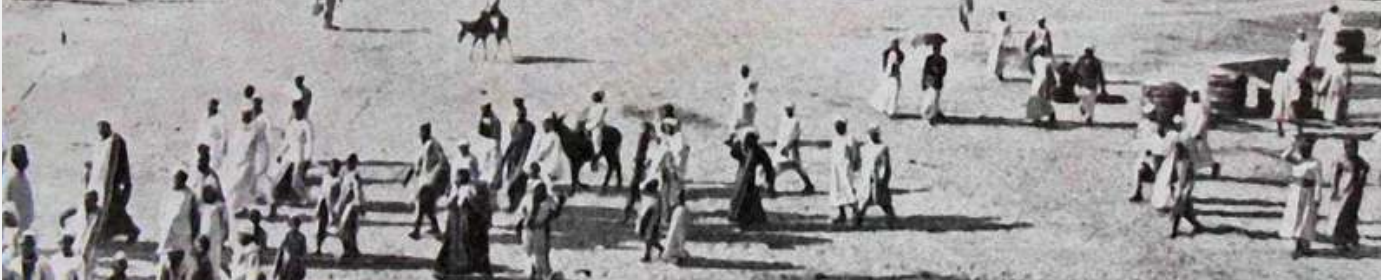

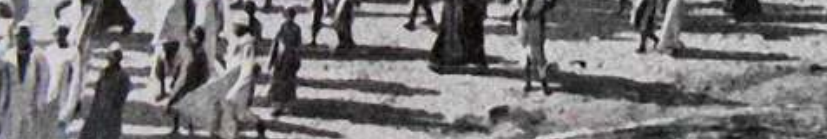

692

de 1820

à nos jours

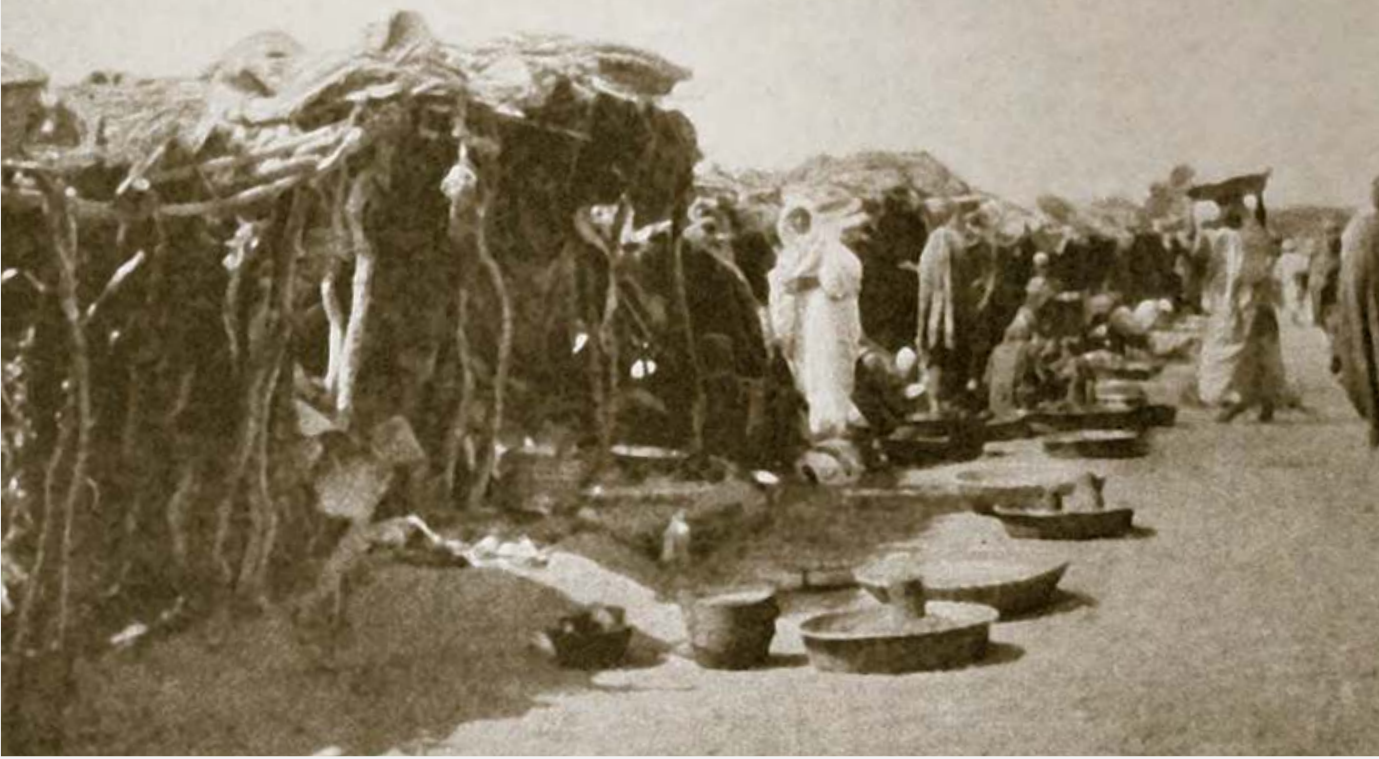

Omdourman in L'Illustration du 11 mars 1911 et son marché dans les années vingt. 
en bref, il y avait peu dans l'apparence et les caractéristiques de la ville, pour impressionner le nouvel arrivant sans idée préconçue sur sa beauté, à part le charme des palmiers. Omdurman, d'autre part, malgré son absence de beauté, était infiniment plus intéressante, par sa population locale très dense qui se bousculait dans ses rues et ses marchés. Ici, au moins, il était possible de se faire une idée des conditions de vie qui prévalaient avant que la bataille d'Omdurman ne mette un terme abrupt à l'autorité sauvage et tyrannique des mahdistes; ici on pouvait encore voir les Soudanais exercer leurs métiers de la façon dont ils les avaient toujours pratiqués depuis le démarrage des entreprises mécaniques et industrielles dans le pays, aux jours reculés où le nom de Soudan ne signifiait rien dans les esprits, sauf pour une petite poignée Anglais qui s'y intéressaient.

J'ai dit qu'Omdurman représentait le centre de l'activité marchande mais en plus, et c'est toujours le cas au moment où j'écris, Omdurman garde son statut de premier port du Soudan; les ateliers du département des vapeurs et bateaux étaient situés sur ses rives, et le commerce, comme la prospérité générale, se développaient un peu plus chaque jour. Le quartiergénéral de l'ancien département des canonnières, devenu plus récemment le département des vapeurs et bateaux, était situé à l'extrémité nord de la ville, à environ un mille de Bab el-Khiblie, et les maisons de ce secteur avaient pour cette raison été préservées de la démolition générale qui a touché une grande partie de la ville à l'arrivée des Anglais. Elles étaient maintenant occupées par des artisans et des travailleurs employés au service des steamers, ou autour des chantiers navals.

Au moment de mon arrivée, le Département était fort occupé à la construction d'un dock flottant, dont la réalisation avait été ordonnée par Lord Kitchener quelques mois avant son départ du pays. De l'aube jusqu'au coucher du soleil, l'endroit résonnait du bruit des marteaux frappant l'acier et le fer; il faut signaler ici que les ouvriers locaux n'ont pas perdu de temps pour apprendre ces ficelles du métier qui sont si populaires à leurs frères occidentaux et ils se sont vite rendu compte qu'un couple de jeunes garçons occupés à marteler avec énergie une pièce d'acier produit plus de bruit que si l'ensemble de l'équipe de travail était à son poste. Une telle méthode présente l'avantage d'être beaucoup plus facile...

Les vieux steamers, dont certains avaient servi régulièrement depuis les premiers jours de Gordon, étaient en train d'être rénovés et adaptés, et des bateaux supplémentaires ont été ajoutés à la flotte, comme les fonds du département le permettent. Les canonnières qui ont rendu de grands services lors de la bataille de Karari, n'ont rien perdu de leur importance aux yeux des locaux, qui les regardent toujours avec des sentiments mêlés de vénération et de crainte. 


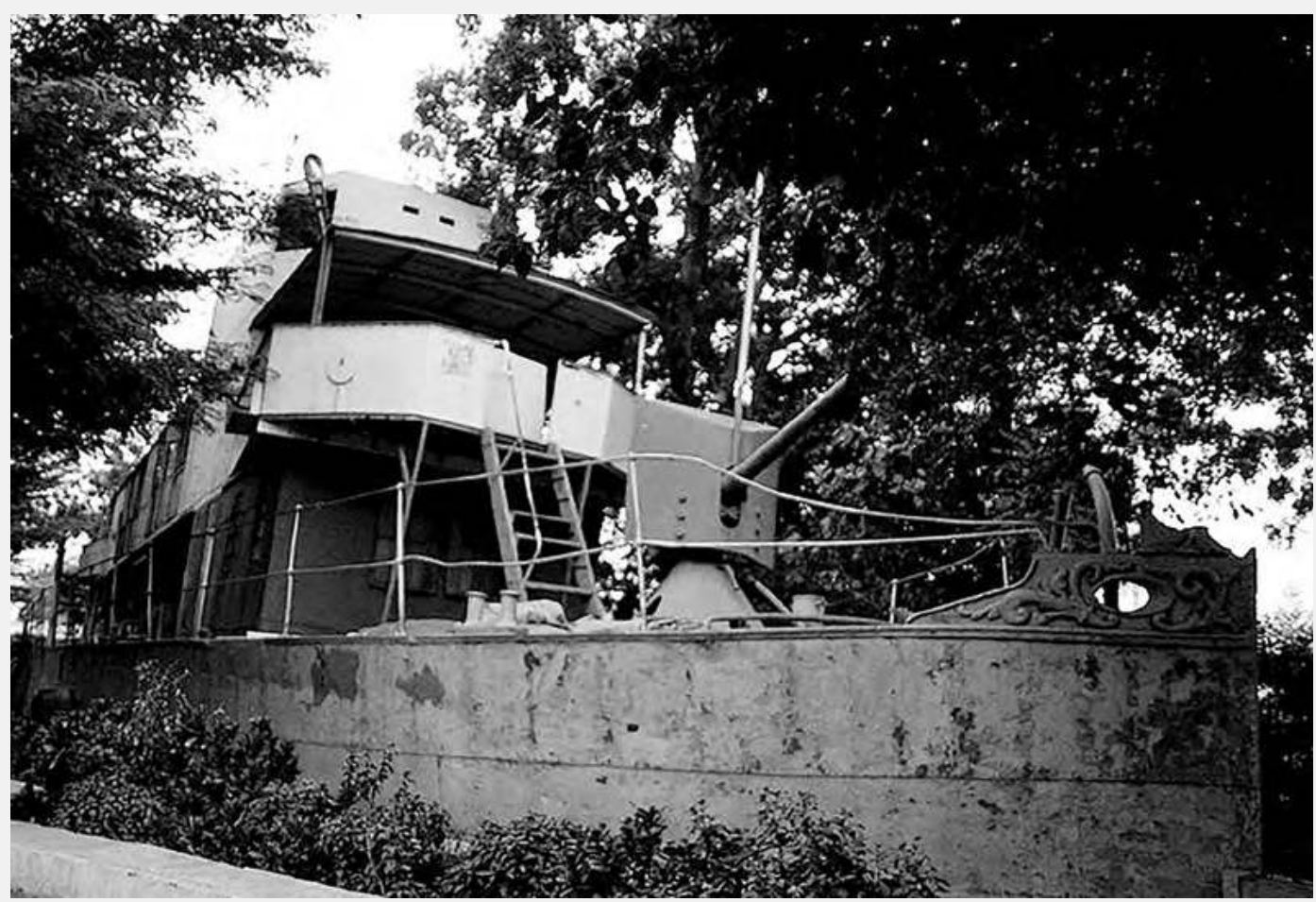

le Soudan

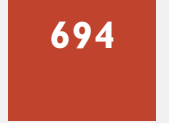

de 1820

à nos jours

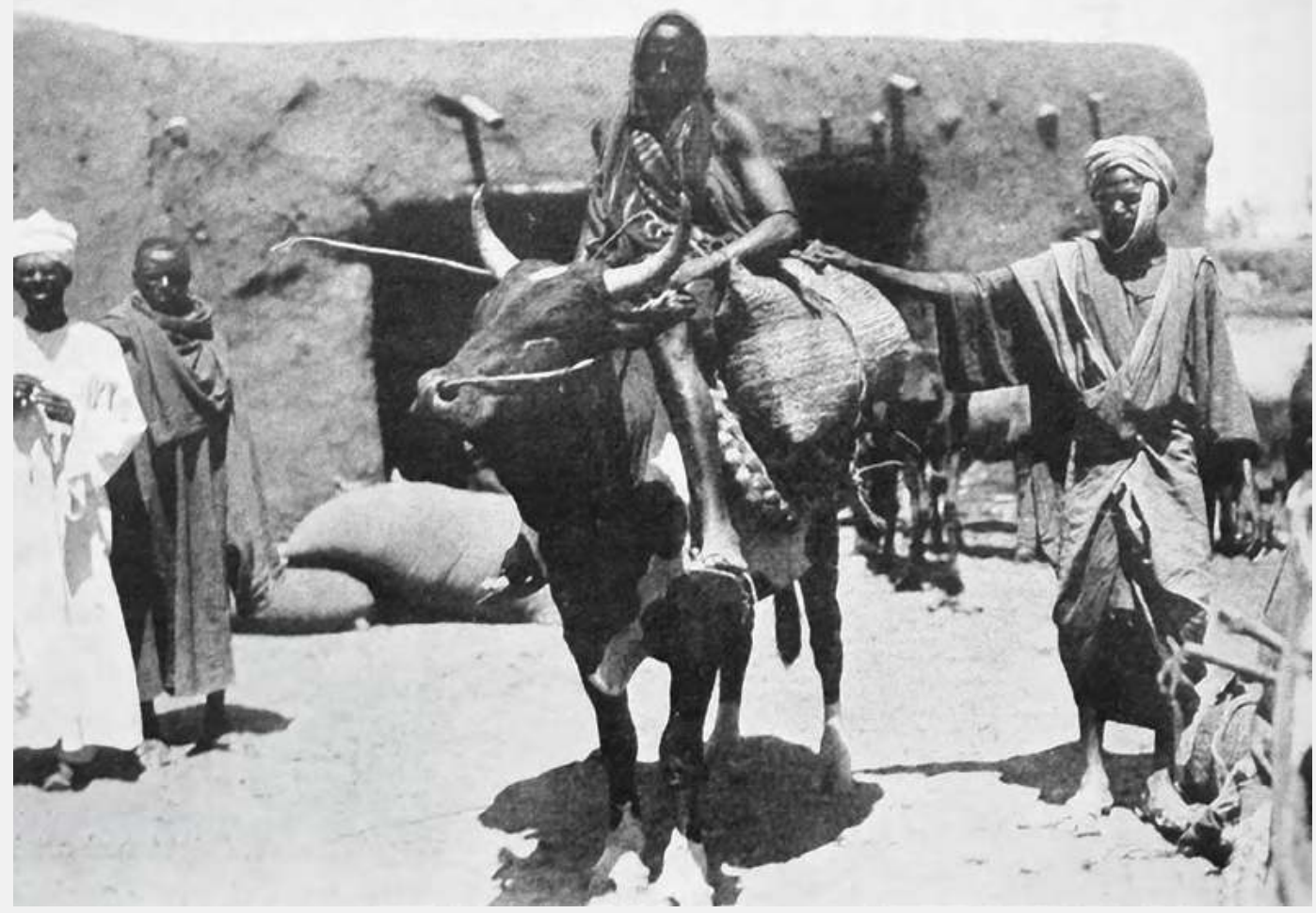

Canonnière et femme au marché d'el-Obeïd en 1912. 
La vie du souk [...] était sensiblement identique à ce qu'elle était dans les jours qui ont précédé l'occupation britannique, avec cependant une différence notable. Il n'était plus nécessaire pour les filles et les jeunes femmes de rester cloîtrées dans leurs maisons pour réduire le risque d'être repérées par les émissaires du Khalife, qui avaient ordre de s'emparer des membres les plus jeunes de la population féminine qui avaient la prétention d'avoir belle apparence. [...]

Les Soudanais du Nord, même s'ils professent l'islam, n'ont jamais reconnu la loi qui existe dans d'autres pays musulmans, et qui régit le traitement des femmes, de sorte qu'elles peuvent sortir en rue sans porter de voile, et on peut les rencontrer à chaque coin de rue, quand elles vont ou rentrent du fleuve ou des puits, pour l'approvisionnement quotidien en eau, ou au souk, faisant leurs achats de farine et des autres denrées nécessaires pour la famille. [...]

Bien sûr, un grand nombre de femmes n'avaient pas d'ambition plus élevée que celle de passer le reste de leurs jours dans le harem du saint homme qui régnait sur elles, mais il y en avait beaucoup pour qui la liberté de chaque jour de l'existence était beaucoup plus attrayante, et pour cellesci le nouveau régime était de loin préférable, en leur permettant dorénavant de faire leurs courses quotidiennes au marché en toute sécurité.

Des générations passées à tenir en équilibre sur leur tête des jarres d'eau, vides ou remplies, ont doté les femmes soudanaises d'une grâce parfaite et d'une liberté dans les mouvements qui est très séduisante. Leurs vêtements consistent d'habitude en deux grandes pièces de coton blanc ou bleu, l'une qui est portée autour de la taille et tombe comme une jupe, tandis que l'autre, couvrant la tête et les épaules, sert de corsage. Cette dernière cependant manque fréquemment ou est portée de telle façon qu'elle perd son caractère de vêtement. Elles sont de nature plaisante, rieuses, vivant l'instant et, non troublées par les rêves de vote pour les femmes, elles paraissent extrêmement heureuses dans le service de leurs maris.

La religion musulmane, elle aussi, en reconnaissant le simple désir ou le caprice de la part du mari comme une justification suffisante pour établir un divorce sans réplique, partage la responsabilité du relâchement moral qui prévaut au Soudan. Il y a, bien sûr, de très nombreux cas de femmes qui vivent un mariage heureux, et passent le restant de leur vie comme femmes et mères honorées, mais d'autre part, le mariage tel du moins qu'il s'applique à la femme, ne lui garantit pas la permanence des liens. Cent raisons peuvent survenir dans l'esprit du mari, qui sont suffisantes pour qu'il puisse baser dessus sa demande de divorce; et il obtient le divorce; la femme qu'il a rejetée est considérée comme ayant reçu une ample compensation pour la séparation par le remboursement de sa dot. 
[...] Dans la question du divorce, l'Anglais n'est pas toujours sans prendre avantage d'un système qui est, ou devrait être, étranger a ses principes, pour sécuriser pour lui-même une amie temporaire. Heureusement, de tels faits ne sont pas fréquents et durant mon séjour au Soudan, j’ai seulement rencontré deux Anglais qui s'étaient mariés avec des femmes indigènes. Assez curieusement, ces deux hommes sont maintenant, je crois, tous deux mariés avec des femmes de leur propre nationalité. Je connais mal ce qui constitue un mariage aux yeux de la loi anglaise et ce qui ne l'est pas, mais dans aucun des deux cas évoqués il n'y a eu aucun divorce formel avec la femme de couleur avant le second mariage, et je suppose que le fait qu'une des parties contractantes soit musulmane et le fait que la cérémonie a été de rite musulman seulement rend nul le contrat pour autant que la loi anglaise soit concernée, mais il est fort probable que la question de la légitimité de possibles enfants ait été négligée.

Il y a très peu de femmes soudanaises de Khartoum ou des autres stations du Nord qui ne regardent pas le fait de vivre avec un homme blanc autrement que comme un honneur, et dans les premiers jours de l'occupation anglaise il y avait peu d'hommes en position stable qui ne pouvaient le leur conférer. Devenir la mère d'un enfant à la peau blonde est une situation recherchée avec empressement; il n'y a pas de stigmatisation attachée à ce fait dans les mentalités, et fréquemment ne pas avoir un tel enfant était regardé plus comme une disgrâce que comme une vertu. Les filles se marient quand elles sont très jeunes. J'en ai souvent connues mariées à dix ans et mères à onze. La naissance d'un premier-né de sexe masculin est l'ambition de tout Soudanais, homme ou femme. Car après, la naissance d'une fille est bienvenue, en prévision de la dot qui sera payée à ses parents lorsqu'elle trouvera un mari, mais la naissance d'un enfant du sexe faible est considérée comme une atteinte à l'honneur des parents.

Dans les quartiers indigènes d'Omdurman, on peut trouver toutes les nuances en matière de beauté féminine [...]. Parmi les enfants il y a aussi un grand nombre de couleurs. Beaucoup des petits polissons allant pieds nus qu'on peut voir sur la plage d'Omdurman ont des cheveux dorés; beaucoup d'entre eux ont un teint du blanc le plus pur. C'est d'un certain point de vue une chose lamentable de voir cette progéniture des pionniers occidentaux laissée sans surveillance et qui va assimiler le caractère et les défauts de la race de la mère; mais je pense que s'il faut faire quelque chose, il est plus sage de laisser ces enfants dès le départ, plutôt que de courir le risque de gâcher le bonheur de la future génération en les ramenant en Europe. [...]

Les hommes, membres d'une race récemment assujettie à un régime despotique dénué de tous les principes essentiels concernant le travail dur ou administratif, m’ont frappé par leur intelligence et leur astuce, 

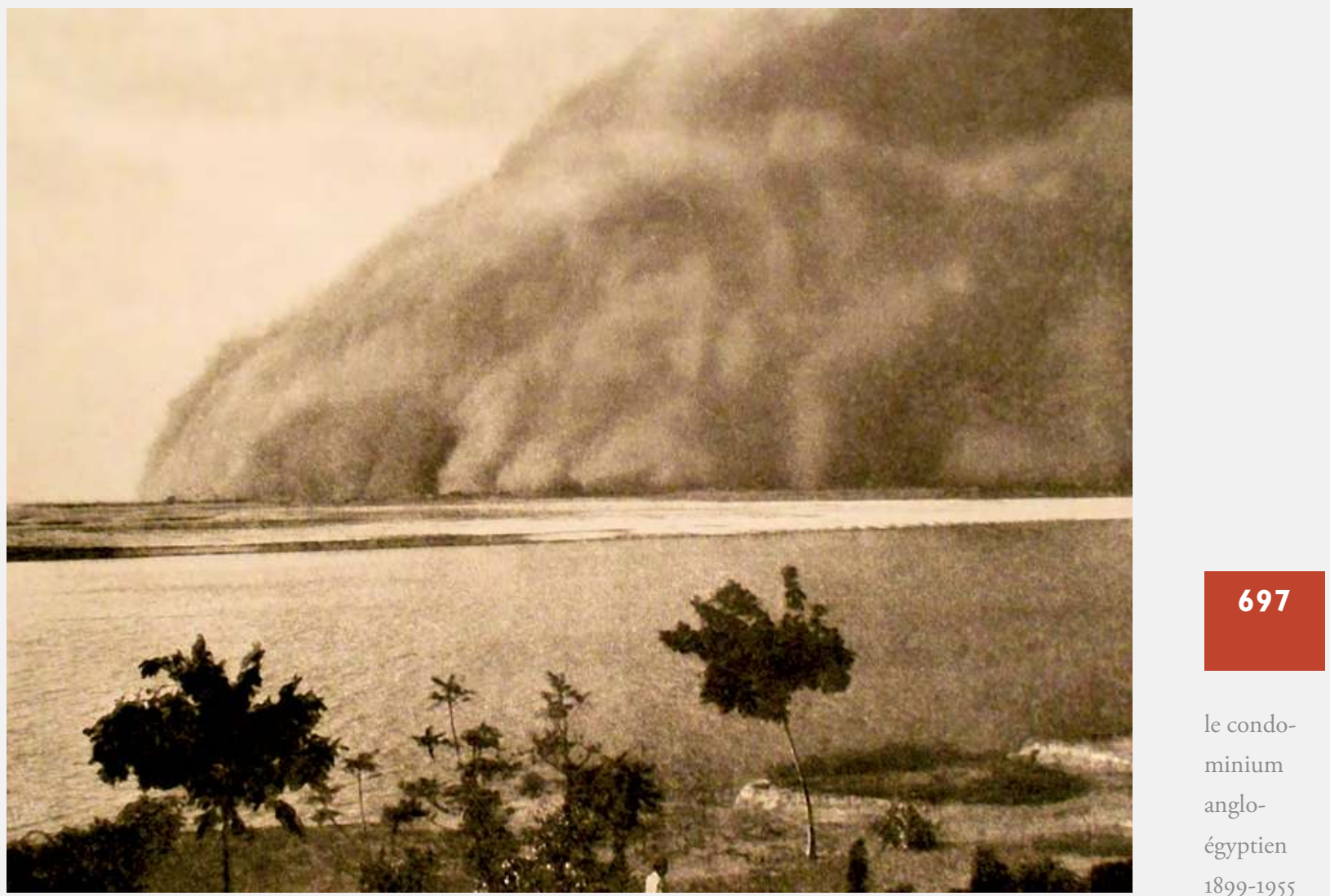

le condominium angloégyptien 1899-1955

Arrivée du haboob sur Khartoum en 1906. 


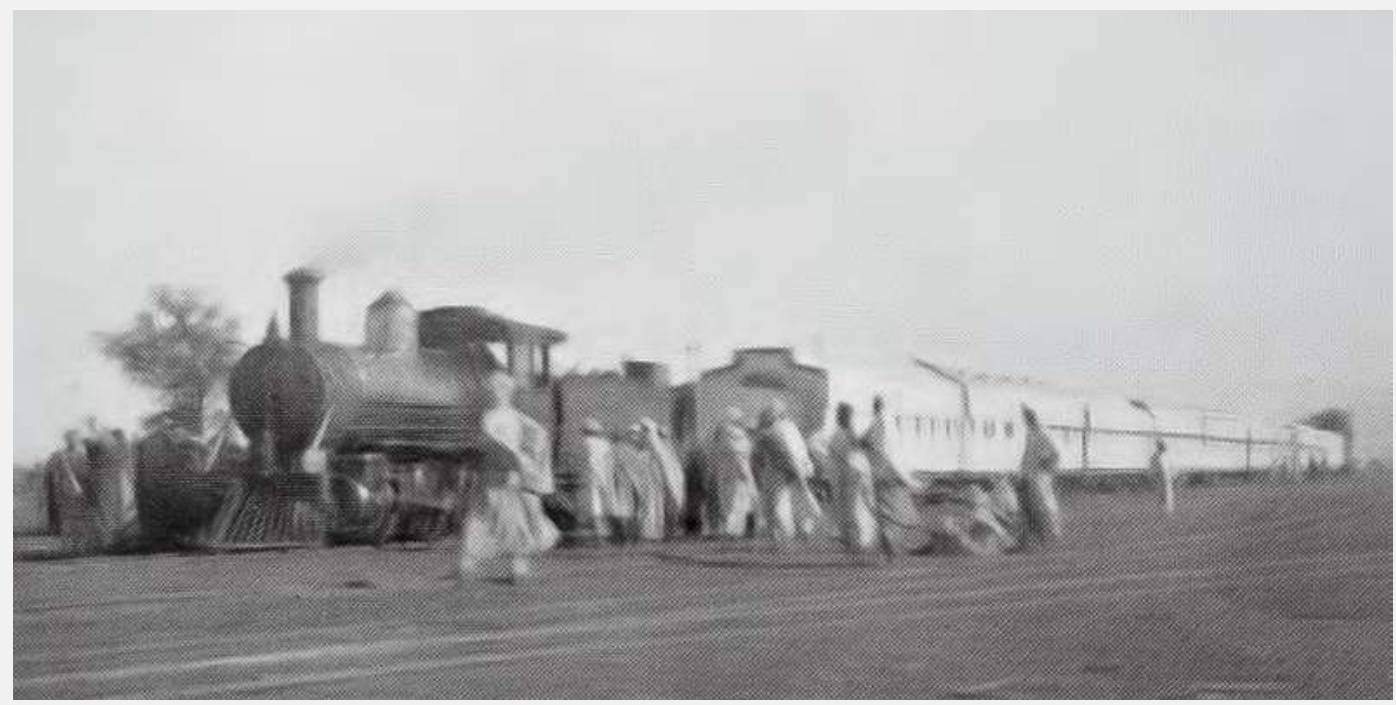

le Soudan

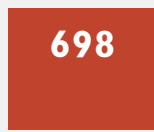

de 1820

à nos jours

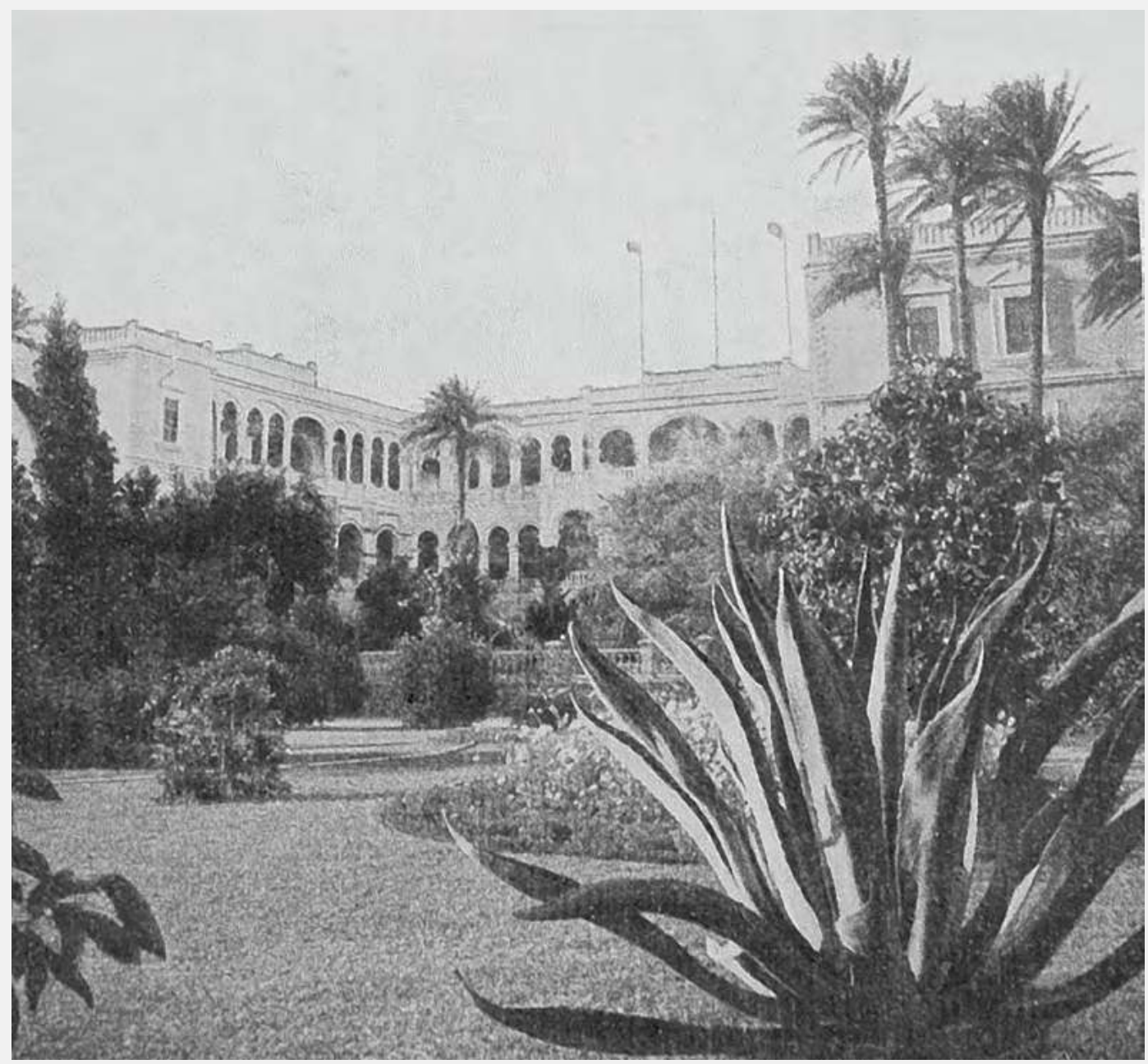



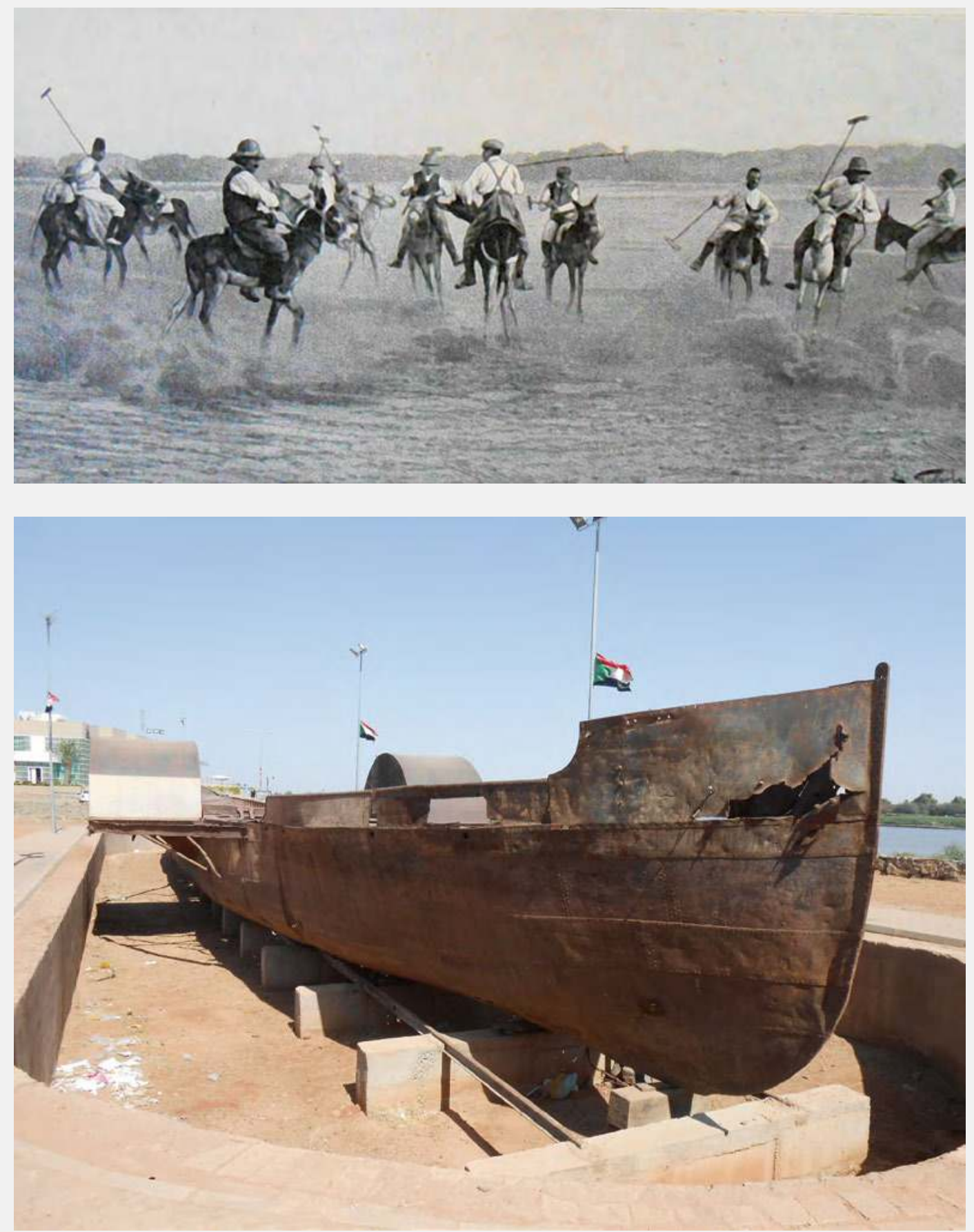

le condominium angloégyptien 1899-1955

4 Le train du Sirdar en 1911.

4 Le jardin du palais du Sirdar en 1907.

Partie de polo à Omdurman en 1907.

Bateau à aubes (steamer) en cours de restauration à Omdurman en 2013. 
et mes observations ultérieures n'ont pas modifié mon opinion. J'ai entendu dire qu'ils sont et butés et paresseux, bien que parfois comprenant une part de vérité, et ces déclarations m'ont toujours choqué parce qu'étant une description exagérée et injuste des véritables Soudanais. Admettons qu'ils ne soient pas tous exempts de paresse; que la majorité d'entre eux préféreraient une vie tranquille dans leur famille, ou à passer le temps assoupis sur les rives du Nil, [...], malgré cela je pense que cette race, dans ce qu'elle préfere, n'est pas du tout originale.

Encore, il y a ces accusations d'obstination; pour moi, ils sont obstinés seulement dans les circonstances où l'obstination cesse d'être un défaut. Ils ont horreur [...] de l'homme qui donne un ordre et ensuite change d'avis tout le temps. Si on les laisse comprendre une bonne fois ce qu'on attend d'eux, tout de suite ils vont le réaliser comme des hommes. J'ai vu une équipe travailler durant 14 heures durement, et sans jamais un murmure ou une allusion à la fatigue, ils travaillèrent jusqu'au lever du soleil. [...]

L'esprit d'émulation est fort entre eux, et souvent la difficulté réside non pas à les amener à réaliser quelque chose, mais dans le fait de le réaliser seuls. Et en ce qui concerne des activités où la dextérité et la capacité de réfléchir pour aboutir à un résultat sont nécessaires, une simple visite dans les boutiques, où on peut observer le tisserand, le bijoutier et le forgeron au travail, suffira à convaincre le plus grand sceptique que les Soudanais ne manquent ni d'intelligence ni d'ingéniosité.

Avec des outils tellement sommaires qu'ils seraient certainement rejetés comme étant inutilisables par tout forgeron ou bijoutier européen, les indigènes du Soudan produisent les bijoux filigranés les plus délicats, souvent avec des formes qu'ils ont conçues, avec une rapidité étonnante. Leur outillage le plus souvent ne consiste qu'en un lourd marteau, une enclume de facture locale grossière, et un creuset pour la fonte. Ils sont véritablement un parfait exemple de patience et d'application combinées, et constituent une réfutation permanente des accusations de paresse et de stupidité.

Telles étaient les premières impressions générales que je ressentis concernant la population du Soudan [...]. Mon lit, en cette première nuit, était disposé sur la plateforme supérieure d'un vapeur, sous le ciel nu, et je me rappelle que, même si j'étais tombé endormi, avec de temps en temps le bruit d'un tam-tam ou l'aboiement d'un chien saluant le lever de la lune, mes impressions avaient commencé à changer, sous l'influence magique de l'Afrique, de l'Afrique des Africains. Mes sensations, cependant, quand je me réveillai brutalement dans les premières heures du matin, à moitié aveuglé par un vent de sable particulièrement violent, qui faisait 


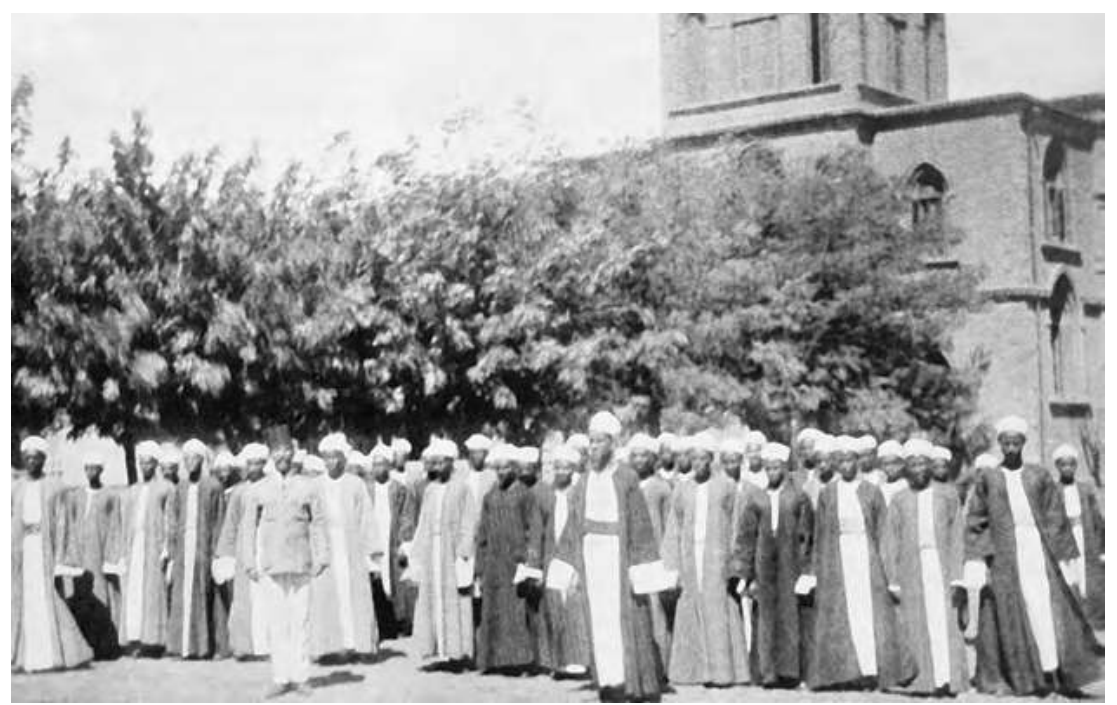

Élèves du Gordon College: beaucoup sont des fils de chefs et de notables (1912).

de son mieux pour me dépouiller de tout mon maigre couchage, sont plus faciles à imaginer qu’à décrire. Traînant mon lit derrière moi, je me laissai tomber dans une cabine où la température atteignait entre $38^{\circ} \mathrm{C}$ et $50^{\circ} \mathrm{C}$, et là, en compagnie d'innombrables moustiques [...], je passai le reste de la nuit, pour me réveiller au matin avec une figure boursouflée à m'en rendre méconnaissable, grâce à l'affectueuse attention que m'avaient témoigné mes dynamiques compagnons de cabine.

Du Congo au Nil: Ouadä, cinq ans d'arrêt. Le général français Jean Hilaire quitte Abéché, la grande ville de l'est du Tchad, en 1917, pour rentrer en France par le Soudan et l'Égypte. Il reçoit un accueil chaleureux à la frontière et traverse le Darfour récemment reconquis. Le train du Sirdar le conduit jusqu’à Khartoum. Autant il apprécie le faste et la qualité de l'accueil, qui lui sont réservés, autant il est surpris, voire choqué, des préjugés de caste et de race des officiers.

《À Khartoum où nous fîmes notre entrée dans l'après-midi du dimanche de Pâques (8 avril), nous fûmes au palace même, les hôtes du Sirdar et de l'infiniment gracieuse $\mathrm{M}^{\mathrm{rs}}$ Stack; le général s'exprimait assez bien dans notre langue, tout à fait familière par contre à la générale, qui avait été élevée en France.

[...] La ville, la première digne de ce nom que je voyais après trois années d'exil en pleine brousse africaine, me produisit la plus flatteuse impression. Le palais du gouverneur, élevé sur les plans de Lord Kitchener, et commencé par lui, est un monument superbe, à la fois imposant et élégant, avec ses deux façades recouvertes de marbre blanc, la principale 
le Soudan

\section{2}

de 1820

à nos jours décorée d'un escalier majestueux, également de marbre, regardant la ville et donnant sur un vaste parc anglais, l'autre surplombant la berge du Nil et reflétant dans les eaux calmes sa monumentale blancheur. La ville entière, d'ailleurs, édifiée aussi sur les plans du vainqueur d'Omdurman, a vraiment très grand air avec ses larges avenues rectilignes se croisant à angle droit, toutes ombragées de beaux arbres tropicaux, ses jolies villas aux frais jardins, ses vastes monuments, ses hôtels luxueux, ses riches magasins, ses squares magnifiques, toujours parés d'une végétation luxuriante.

[...] L'on nous fit donc admirer, en des inspections ou des revues d'une ordonnance protocolaire, parmi des cortèges d'officiers et des cénacles de professeurs, de conservateurs, de savants chargés de nous documenter, entre autres merveilles, le fameux Gordon College, à la fois faculté, institut, muséum, laboratoire d'expériences de tous ordres, l'école militaire "sudanese", pépinière d'officiers indigènes dont les élèves, cadets d'un noir d'ébène, manœuvrèrent devant nous avec un entrain endiablé, de riches jardins d'essais, des cultures modèles, riz, cotons sélectionnés, irriguées par tout un lacis de canalisation, les forges et ateliers de construction et de réparation fluviale et ferroviaire de la rive gauche [...]

Sur les officiers indigènes du cadre égyptien, quels que fussent leur grade, même supérieur, leur naissance, même effendis, beys ou pachas, pesait, plus lourdement encore, un incroyable mépris de race poussé jusqu'à l'ostracisme absolu. Et cependant, la plupart de ces officiers égyptiens, en général de teint clair et de type aryen très pur, paraissaient fort distingués d'allure, de manières, de savoir. Les Britanniques ne leur adressaient la parole et sur quel ton, que dans le service, ne leur donnant jamais la main et les tenant inexorablement à l'écart de leurs réunions de sport, de club, de société. À aucune des réceptions que nous offrirent si cordialement, à el-Fasher, el-Nehoud, Khartoum, mes camarades anglais, il ne nous fut donné de voir un seul officier égyptien, même du grade de major ou de colonel... À tel point que lorsque, à el-Fasher, ayant dû me débarrasser de mes deux chevaux, je les eus cédés aux deux premiers acquéreurs qui se fussent offerts, un capitaine et un vétérinaire militaire du même rang du cadre égyptien, je dus subir, le lendemain, à ce sujet, les confidences attristées, sinon indignées, du major Kirke... Kirke Bey pourtant!

Il ne me laissa point ignorer que, conformément au protocole britannique, des officiers britanniques du cadre anglais auraient seuls été qualifiés pour l'honneur d'une telle acquisition, à l'entière exclusion d'entités aussi inférieures et négligeables que doivent l'être, aux yeux d'officiers de race européenne, donc hautement supérieure, des officiers égyptiens. Je le priai de daigner excuser ma complète ignorance d'un protocole aussi 
nouveau pour moi et dont je prenais bonne note. Mais je ne lui dissimulai point que, chez nous, tout autre est l'esprit de camaraderie, essentiellement cordial, qui préside aux relations cordiales entre officiers français et indigènes, abstraction faite des différences de pigmentation épidermique et compte tenu uniquement de la communauté de devoirs et de sacrifice pour le même drapeau... Cette explication ne fit qu'aggraver, manifestement, la stupéfaction indignée du digne major, au demeurant, le meilleur fils du monde, en dehors de ses préjugés de caste et de race.

Mais je dois avouer que je ne fus plus étonné, par la suite, d'entendre des officiers supérieurs égyptiens, chaque fois qu'au cours de quelque exhibition militaire, ils pouvaient m'approcher à l'écart des officiers britanniques, se plaindre amèrement à moi, à voix basse, mais avec des flammes dans leurs grands yeux sombres, de l'ostracisme injurieux que l'on faisait ainsi peser sur eux... "Pourquoi mon colonel, grondaient-ils véhéments, mais d'une voix prudemment contenue, faut-il que ce soit cette race abhorrée, au lieu des Français, si généreux et tolérants, qui règne sur notre antique et sainte terre où, depuis Bonaparte, votre drapeau n’a jamais cessé d'être aimé et regretté?”

Itinéraire de Yaoundé à Khartoum, septembre 1923-mars 1924. À la fin d'un premier terme aux colonies, Henri Nicolas, jeune administrateur français, a quitté Yaoundé le 12 septembre 1923 en Panhard-Levassor modèle 1912, en direction du Nil. Après un périple de plus de six mois, il arrive en vue de Khartoum le 5 mars 1924, par le chemin de fer qui relie el-Obeïd à la capitale du condominium anglo-égyptien.

1 Nous arrivons à Khartoum un peu après six heures du matin. [...] Je me fais conduire au "Grand Hôtel" où j'arrive par une large avenue ombragée traversant le quartier résidentiel de cette ville qui paraît encore sommeiller sous la verdure de ses feuillages qu'une radieuse lumière transperce d'innombrables flèches d'or. L'hôtel, vaste bâtiment précédé d'un fort beau jardin, étale le long de l'avenue qui borde le Nil Bleu sa large façade à un étage surmonté d'un toit en terrasse. Ma chambre, au rez-dechaussée sur le jardin, est une grande pièce, haute de plafond, au sol pavé d'un carreau rouge bien luisant et où les meubles ont un peu l'air de jouer aux quatre coins.

Cet après-midi je suis allé au palais de son Excellence le gouverneur général. J'y ai déposé mon passeport et une demande d'audience pour présenter mes respects au chef de la colonie. Après un court moment d'attente, on me dit que le gouverneur général Sir Lee Stack est actuellement au Caire mais qu'en son absence je serai reçu demain à 11 heures par le haut-fonctionnaire qui assure son intérim, le Civil Secretary. 
le Soudan

\section{4}

de 1820

à nos jours
Cet après-midi j'ai fait un tour dans Khartoum. La ville européenne s'étend le long du Nil Bleu sur les bords duquel se trouvent, avec le palais et de jolies villas résidentielles, les bâtiments des grands services publics et l'imposante façade du Gordon College. Au-delà des casernes s'étend une grosse agglomération indigène qui compte environ 5000 habitants. En rentrant par les jardins qui constituent le plus bel ornement de Khartoum, je me suis arrêté devant le très beau monument de Gordon [...].

Le 7 mars, [...] j'ai descendu les marches conduisant à l'embarcadère où est rangée une belle et grande vedette dont les quatre hommes d'équipage, tout de blanc vêtus, attendent debout que je sois installé sur la banquette tapissée de l'arrière. [...] De très humble bourgade qu'elle était, Omdourman avait été promue au rang de capitale quand le Mahdi avait décidé d'abandonner celle fondée par Méhémet Ali, Khartoum la maudite. [...] Omdourman, qui n'a rien perdu de son importance depuis qu'elle a dû renoncer à son rang de capitale, me frappe par la largeur de ses rues principales, bordées de hautes maisons à étage bien construites et où circule une foule où l'on ne voit pour ainsi dire pas d'Européens, le nombre très restreint de ceux qui habitent la ville — à peine 200 — étant complètement noyé dans la masse des natives qui compte environ 50 ooo âmes. Il s'agit donc ici d'une de ces belles et grandes cités indigènes où l'impression de dépaysement est totale pour qui la visite. $\$$

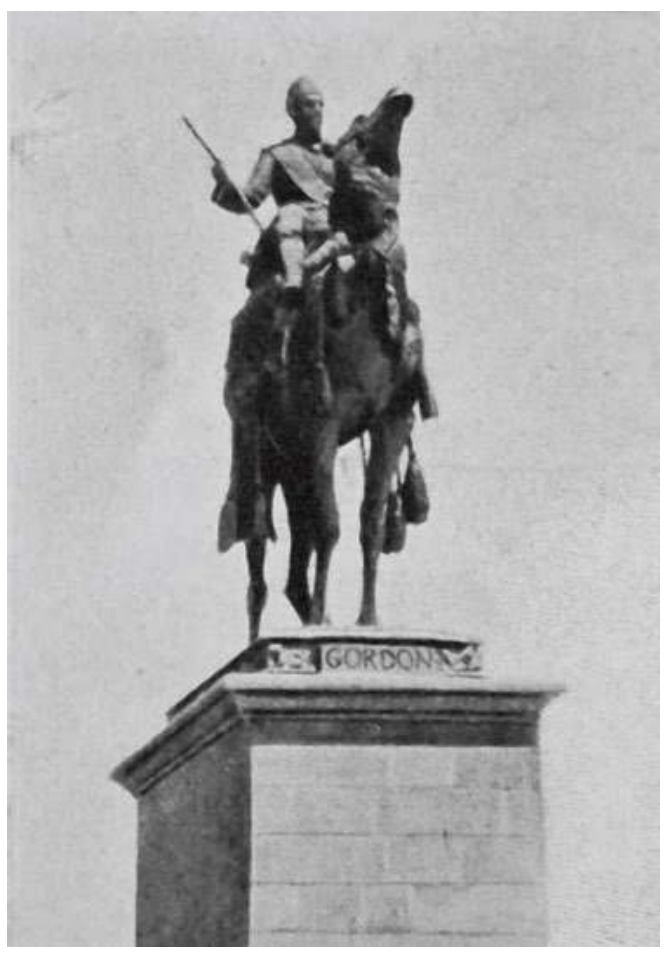

Statue de Gordon en 1907

et en 1911 (cette statue a été rapatriée en Grande-Bretagne après l'Indépendance).

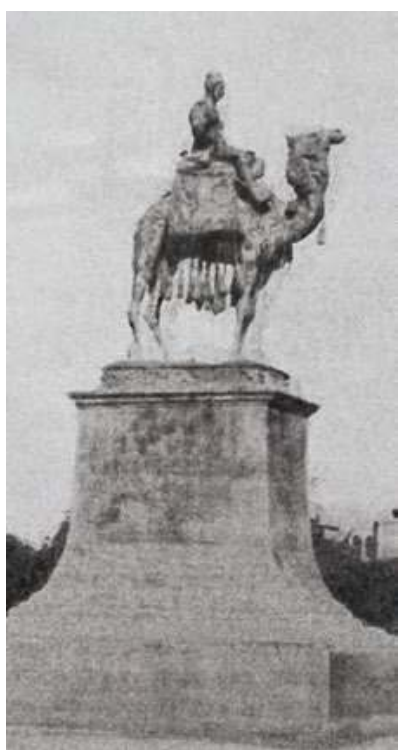




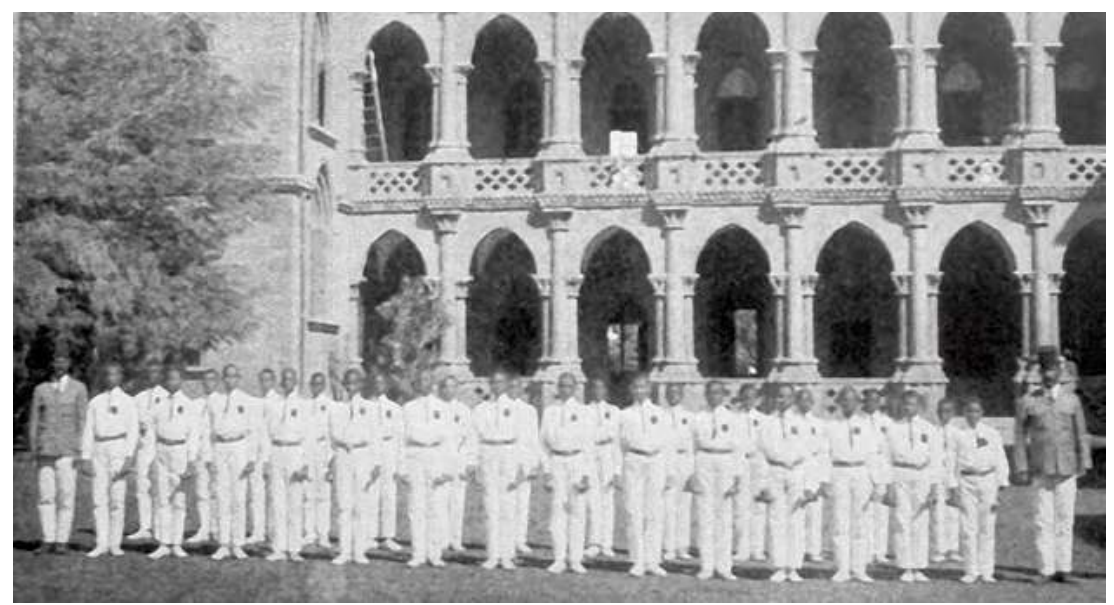

Élèves du Gordon College en uniforme (1912).

\section{Récit de Belges qui, partis pour le Congo par la voie du Nil, sont de passage au Soudan en 1929. \\ Le Gordon College}

Cette université a été bâtie par souscription publique, à laquelle, répondant à l'appel de Kitchener, l'Empire britannique entier contribua. Des professeurs anglais et égyptiens y instruisent de jeunes indigènes, venus de toutes les parties du Soudan, et destinés à devenir des fonctionnaires subalternes. [...] Il est permis de réfléchir à ce qui se passera lorsqu'ils seront assez nombreux pour exiger une part plus active au gouvernement. Nous les civilisons - me dit un officier anglais - et c'est d'ici que partira un jour le mouvement nationaliste qui s'efforcera de nous chasser du pays. Il n'y a cependant pas moyen, croyez-moi, de les traiter en égaux, car ils se méprendraient sur les causes d'un excès de considération, qu'ils interpréteraient comme une marque de crainte à leur égard.

\section{Les courses à Khartoum}

Pour une livre (bakchich compris) nous aurons à notre disposition une superbe Ford, dont le chauffeur nous attendra pour nous ramener au Grand Hôtel. Les race tracks sont situés en plein désert. Les cabines des paris [...] sont assiégées par des natives tirés à quatre épingles et coudoyant les blancs. Des soldats circulent, appartenant à la Sudan Defence Force, très smart dans leur manteau court serré à la taille et leur casque plat orné d'un petit plumet.

Les tribunes sont couvertes et tant de spectateurs y sont réunis qu'il est malaisé d'y trouver place, sinon au milieu d'un groupe imposant où, à ma surprise, je n'entends parler que français. Mes voisins sont des Grecs de Khartoum. Toute la vie commerciale de la capitale du Soudan se concentre dans leurs mains. Pas un qui parle sa langue natale. Tous s'expriment avec 


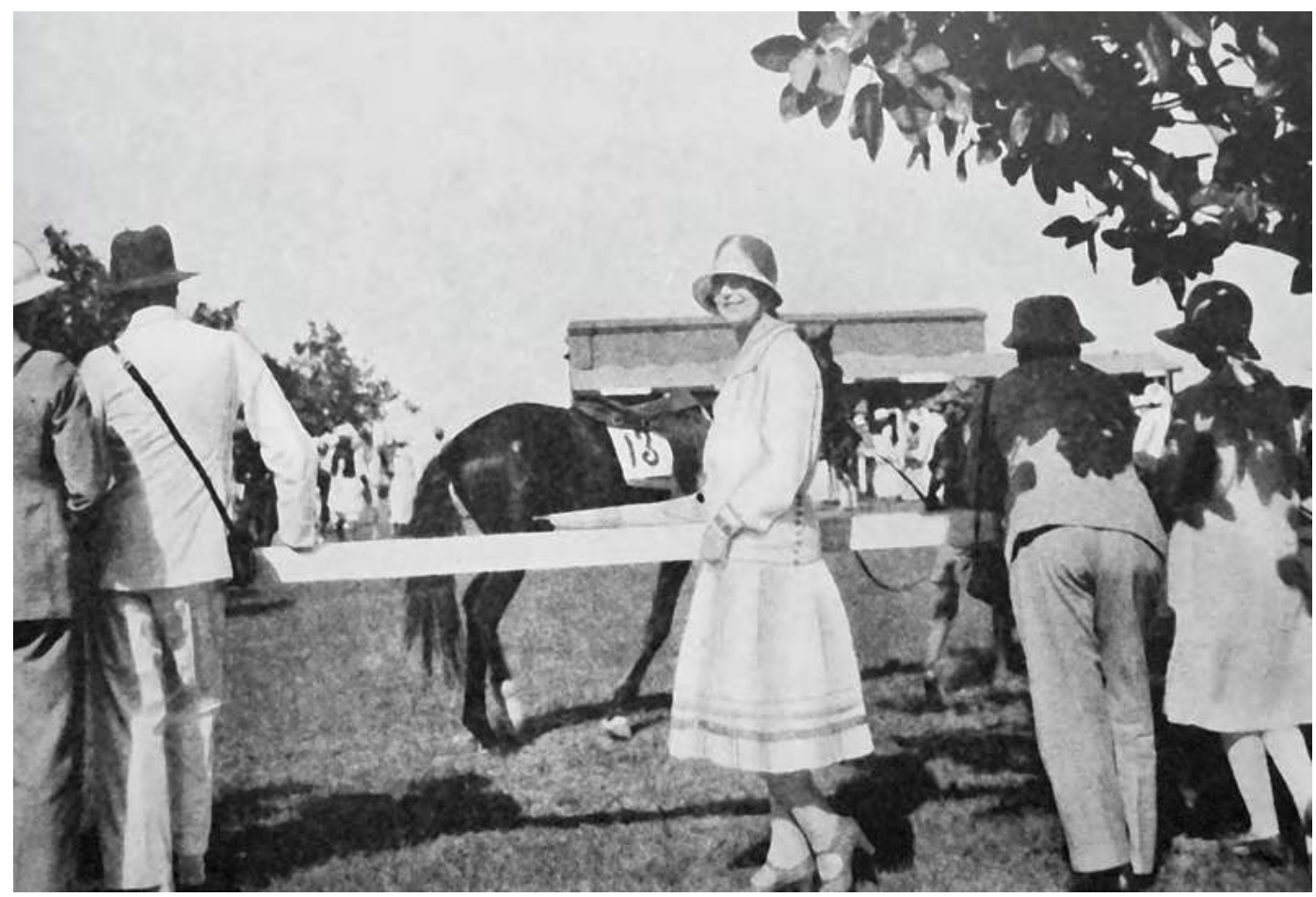

Courses à Khartoum en 1929.

\section{6}

de 1820

à nos jours une correction parfaite, sinon un accent impeccable, ce qui, dans un pays aussi éloigné de toute culture latine, ne laisse pas d'être remarquable et flatteur pour la France. Les Anglais, fonctionnaires ou officiers, leurs femmes et leurs enfants, occupent une autre partie des tribunes; une barrière invisible sépare ostensiblement les deux clans. Les armes et les toges tiennent à ne pas se mêler aux balances de Mercure. Il n'y a pas de noir, même le capitaine de cavalerie aux nombreuses médailles de campagne, aperçu tout à l'heure, qui vienne s'asseoir ici. Aucun règlement écrit ne l'en empêcherait probablement, mais il existe, en contrées anglo-saxonnes, des conventions tacites qu'il est plus nécessaire de respecter qu'un décret du parlement.

J'éprouve quelque surprise à voir des officiers anglais courir côte à côte avec des jockeys de couleur. Parmi ceux-ci, il est vrai, se trouve parfois un cheikh influent, propriétaire de sa monture. D'ailleurs le sport nivelle les différences. Les deux courses principales, cependant, ne sont ouvertes qu'aux membres du Club, tous anglais ou grecs.

Une musique militaire soudanaise sert d'intermède: elle est composée de grands diables vêtus de blanc et coiffés de tarbouches rouges. Il faut, paraît-il, une patience infinie pour leur apprendre la musique, et c'est d'ouïe qu'ils exécutent, étonnamment bien d'ailleurs, la plupart de leurs morceaux. 


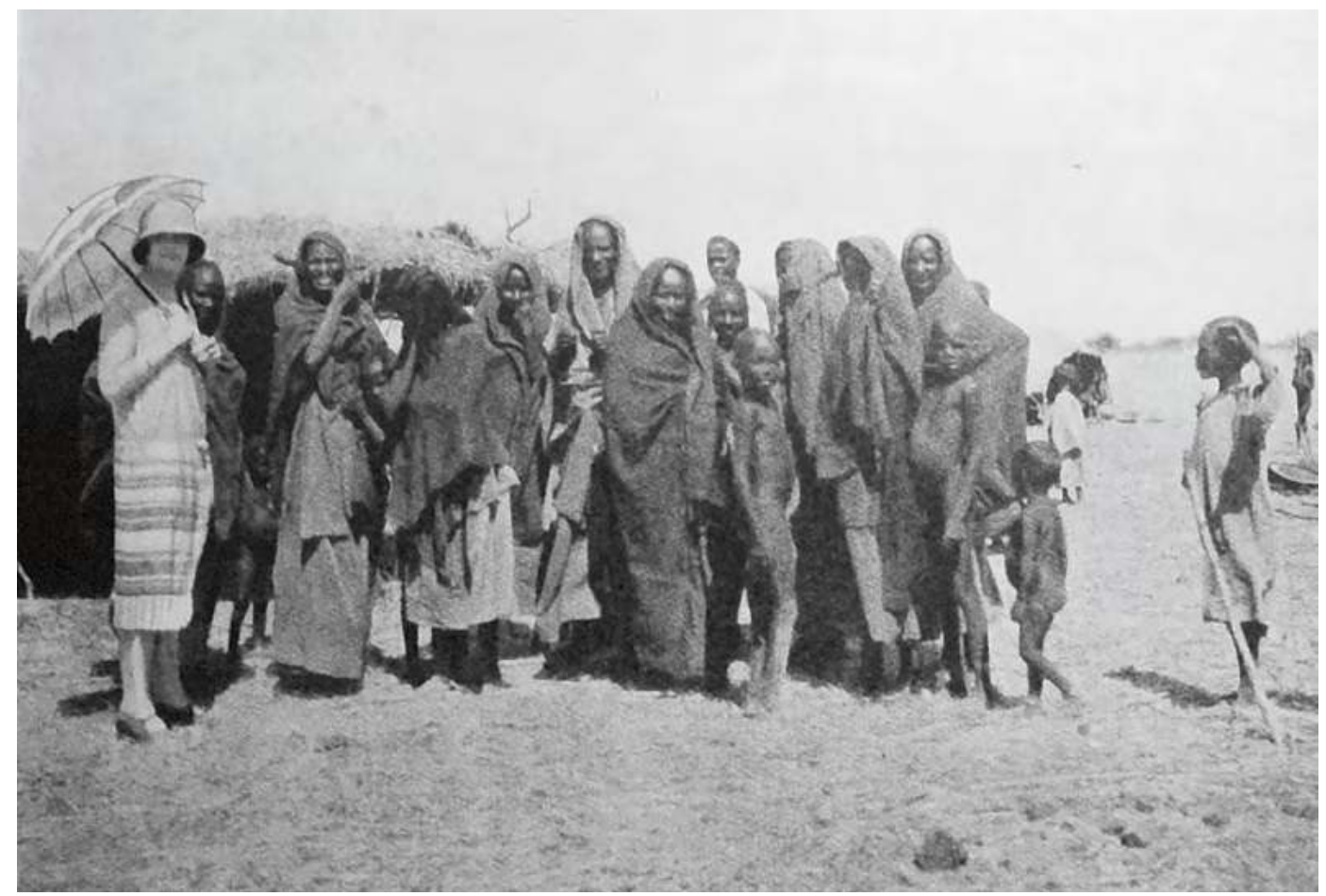

Tourisme au sud de Khartoum en 1929.

Lorsque nous quittons le Club, nous pourrions presque nous croire à Héliopolis ${ }^{1}$ ou à la Nouvelle Orléans... La ressemblance à la sortie est parfaite: les autos sont nombreuses; personne ne retrouve la sienne, et notre chauffeur, celui qui devait nous attendre fidèlement a, bien entendu, fait ce qu'auraient fait tous les chauffeurs du monde en pareil cas, c'est-à-dire qu'il est allé reconduire d'autres clients sans plus s'occuper de nous...

\section{Le développement du Sud}

Un colonel de la SDF à qui je demandais si les Dinkas et les Shillouks étaient heureux sous la domination actuelle me répondit: "Non, ils ne sont pas contents. Nous avons fait régner la tranquillité dans un pays ravagé par les violences et la terreur, et la mariée est devenue trop belle. Les hommes se plaignent aujourd'hui de ce qu'on les empêche de se faire la guerre les uns aux autres, et de ce qu'on leur ait enlevé le meilleur de leur plaisir et la plus noble de leurs occupations. Aujourd'hui la famine règne dans les régions où les populations se multiplient sous l'égide de la pax britannica...”.

1 Héliopolis: ville nouvelle construite en 1905 par le baron

Édouard Empain, au nord du Caire; aujourd'hui quartier intégré dans le tissu urbain de la capitale égyptienne. 


\section{Un bal à l'hôtel}

Ce sera le troisième de la semaine. Jeudi, le Zoo donnait une soirée en plein air; vendredi, une private party avait lieu et aujourd'hui, comme tous les samedis, on dansera au Grand Hôtel. Les fonctionnaires et officiers en résidence ici n’ont vraiment pas à se plaindre de la vie mondaine! Je m’enquiers auprès du portier d'un coiffeur convenable... j'annote à titre documentaire: cette simple coupe de cheveux me coûte 25 piastres ce qui, pourboire compris, fait 50 francs. Nulle part, même à New York, je n'ai trouvé de figaro si dispendieux! Le tarif, je l'ai appris par la suite, est de 8 piastres pour les Anglais habitant la ville. Mais je suis un traveller, c'est-à-dire: gibier dont la chasse est ouverte en toute saison.

Le monde commence à affluer dès après le dîner. Il y a beaucoup plus de smokings que de robes du soir - aussi les danseuses font-elles prime, et les derniers arrivés ont du mal à remplir leur carnet de bal (car il y a des carnets de bal).

Les musiciens - soldats anglais "prêtés" pour la circonstance par l'officier commandant - ont mine excellente. Leurs dinner coats sont impeccables; leur musique, rythmée à souhait, dans la meilleure tradition des boîtes chères, et leurs airs sont les dernières scies américaines.

Une étrangère découvre le Soudan britannique. Odette Keun, amie de l'écrivain H. G. Wells, journaliste et polémiste américaine, publie $A$ Foreigner Looks at the British Sudan en 1930.

《Aujourd'hui, après trois décennies, le Soudan compte six millions d'âmes; le pays se prend en charge et le citoyen britannique ne donne pas un penny pour son développement. Individuellement, selon les standards locaux, le pays est prospère et s'élève par l'éducation. Il existe déjà des médecins indigènes formés au Khartoum Medical College. La sécurité publique est quasiment totale. Comparé à d'autres colonies existant depuis plus d'un siècle, c'est plus calme, plus heureux, plus riche et plus sain. Comment ces résultats étonnants ont-ils été atteints?

Quand les Anglais en ont pris le contrôle et l'administration, ils auraient pu agir en toute impunité comme l'ont fait les Belges au Congo, ou les Allemands dans le sud-ouest africain... ou les Français en Algérie, etc. Chaque race assujettie peut appeler ses maîtres européens "le fléau blanc". Au Soudan, les Britanniques ont innové: dès le départ, les Britanniques animés d'une conscience moderne ont innové: (i) ils n’ont pas spolié le propriétaire indigène de sa terre, (ii) ils n'en ont pas permis l'accès au petit commerçant, à la classe moyenne de Grande-Bretagne, aux petits fermiers, petits commerçants, tous féroces ennemis des indigènes, et (iii) ils se sont abstenus de tout travail forcé ou non rémunéré. 
Les Anglais ont évolué vers le succès très rapidement en mettant ces principes en pratique. Ils ont formé des agronomes, des entomologistes, des vétérinaires... Ils ont formé des indigènes comme sages-femmes. Peut-être seront-elles un progrès pour la suppression des mutilations génitales féminines.

L'éducation a été un point fort des réalisations de Khartoum: en 1928 il y avait au Soudan 11 écoles primaires, 80 écoles élémentaires ou kutabs, 489 écoles indigènes subsidiées, 3 écoles professionnelles, un collège pour filles et 17 écoles primaires, avec un total de 28315 élèves. La demande d'éducation est croissante et des efforts soutenus sont accomplis pour subvenir aux besoins. Il faut aussi mentionner le Gordon College, où les indigènes sont formés comme professeurs, ingénieurs, et à des postes d'administration.

Les progrès sont évidents mais concernent quasi exclusivement le Nord. Le Sud présente une situation plus difficile avec une multitude de races païennes. Les missions chrétiennes y règnent en maître et il est préoccupant de penser que ces presbytériens, baptistes, catholiques romains, anglicans, prennent une influence croissante sur les noirs. Aussi performants soient ils, ils privilégient les conversions et peuvent être un facteur de division des communautés. Ce devrait être le rôle principal de l'État que d'assurer l'enseignement.

À propos de Gordon, quelle légende sentimentale a été tissée autour de lui! Voilà un homme dont la statue orne la principale avenue de la ville dont une école porte le nom. Si l'on creuse au-delà des deux épisodes qu'on lui associe, la défense de Khartoum (qu’aurait-il pu faire d'autre, ayant l'ennemi aux portes) et sa décapitation — il y a par ailleurs de pires façons de mourir - et si l'on étudie son parcours personnel, on s'aperçoit qu'il était par essence un aventurier, cruel en Chine, désobéissant et indiscipliné comme officier, pas plus brave que le plus ordinaire des soldats, et un fanatique religieux de la pire espèce. Son refus de rencontrer Slatin parce qu'il s'était converti à l'islam est un incident odieux qui le rend semblable au Mahdi, l'un protestant, l'autre musulman.

Quel est le rêve arabe qui obsède l'esprit anglais, avec Lawrence d'Arabie tentant de développer l'unité arabe, ce que même le prestige du Prophète n’a pas réussi? Qu’est-ce qui a persuadé ces brillants administrateurs modernes à Khartoum qu'une "civilisation" arabe existe? Se peut-il que ces Britanniques, à l'étranger, soient les victimes inconscientes d'un enseignement anglican restrictif qui crée par réaction un enthousiasme pour des cultures totalement différentes et barbares? Ceci mériterait une psychanalyse.

Au Sud, les païens qui ignorent l'arabe devraient être scolarisés en anglais, pour les ouvrir à la modernité plutôt que de leur faire suivre les dogmes religieux du passé. 


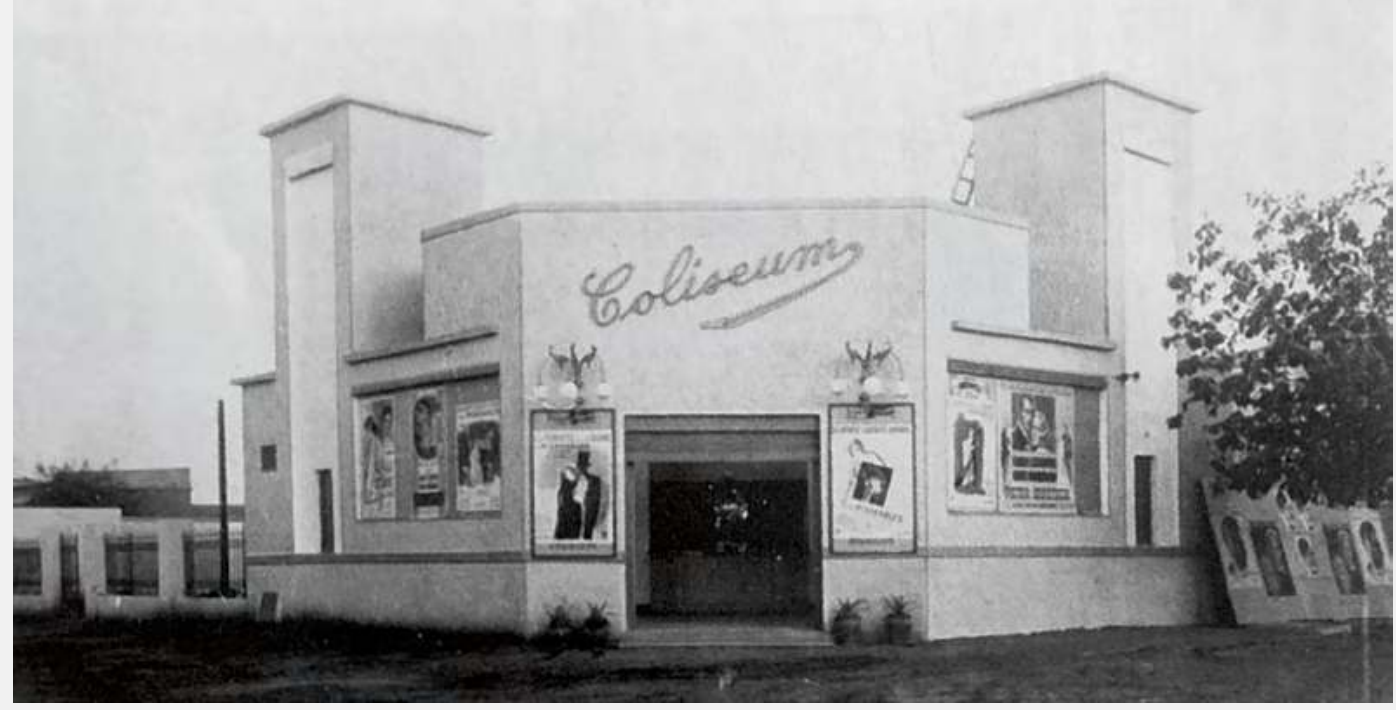

le Soudan

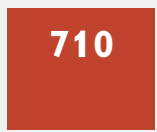

de 1820

à nos jours

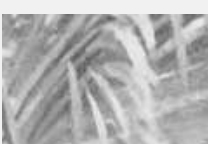

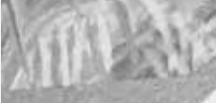

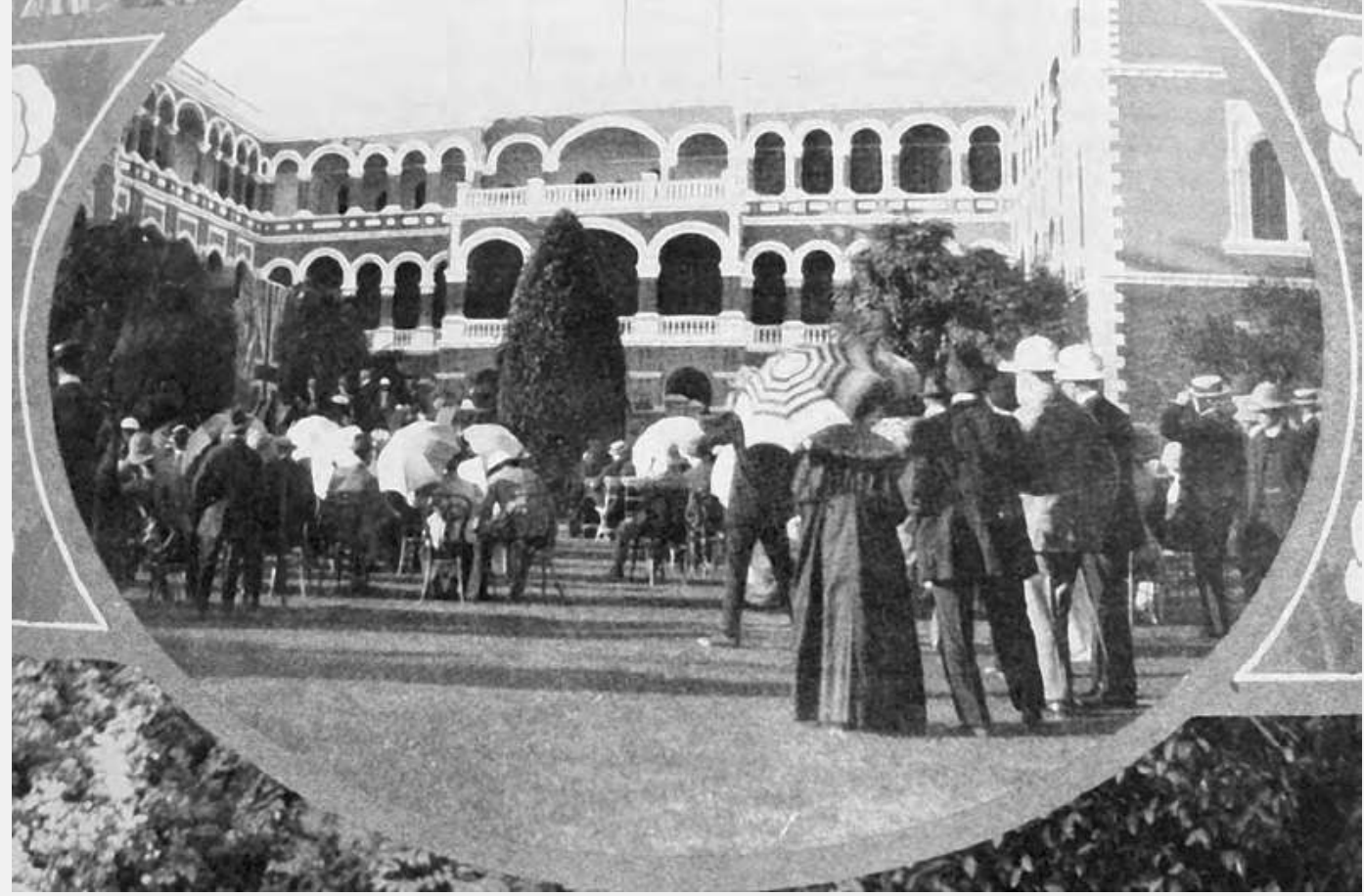

Le cinéma Coliseum (1935) et party au palais du Sirdar (1912). 


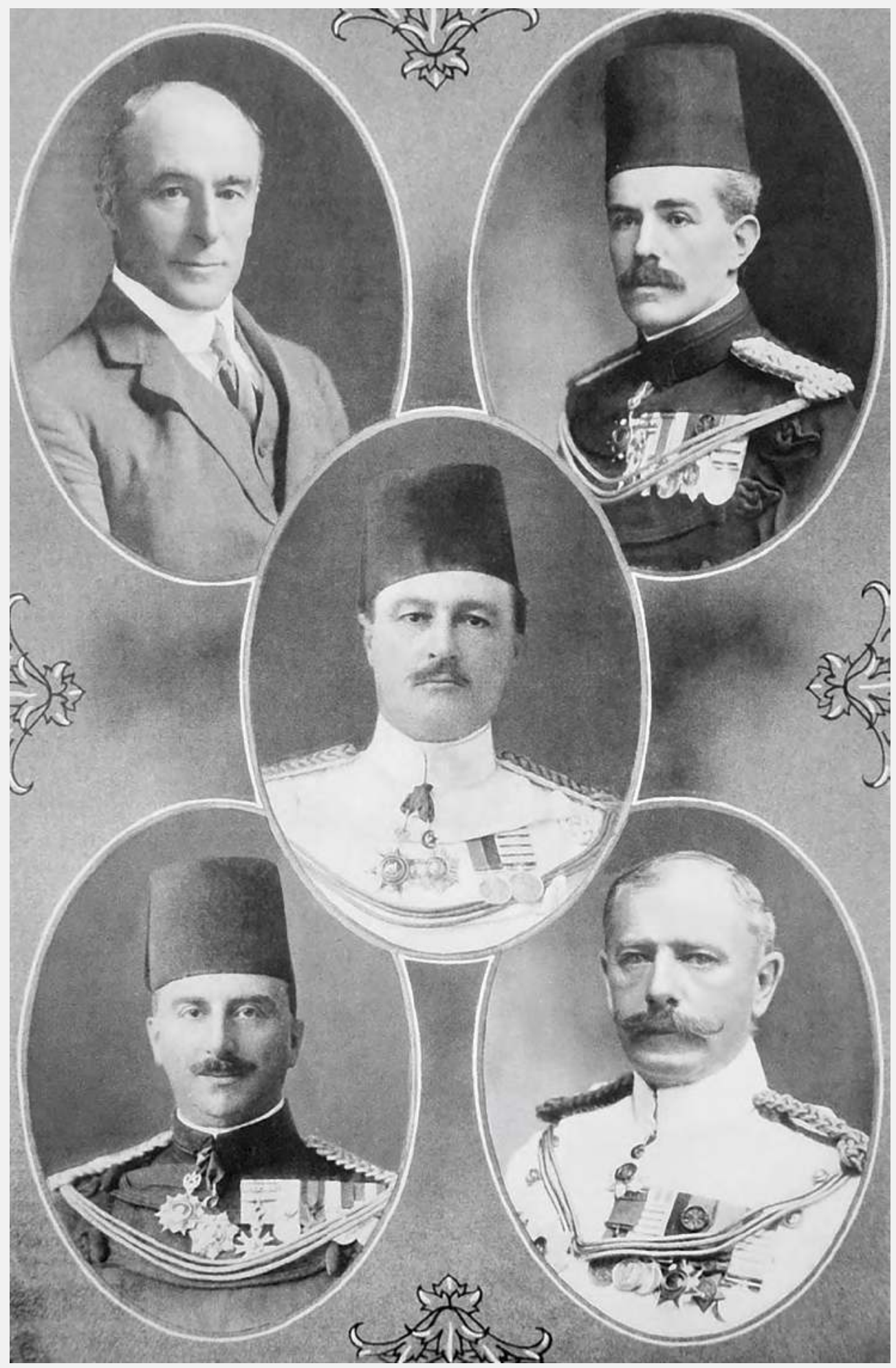

le condominium angloégyptien 1899-1955

Chefs de province au Soudan en 1912. 
le Soudan

\section{2}

de 1820

à nos jours
Un cinéma existe mais, grâce au manque d'enthousiasme des autorités, il n’a pas encore été perverti par Hollywood, et, dans l'intérêt de ce pays en formation, le prestige de l'homme blanc ne devrait pas être menacé.

On peut ironiser sur le soin porté au dress-code pour les dîners, dont l'étiquette semble indispensable à la continuité de l'Empire jusque dans les coins les plus reculés du territoire. Tous les efforts sont déployés pour lutter contre l'inertie insidieuse qui menace l'expatrié à l'étranger. Peut-être aussi ceci ajoute-t-il au prestige de la race qui gouverne, dans l'esprit des autochtones. [...] C'est incomparablement mieux que le laisser-aller des Français dans leurs colonies, sans col ni chaussettes, la chemise déboutonnée...

La déconcentration est un concept clé dans l'organisation du Soudan, en s'appuyant sur les chefs traditionnels qui ont vu leur fonction héréditaire confirmée par l'administration. L'alternative aurait été une centralisation lourde à Khartoum, avec des coûts salariaux plus importants. Un des paradoxes les plus étranges du Soudan, c'est son caractère autocratique en principe. Le gouvernement du Soudan est responsable non pas devant le Colonial Office, obligé de gérer les peuples inférieurs, et qui n’a jamais appris aucun savoir-faire, mais devant le Foreign Office, qui laisse le Soudan gouverner tous les aspects pratiques.

De plus, la santé financière du Soudan n'en fait pas un poids pour le Chancelier de l'Échiquier et n'a pas eu à souffrir du Parlement britannique, ce cauchemar impitoyable pour l'administration. Le code pénal a été élaboré à Khartoum, à partir de sources différentes: il est basé sur celui de l'Inde, mais la loi anglaise s'applique en matière commerciale, alors que la majorité des différends sont réglés sur base des coutumes des différents groupes ethniques et dans une certaine mesure de la loi coranique.

Au départ, l'application de la loi anglaise dans les tribunaux était prédominante mais, avec la sagesse de s'appuyer sur les chefs traditionnels, la revendication "Le Soudan aux Soudanais" pourra être prévenue.

Le succès de l'expérience soudanaise est lié à la qualité des administrateurs. Plusieurs semaines de visite me l'ont confirmé: les autochtones sans aide auraient été incapables de l'amener à son développement actuel, résultat des efforts d'un petit nombre d'étrangers qui gouvernent ce pays. À l'encontre du révéré Mr. Kipling, mon expérience des colonies m’a montré que l'homme blanc est suprêmement prêt, non pas à porter son fardeau sur ses épaules, mais à se transformer en boulet aux dépens de l'autochtone. Mais pas au Soudan: ici, le miracle s'est réalisé.

Il est dommage [...] que le Soudan ait été partagé avec l'Égypte, et que la livre égyptienne soit en usage dans le pays. Il serait préférable que l'Angleterre se propose de régler les 750 ooo livres — le septième ou le huitième du coût d'un navire de guerre — somme que l'Égypte continue 
à payer et qui constitue la base de sa revendication sur le Soudan. Les progrès du Soudan sont le fait exclusif des administrateurs anglais. Introduire auprès d'eux, avec un pouvoir égal de commandement, des collègues égyptiens sans expérience, détestant les Anglais - et eux-mêmes traditionnellement détestés des Soudanais —, infectés du nationalisme le plus virulent, risquerait d'entraîner l'arrêt du développement actuel, et peut-être un retour en arrière. Tous les efforts consentis pourraient n'aboutir qu'à la destruction et au néant. Les Anglais ont libéré le Soudan de l'esclavage et de l'oppression, ils en ont lancé le développement économique; un retrait prématuré remettrait l'ensemble des résultats positifs en question.

Une visite à Souakin, avril 1942. Gaétan Fouquet, journaliste et grand voyageur, profite d'un séjour forcé à Port-Soudan, où il attend une correspondance entre deux vapeurs des lignes de la mer Rouge, pour visiter Souakin.

Ce que l'on nomme là-bas la route de Port-Soudan à Souakin n'est pas du tout ce que nous appelons en Europe une route. Ce n'est pas davantage une piste, ni même un tracé. C'est la ligne idéale, qui joint les deux villes, et que rien, apparemment, ne distingue sur le sol du sol avoisinant. Il en est souvent ainsi dans le désert. De place en place, la rencontre d'un vieux bidon d'essence éventré, ou de la mâchoire blanchie d'un chameau mort à la peine, est le réconfortant indice que vous êtes bien sur la "route". Nul cantonnier ne s'est jamais hasardé entre ces repères, reconnaissables aux yeux des seuls indigènes. Aussi le chemin n'est-il pas toujours facile! [...] Sur notre route, il y avait beaucoup d'accidents de terrain, et la vieille Ford s'était laissée choir dans une sorte d'entonnoir sableux, d'où seul un attelage de chameaux devait pouvoir la faire sortir. Il n'y a que trente kilomètres de Port-Soudan à Souakin. Nous en avions heureusement déjà fait plus de vingt-cinq, qui nous avaient pris, c'est vrai, cinq heures de temps et des efforts de galériens. Nous avions beaucoup plus trâné notre véhicule qu'il ne nous avait transportés. J'étais ravi à l'idée de l'abandonner enfin à son triste sort, et de m'en aller sur mes deux jambes et les mains dans les poches... Je partis à l'aventure, informant mon compagnon que j'allais lui envoyer tout le secours nécessaire. Souakin brillait à l'horizon comme un petit tas de cailloux blancs déposés sur le sable.

Une grande muraille crénelée entourait cette cité de rêve dont j’aperçus bientôt la porte monumentale. [...] J'arrivai bientôt devant un porche solitaire, et que flanquaient deux tours carrées. Des canons rouillés menaient une garde de pure forme. Les battants du portail étaient grand ouverts. J'entrai dans une ville de légende. Mes pas silencieux se marquaient sur le sol d'une rue rigoureusement déserte. Toutes les fenêtres et les portes étaient closes. Pas un murmure, pas un bruit, pas une âme qui vive... [...] Je débouchai bientôt 


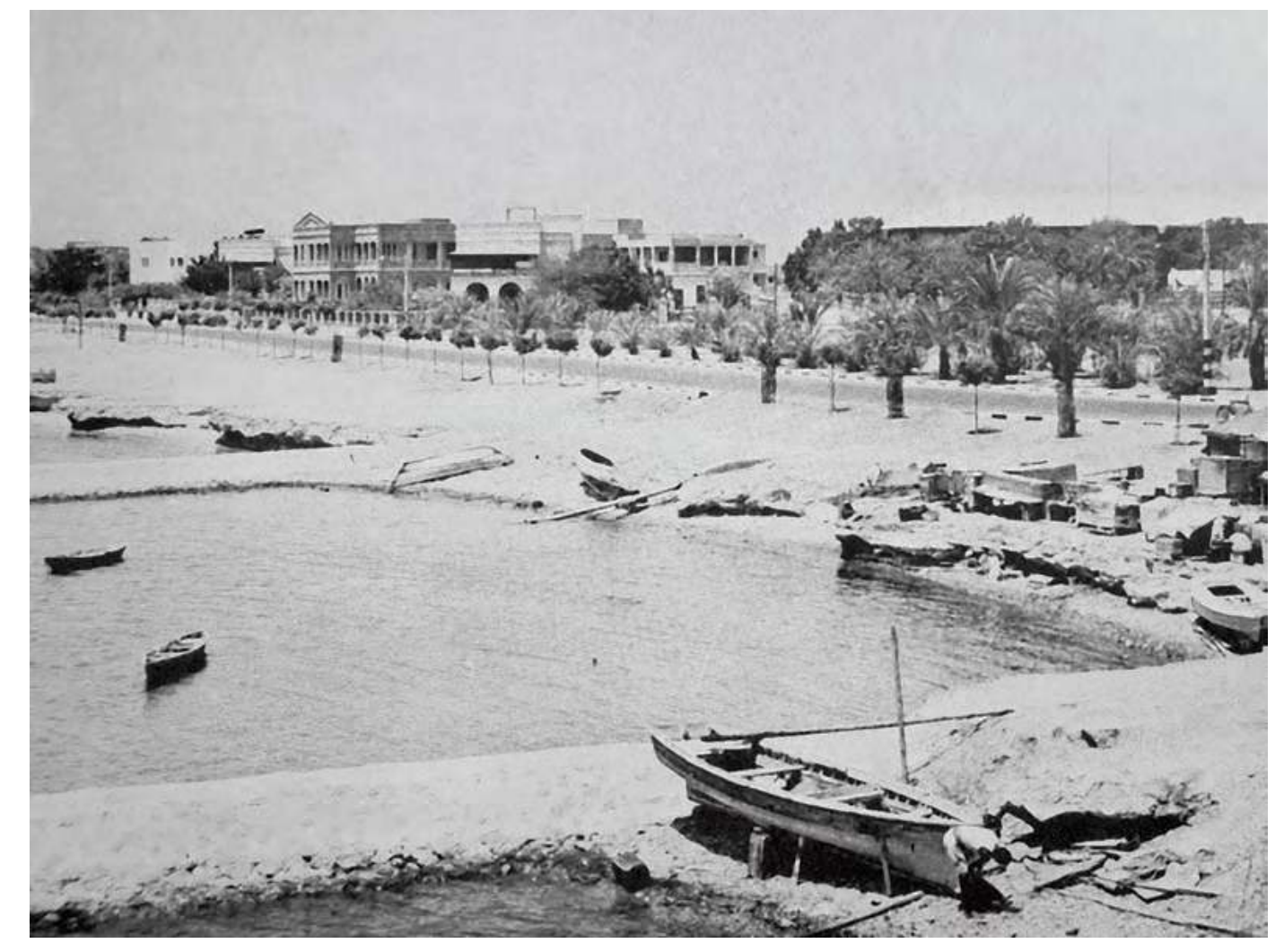

\section{Port-Soudan.}

de 1820

à nos jours

sur une courte esplanade, au bord d'une lagune. De l'autre côté de l'eau morte, un amoncellement de palais, aux balcons de bois ajouré. Je crus soudain entendre une pauvre mélodie s'élever dans l'air immobile et percer le silence. Dans une rue voisine, sous un portail, un aveugle accroupi tirait d'un violon monocorde des sons acides et crispés. En face, un petit café indigène, où deux Soudanais s'étaient endormis devant des tasses vides. [...]

Je savais qu'une exploitation française existait toujours à Souakin. "Les fils de Gaston Debas" ainsi se nomme cette firme dont le siège se trouve au Caire, mais qui possède à Souakin un moulin à coton. [...] Au mot de "franćaoui", le cabaretier s'agita davantage; que je ne fusse pas Anglais mais Français, cela dépassait tout de même les limites de l'imprévisible. Bientôt il me confiait à son marmiton pour que celui-ci me conduise au moulin des “fils de Gaston Debas". [...] C'était une sorte de fabrique à l'ancienne mode, de l'autre côté des murs, face à la mer, dans un repli de terrain. Trois Français m'y reçurent, [...] qui vivent là deux mois par an au moment de la récolte du coton. On donna des ordres pour que trois chameaux soient envoyés sans retard au secours de mon malheureux automobiliste. On me fit manger et boire. Puis on me proposa de visiter l'usine. Au temps de la prospérité 
de Souakin, elle avait failli devenir d'une extrême importance. Mais la création de Port-Soudan, où était maintenant dirigé par chemin de fer tout le coton du Soudan, avait réduit son activité à un tel point qu'on se demandait chaque année si l'on allait une fois encore allumer les chaudières.

Dans les "moulins à coton" on ne fait que nettoyer le coton, qui arrive par balles énormes, sur le dos des chameaux, directement des champs de production. On en peigne les fibres, qu'on débarrasse de la graine et des impuretés les plus grossières. On le sèche et on l'aère. Ce dernier travail s'effectue d'une façon bien primitive: des ouvriers noirs, dans un vaste grenier, de leurs pieds et de leurs mains, soulèvent la neige blanche, la dispersent, la brassent et l'agitent. Les hommes chantent en chœur, comme tous les ouvriers arabes, pour se donner du courage et, au milieu d'un épais et livide nuage, les gestes deviennent rythmés et cadencés, comme une danse étrange et parfois très belle. On dirait un ballet futuriste. Pour tout avouer, ce n'est pas très bon pour les poumons! Mais au Soudan, la main-d'œuvre ne coûte pas cher. Quand le coton est sec, il s'agit de le presser, pour le transport jusqu'aux filatures, en balles serrées et pesantes. Des presses hydrauliques font ce travail. Mais, au début, il faut commencer toujours par comprimer les premières couches de coton, à force d'homme. Des nègres descendent dans le moule quadrangulaire où la balle sera confectionnée et commencent de presser le coton avec leurs pieds. Hélas, il est arrivé vingt fois que la machine déclenchée trop tôt ait comprimé, en même temps, le pauvre noir [...] Les magnifiques moulins à coton de Port-Soudan, de Khartoum et Omdurman, ont fait la fortune des firmes anglaises; mais elles n'ont guère apporté de bonheur aux Nubiens aujourd'hui prétendus libres...

J'étais depuis plus trois jours installé au moulin de Souakin [...] que chaque saison, implacablement, précipite un peu plus dans la ruine. Souakin est composée de deux parties: l'une sur le rivage, entourée d'une muraille crénelée, contenait les marchés, les cafés, les souks, les caravansérails. L'autre partie, où se trouvaient les riches magasins et les demeures patriciennes, est bâtie sur un îlot rigoureusement circulaire, au milieu d'une lagune. Une chaussée relie à la terre ferme cette île, qu'on dirait un beau navire ancré dans un port.

Il reste encore une somnolente animation dans ce qui reste des souks de la ville terrestre. Deux ou trois cafés constamment déserts et deux ou trois marchands qui ne vendent guère que des graines de dourah, des peaux de chèvres et du sel. Quant à la ville insulaire, un mortel silence l'enveloppe; d'admirables demeures bordent, dans cette île, le front de mer et baignent directement dans les eaux. On peut visiter les plus belles d'entre elles, qui sont encore gardées par de vieux domestiques. Avec ses moucharabiehs 


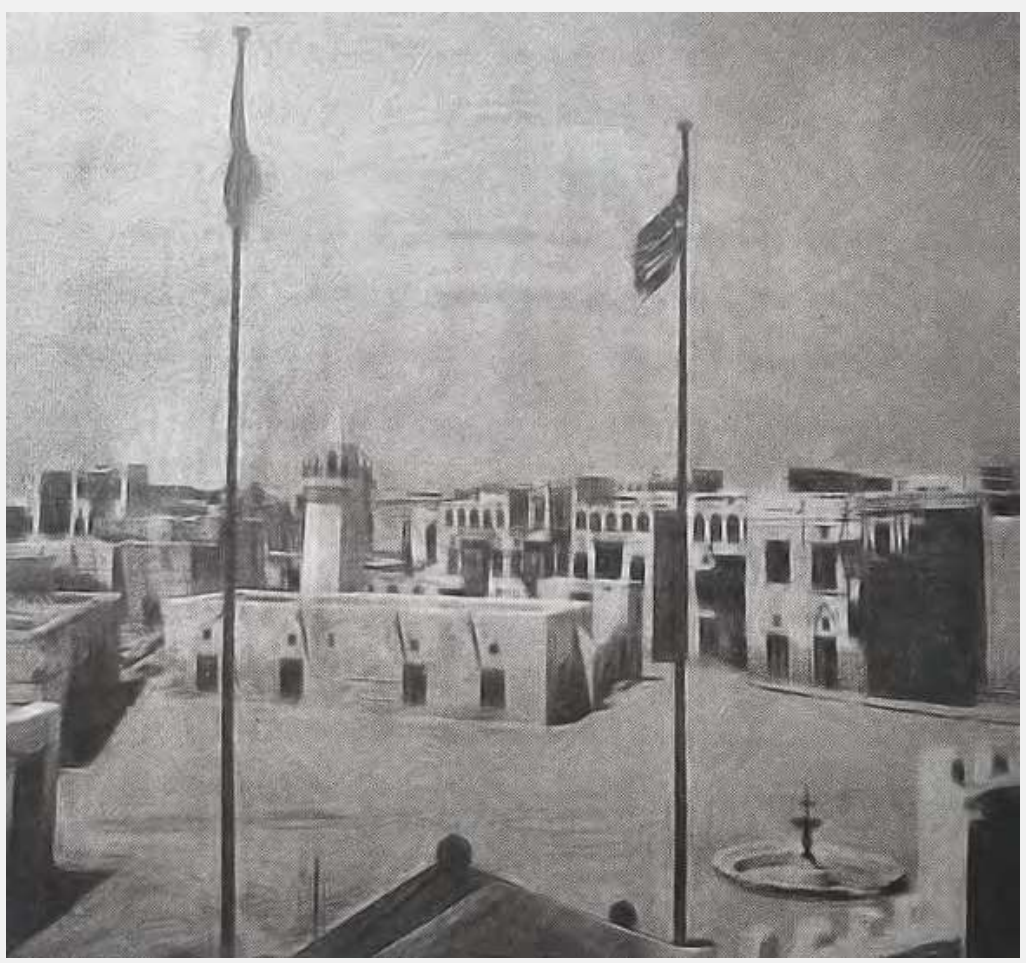

le Soudan

716

de 1820

à nos jours

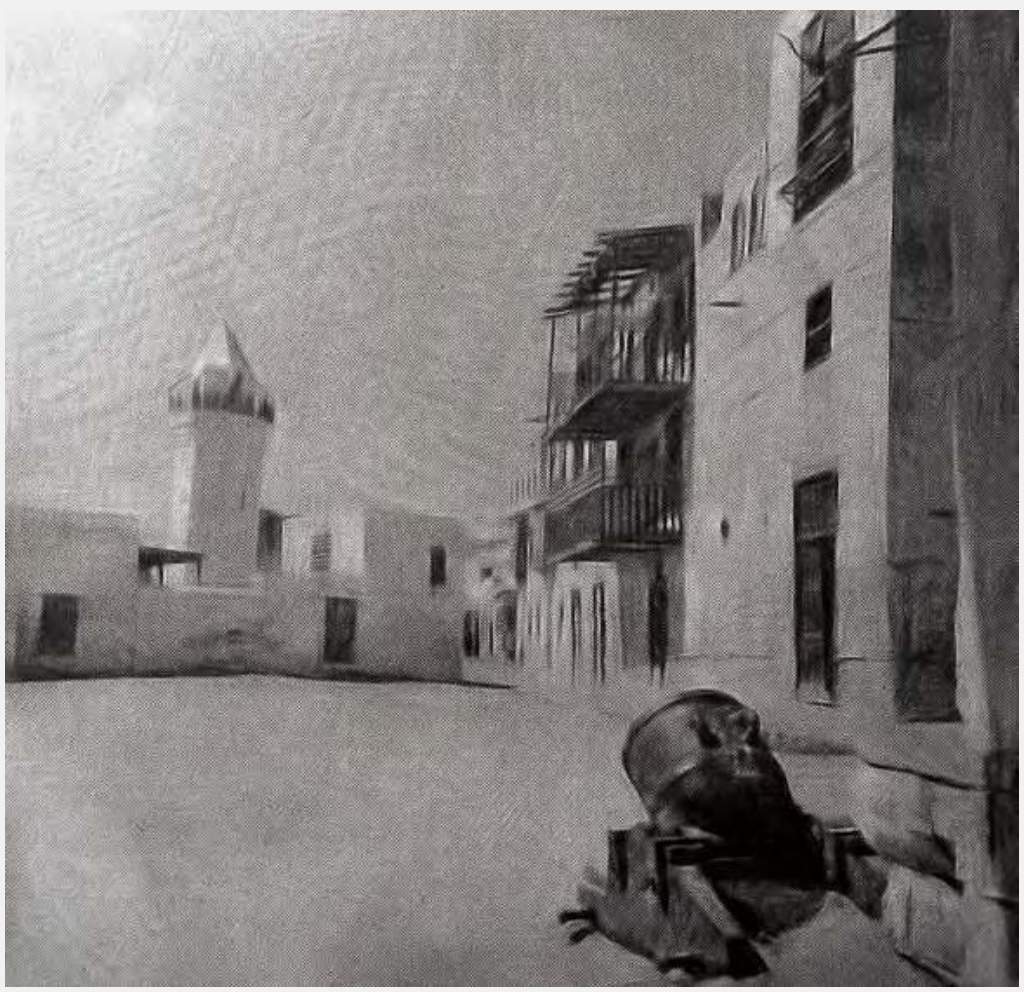

Souakin. 

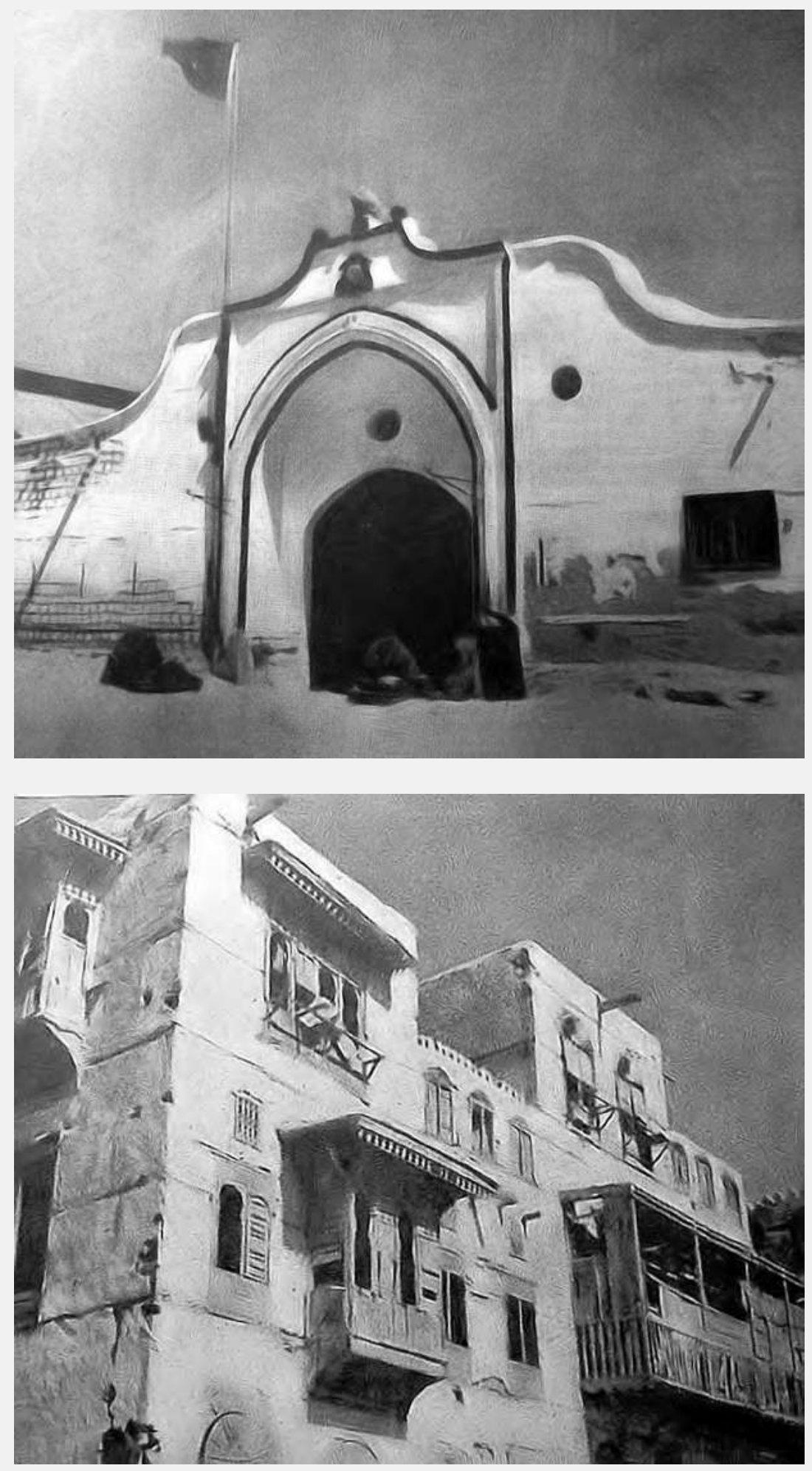

le condominium angloégyptien 1899-1955 Souakin. 


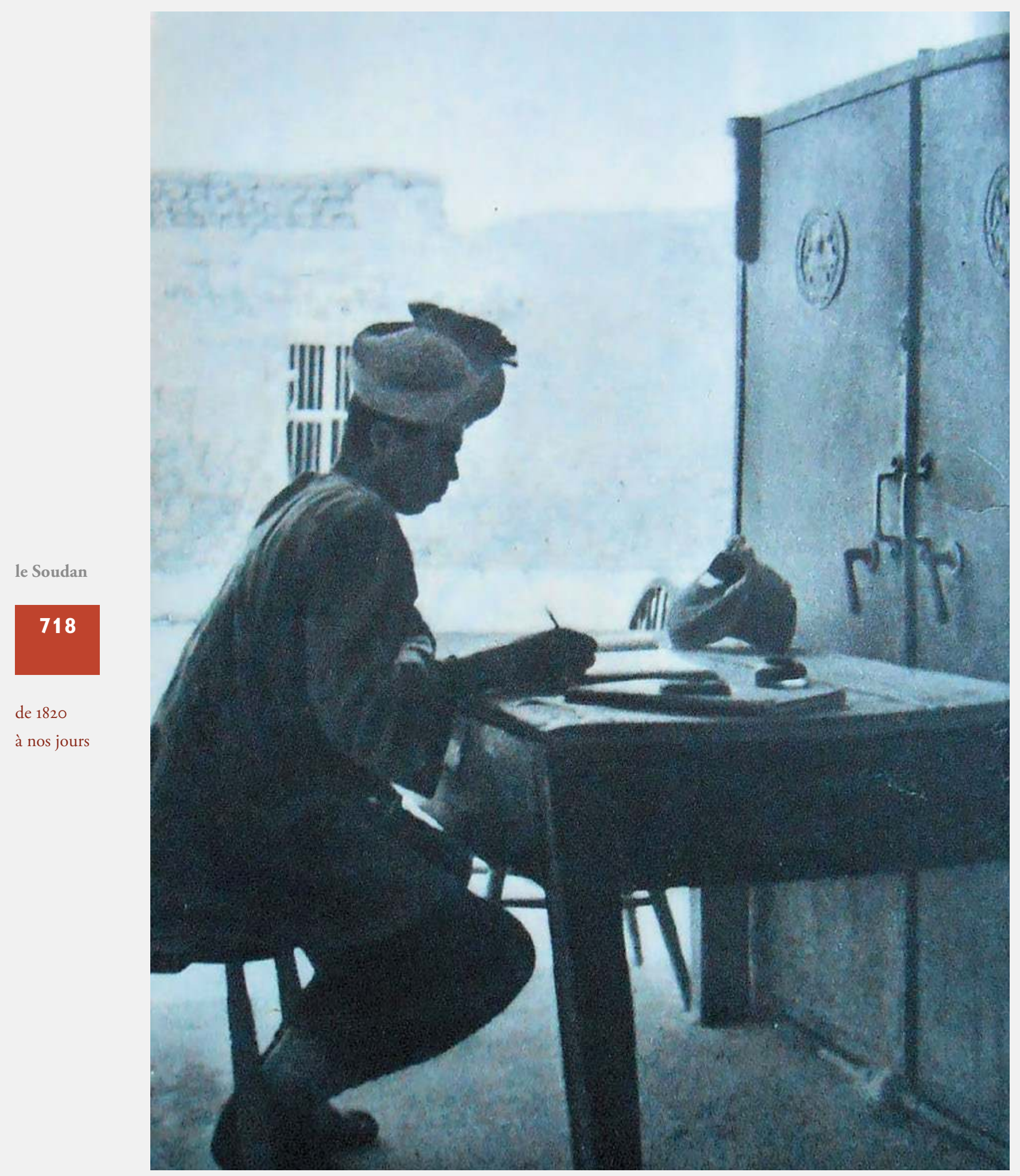


de bois sculpté comme une véritable dentelle, voici l'ancienne demeure des "Shennani", l'une des plus vieilles familles de Souakin et qui fut pendant des siècles la plus prospère. Voici le palais de "Khorsid Effendi", le grand armateur, qui posséda jusqu’à vingt boutres: sa façade couverte d'alvéoles de plâtre fait penser aux rayons d'une ruche. Jadis des fä̈ences persanes d'une grande valeur ornaient chaque muraille, du haut en bas. Il n'en reste plus que la trace. À l'intérieur, les voûtes des plafonds sont encore peintes d'harmonieuses arabesques et d'épais tapis recouvrent encore le sol de leur luxe ouaté. Des douzaines d'autres princières demeures se mirent dans l'eau glauque. Toutes sont victimes des injures du temps, la plupart sont dans le plus lamentable délabrement; de certaines, il ne reste déjà plus que de branlantes murailles.

La Muhafaza, ancien hôtel du Moudir, aujourd'hui siège d'un bureau d'administration, où nul administré n'entre plus jamais, est gardé par deux policiers en turban, ahuris de voir quelqu'un se présenter à leur guérite. À côté, voici les bâtiments imposants du service des Douanes, dans lesquels un coffre-fort de dimensions gigantesques contint jadis des fortunes. Aujourd'hui, un gratte-papier nègre y range son écritoire et des registres parfaitement honoraires. Enfin, au tournant d'une venelle, l'ancien local de la National Bank laisse battre au vent une porte de bois sculpté qui ne déparerait pas le plus riche de nos musées. Les mosquées elles-mêmes ne sont plus que ruine $[\ldots]$.

Les propriétaires de ces riches maisons, fils des marchands millionnaires et eux-mêmes ruinés à jamais, sont commis aux écritures dans quelques villes de la Basse-Égypte. Leurs maigres ressources ne leur permettent même pas de protéger de la ruine le seul bien qui demeure de leur héritage: la maison familiale. Reviendront-ils jamais à Souakin? S'ils tardent encore un peu, ils ne retrouveront plus rien qu'un tas de gravats, de ce qui fut le palais de leurs pères. [...]. Trois mille habitants vivent aujourd'hui là, où [prospérait une riche cité], il n'y a guère plus d'un quart de siècle. Demain, Souakin ne figurera plus même sur les cartes. Seuls, les livres d'histoire en perpétueront le brillant souvenir.

\section{Quelques personnalités ayant visité Khartoum durant le condominium}

La douane

de Souakin

en 1942

(l'armoire blindée est encore en place de nos jours). (voir photographies p.720). En mars 1910, l'ancien président américain Theodore Roosevelt et $\mathrm{M}^{\mathrm{rs}}$ Edith Roosevelt sont venus en touristes, pour chasser dans le sud du pays. Le roi George V fait en 1912 étape au Soudan. Le Hongrois László Almásy, qui inspira le héros du best-seller Le Patient anglais, est photographié devant le Grand Hotel à Khartoum vers 1929, durant le tournage d'un documentaire sur le désert. Lord Baden Powell, fondateur du scoutisme, s'arrête en 1935 à Port-Soudan, en route pour Mombasa. À cette occasion, 1024 scouts du Soudan se sont rassemblés pour l'accueillir —

\section{9}

le condominium angloégyptien 1899-1955 


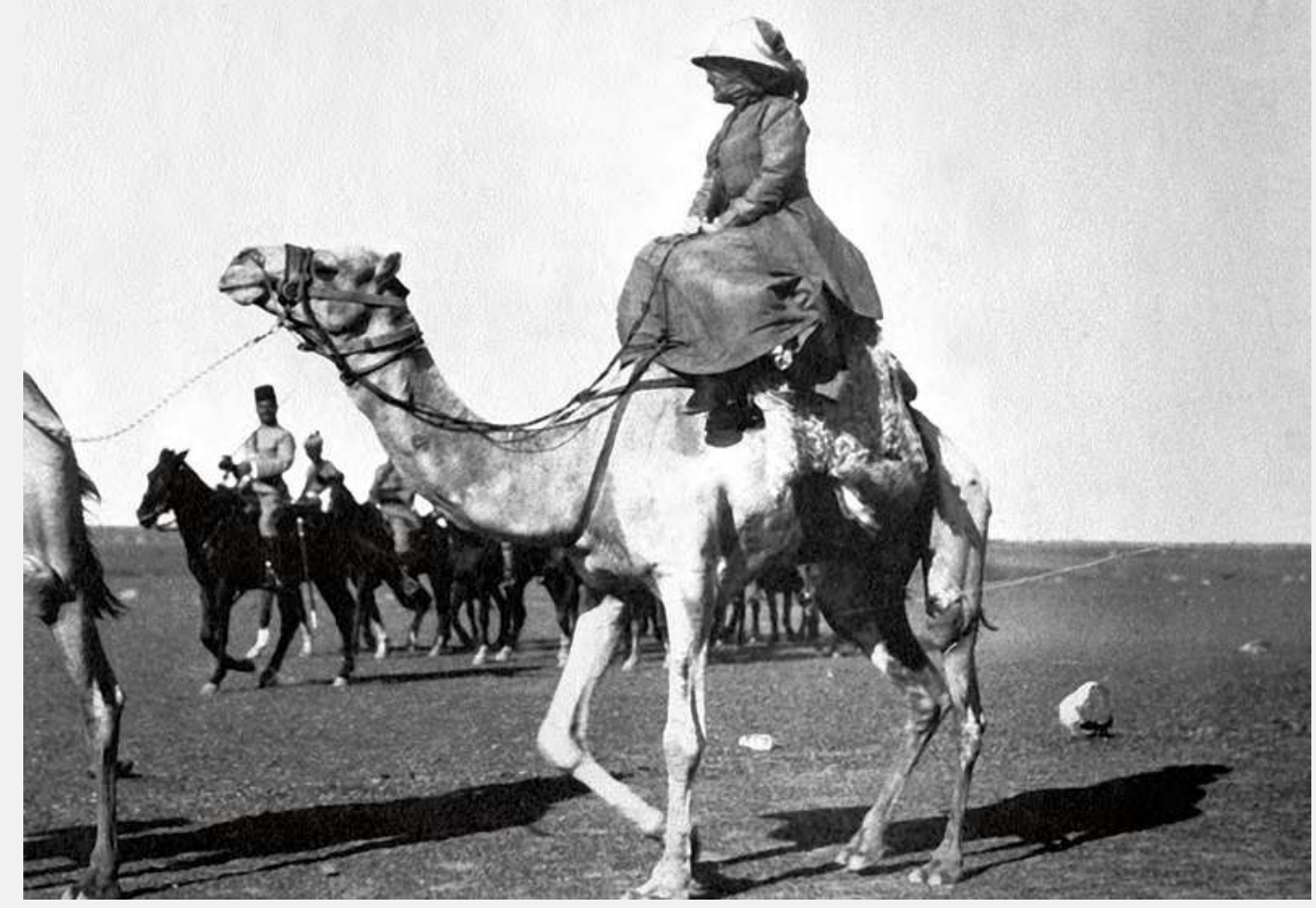

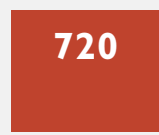

de 1820 à nos jours
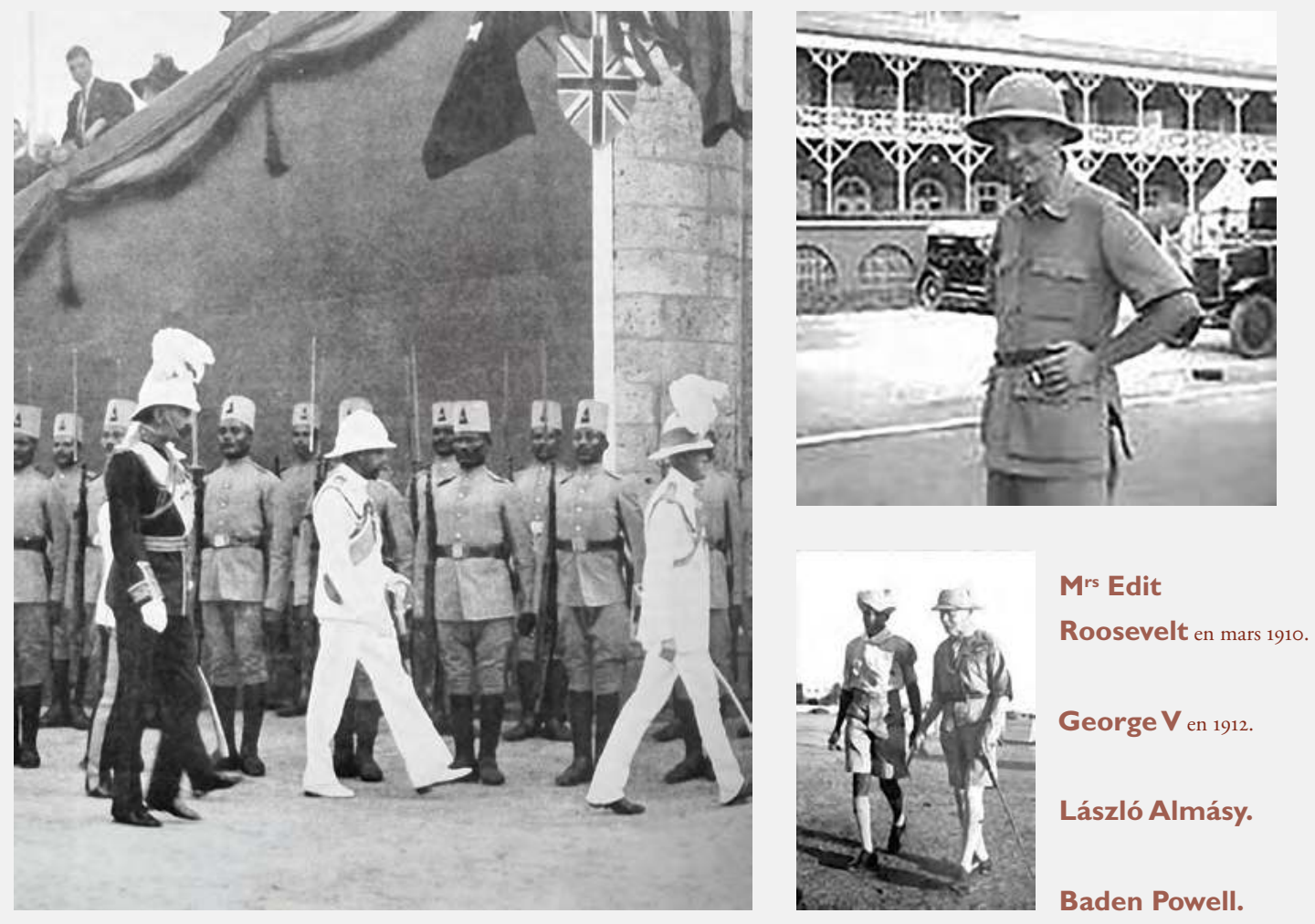


\section{Babikir Badri : un visionnaire}

Babikir Badri (1856-1954) expérimenta dans sa jeunesse l'école coranique dont, dans son autobiographie $M y$ life $^{1}$, publiée en arabe puis en anglais, il décrivit amplement le caractère rude.

Il fit partie des troupes mahdistes écrasées par l'armée angloégyptienne commandée par le général Kitchener, lors de la bataille de Karari, en 1898. Rescapé du massacre, il connut la période de débâcle et d'incertitude qui suivit l'effacement du régime mahdiste et migra dans la région du Nil Bleu: il s'installa dans le village de Rufáa, à 140 kilomètres de Khartoum et d'Omdourman, au bord du fleuve. Il ouvrit là une école laïque pour les filles. Celles-ci n'avaient pas accès aux écoles coraniques traditionnelles qui étaient exclusivement destinées aux garçons.

\section{Une école laïque pour filles - 1907}

Babikir Badri était un homme profondément religieux et largement respecté pour sa connaissance du Coran. Mais il développa aussi l'idée que les filles devraient recevoir un minimum d'éducation — notamment de façon à ce qu'elles puissent devenir de vraies compagnes pour leurs maris. Le fait que Babikir ait eu treize filles (et plusieurs fils) a peut-être influencé sa conception de l'éducation. En 1904, il demanda aux autorités britanniques la permission d'ouvrir une école élémentaire pour les filles. Redoutant une réaction négative de la population liée au caractère radicalement innovant de cette initiative, la commission britannique pour l'éducation au Soudan refusa d'accéder à la requête. Une nouvelle demande formulée en 1906 reçut le même accueil négatif. Mais Babikir était une personne déterminée, comme les Britanniques allaient l'apprendre.

Finalement sa requête fut acceptée par Sir James Currie, le directeur du département de l'éducation du condominium anglo-égyptien au Soudan. En donnant son approbation, James Currie note: 《KJ'aurais préféré pour ma part que le gouvernement ne se lance pas dans cette action [l'éducation des filles] avant un certain temps. Mais... je ne vois pas non plus quel dommage pourrait être causé en commençant quelque chose [pour l'éducation des filles] ici à Rufa'a.

1 Cette autobiographie en deux volumes, publiée en arabe en 1961 et traduite ultérieurement en anglais (1969-1980), est considérée comme un classique de la littérature soudanaise et constitue une référence importante sur la période mahdiste et sur celle du condominium anglo-égyptien. 
En 1907, Babikir ouvrit cette école laïque pour filles, dans une case de terre crue, avec pour élèves neuf de ses filles et huit filles de ses voisins. Cette école qu'il nomma judicieusement et avec une sagesse prémonitoire Ahfad — c'est-à-dire, en arabe, "pour nos petits enfants" — fut la première école pour filles du Soudan. Après une inspection par Currie qui se révéla satisfaisante, l'école reçut un subside du gouvernement.

Les idées de Babikir Badri sur l'éducation des filles étaient opposées à la vision traditionnelle des Soudanais, réticents et suspicieux à l'idée d'envoyer leurs filles à l'école. En plus de l'éducation proprement dite, l'école ouvrit son enseignement à la nutrition et aux soins de santé, dans l'objectif d'améliorer la santé des enfants.

En 1943, l'école fut déplacée à Omdourman. Quand il meurt en 1956, Babikir Badri est internationalement acclamé comme un pionnier de l'éducation dans son pays où il s'est vu conférer le titre de cheikh.

\section{La faculté Ahfad pour les femmes - 1966}

À partir de ces débuts modestes, la famille Badri a développé l'éducation privée au Soudan grâce à trois générations d'éducateurs. Le fils de Babikir, Yousouf, poursuivit le travail de son père et, en 1966, créa la faculté universitaire «Ahfad» pour les femmes à Omdourman. Le professeur Yousouf Badri, quand il décéda en 1995, fut lui aussi reconnu comme un pionnier de l'éducation pour les femmes au Soudan. Son fils, le Dr Gasi Badri, a continué à développer l'enseignement et les innovations pédagogiques d'Ahfad.

\section{Le statut universitaire complet est reconnu - 1995}

Sur base de l'extension des matières enseignées et du volume croissant d'étudiants, le conseil national soudanais de l'enseignement supérieur accorda à Ahfad le statut universitaire à part entière en 1995 . L'université Ahfad pour les femmes est la plus ancienne et la plus importante université privée du Soudan. Elle est probablement également la plus ancienne université privée pour les femmes en Afrique.

\section{L'université Ahfad pour les femmes aujourd'hui}

Actuellement, l'université Ahfad pour les femmes accueille plus de cinq mille étudiantes qui viennent de toutes les régions du Soudan et de nombreux pays voisins. Les étudiantes peuvent suivre les cours de six facultés, qui délivrent un enseignement moins académique que pratique et tourné vers la vie professionnelle 